

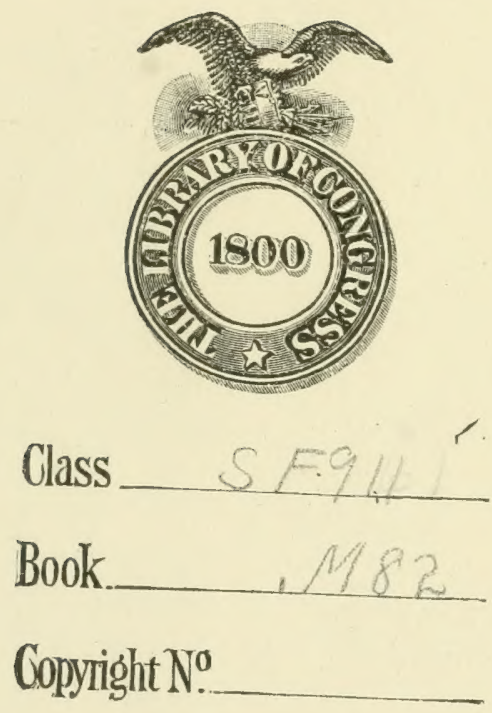

Copyright No.

COPYRIGHT DEPOSYT. 
7 







\title{
INTERROGATORY SURGERY
}

\author{
FOR
}

\section{STUDENTS OF VETERINARY SCIENCE}

\author{
BY R. C. MOORE, D. V.S. \\ Proffsior of SURgery AND ANATOMY \\ Kansas CITy Veterinary COLlege
}

PUBLISHED BY THE AUTHOR

Kansas City, Mo., 1904 

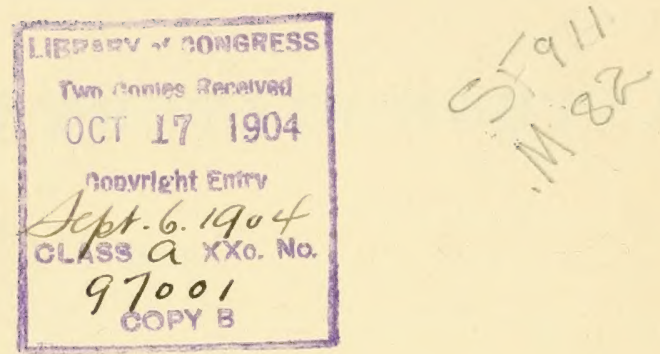

$\begin{array}{rr}c & \vdots \\ c & \varepsilon \\ e & \varepsilon \\ c c & c\end{array}$ 


\section{INTRODUCTION.}

CINCE the time of Socrates the question method has been recognized as valuable in teaching, the pupil being more likely to grasp the thought of the text if direct questions covering the principal points in the lesson are before him. The questions are valuable in review and provoke members of the class to quiz one another. This thought and the author's personal experience has induced him to compile these questions on regional surgery. Moller's Regional Surgery, being the adopted text at the Kansas City Veterinary College, has been used largely for the subject matter of tise questions. The figures to the right of the heading of each topic indicate the payes at which that topic is discussed.

The excellent works of Liautard, W. Williams and V. L. Williams have also furnished much valuable information. The writer is also indebted to Professors Strangeway, Chaveau, and McFadyean for valuable discussions on anatomy.

The assistance of kind friends in the arrangement of the work has renewed obligations that will not soon be forgotton.

If this little work proves to be useful to the student in becoming proficient in this branch of Veterinary Science the author will feel well repaid for the time spent in compiling it.

$$
\text { R. C. Moore, D. V. S. }
$$

Kansas City Veterinary College.

Kansas City, Mo., I904. 


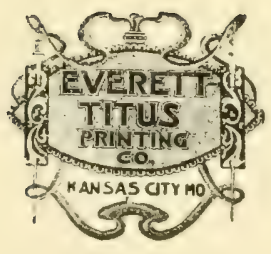


COPYRIGHTED $\mathrm{rgO}_{4}$

$\mathrm{BY}$

R. C. MOORE, D. V. S. 


\section{REGIONAL SURGERY.}

\section{Diseases of the Lips and Cheeks.-Page I}

1. How are such wounds usually made?

2. Do the tissues of this region heal readily, if so, why?

:3. What conditions retard the healing of such wounds?

4. Why do wounds of the commissures of the mouth cause the most trouble?

5. What would be the probable result of an injury to Stenson's duct?

6. How could a wound of this region cause facial emphysema?

7 Is it possible, in wounds of this region, to get union by first intention?

8. In what kind of wounds in this region can the interrupted suture be used to advantage?

y. Under what conditions would either the quill or button suture be useful?

10. How should the animal be fed where union by first intention is expected?

11. Where could the purse-string suture be used to advantage?

Acute Inflammation of the Lips and Cheeks.-- Page 3

I. What are the chemical causes for such inflammation?

2. What animals are subject to spontaneous gangrene of the cheeks?

$\therefore$ What does pus formation around the edges of a gangrenous wound indicate?

4. What is the prognosis of such wounds?

i. What are the causes of such gangrenous wounds?

i. What is the treatment?

\section{Tumcrs of the Lips and Cheeks.-Page 4}

1. What animals are liable to be affected with warts in these regions?

2. What tissues do they involve?

3. How should they be treated?

4. What is the cause of cystic tumors in this region?

5. Under what circumstances do they become troublesome?

6. What is the treatment?

7. What is atheroma of the false nostril?

8. How should it be treated?

9. What forms of malignant tumors are found in this region? 



\section{Facial Paralysis. - Page 6.}

1. What is the origin of the facial nerve?

2. What two nerves are given off by it in the Fallopian canal?

3. What part of the body receives inervation from branches given off at the stylomastoid foramen?

4. What parts of the body are motorized by this nerve, after the above branches are given off?

5. What organs would be paralyzed, if this nerve were injured on a level with the anterior end of the maxillary spine?

i). What muscles would be paralyzed if the lesions were central?

7. What are the symptoms of facial paralysis?

$\therefore$. What branch of the facial nerve is injured, when sensation of the skin over the facial regions is lost?

5. What is the difference in the symptoms of uni-facial and bi-facial paralysis?

10. What is the difference in prognosis of central and pariferal paralysis?

11. How should each be treated?

\section{Foreign Bodies in the Mouth.-Page ro.}

1. What animals are most susceptible?

2 What foreign bodies are liable to be sp lodged?

$\therefore$ What are the symptoms?

4. How examine for such bodies?

i. What vessels might be injured by them?

i. How should they be treated?

7. What effect would such lesions have on the general system?

:. How can excessive hemorrhage from the soft palate be controlled?

18. Do wounds of the mouth heal readily?

10. How might rings or bands accidentally invest the tongue?

11. What would be the probable effects?

\section{Diseases of the Tongue.-Page 13.}

1. How may the tongue of the horse be accidentally injured?

2. How may the frenum lingui be torn?

3. How much of the tongue may be removed without permanent injury?

4. What animals suffer most from the loss of the end of tongue?

i) What treatment is advisable in deep lacerations of the tongue? 



\section{Actinomycosis of the Tongue.-Page I 7}

1. What animals are subject to this disease?

2. What are its symptoms?

3. What is the treatment for a case in the early stages?

4. What is paralysis of the tongue?

5. What nerve is involved?

6. What is ranula?

7. What treatment is prescribed for it?

8. How can fracture of the hyoids be detected?

9. How should a simple fracture of these bones be treated?

10. What new growths may be found in the tongue?

\section{Eracture of the Premaxillarv.-Page 22}

1. How may such fractures be produced?

2. What are the symptoms?

3. How should such fractures be treated?

\section{Injuries to the Interdental Space.-Page 23}

1. How may such injuries be inflicted?

2. What tissues may be involved?

3. What are the symptoms?

4. What treatment would be indicated in necrosis of the bone?

\section{Diseases of the Teeth,- Page 25}

1. In what animals are the molars of first importance?

2. What are the symptoms of defective teeth?

3. How could a diagnosis be confirmed?

4. What four irregular and diseased conditions does Möller mention?

\section{Irregularities of Teeth.-Page 26}

1. What are supernumerary teeth?

2. What is polyodontia?

3. What is hyperdentition?

4. Where are supernumerary teeth most often situated?

5. What is the cause?

6. How should they be treated?

7. What is the cause of irregularities in the replacement of teeth? 

$\therefore$ What is the effect upon the mouth?

$\therefore$ On which side of the milk tooth does the permanent one appear, when the former has not been shed?

11. What are the symptoms of difficult eruption?

11. What treatment wolid be advisable?

1:. What is understood by caps?

l:?. What would be the effect if the crowns of a molar milk tooth remained in position too long, during the eruption of a permanent one?

14. What is rotation of a tooth on its axis?

i.i. What irregularities of jaw produce overshot?

16. What irregularities of jaw produce undershot?

17. What is the cause of these conditions?

18. What irregularities of articulation does this cause in the incisors?

1?). What in molars?

20. How do these conditions affect the usefulness of a horse?

21. What would be the effect of deviation of the axis of a tooth backward or forward?

Irregularities of Wear.--Page 29:

1. How do the molar teeth normally articulate?

2. What is the normal annual wear of the molars of herbivora?

$\therefore$ What conditions may cause irregular wear?

4. That are the different pathological forms of mouth caused by irregular wear?

i. What is the angular or sharp mouth, or prognathous jaw?

f. What is the cause?

7. Which side of the lower teeth becomes too long?

s. Which of the upper?

9. What would be the result of no wear to a tooth?

10. How may sharp edges injure the animal?

11. How may they interfere with driving?

12. At what age are these conditions liable to appear?

13. How may faulty muscular action produce sharp edges?

14. How are such conditions diagnosed?

15. How should they be treated?

16. What is a shear-like mouth?

17. What effect does this condition have on the lateral motion of the jaw?

18. What is the prognosis? 

19. What is the treatment?

20. What is the wave-formed mouth?

21. What is the cause?

22. What is the step-formed mouth?

23. What is an elongated tooth?

24. What conditions allow it to become elongated?

25. How should it be treated?

26. What is premature wear?

27. What are the causes?

28. What pathological condition causes a smooth mouth?

29. What is the cause?

31. What is the effect on mastication?

31. What is the treatment?

\section{Diseases of the Tooth Proper.-Page 38}

1. What is caries?

2. What part of the tooth does it attack?

3. Is it of frequent occurrence in the lower animals?

4. What is the cause?

5. What is the treatment?

6. What is a fissured tooth?

7. What is the cause?

S. Which tooth is most liable to suffer?

9. What may be the result of food working into a fissure?

10. How should a fissured tooth be treated?

11. What is dental tartar?

12. What ill effect does it have on the teeth and gums?

13. What animals are most subject to it?

14. What is the treatment?

15. What is necrosis of a tooth?

16. What may cause it?

\section{Diseases of the Alveoli.-Page 42}

1. How do these compare in frequency with other diseases of the teeth?

2. How are the roots of the teeth fixed in the alveoli?

3. How many forms of alveolar periostitis are seen in herbivora?

4. What are they?

5. What is the ossific form? 

6. What effect would it have on extraction?

7. What is the effect of the purulent form on the tissue?

S. How does this cause erosion of the surface of the tooth?

9. What is bone necrosis?

10. What is osteo-myelitis?

11. How may the purulent form cause necrosis?

12. Does the entire membrane necessarily become involved?

13. Are the two forms ever associated?

14. What are the causes?

15. What is the appearance of a tooth where the purulent form is complete?

16. How does it produce fistula of the jaw?

17. In fistula of the fourth upper molar, what would it communicate with?

18. What if it be of the fifth upper?

19. What if it be of an upper pre-molar?

20. What if it be of a lower pre-molar?

21. What are the characteristic symptoms of alveolar periostitis?

22. What is the cause of the offensive odor?

23. Are dogs' teeth liable to be loose under such circumstances?

24. How is the affected tooth changed in appearance?

25. In what animals are epileptiform conditions said to accompany diseased teeth?

26. How may artificial and reflected light be used in examining the mouths of herbivora?

27. In case of external fistula, how determine which tooth is involved?

\section{Removing Teeth.-Page 46}

1. Does the age of the animal make any difference in extraction of teeth?

2. What kind of lever would be necessary to extract the first pre-molar of a horse?

3. How should the forceps be placed upon a molar tooth?

4. What is the first motion in extracting a molar tooth?

5. Is a mouth speculum necessary?

6. What would a liberal hemorrhage from around the tooth indicate?

7. How should a fulcrum be adjusted? 

8. What should be done when the tooth is far enough removed from the alveolus to strike the opposing one?

9. When should trephining be resorted to?

11. Of what importance is the selection of the exact place for trephining?

11. How may such place be located?

1.). What sized punch should be used to remove a molar tooth?

1:) How determine when the blows on the punch are taking effect on the tooth?

14. How proceed if the trephine hole is not exactly over the fang of the tooth?

15. Is it in portant to remove all the tooth?

16. What molars may thus be removed?

17. Is there any danger of the animal swallowing the tooth?

1S. How should the patient be secured?

19. What nerves may be injured in trephining to remove an upper molar tooth?

21!. How may food be prevented from entering the maxillary sinus after trephining for the upper molars?

21 . In extracting, is it important that the direction of the traction correspond to the long axis of the tooth?

\section{Alveolar Periostitis in Dogs.-Page 53}

1. What class of dogs is most often affected?

2. Is there usually more than one tooth affected?

3. Are the incisors ever involved?

4. What effect does this condition have on the gums?

5. What is the character of the odor?

6. What conditions of dogs' teeth sometimes cause symptoms similar to those of rabies?

7. How does tartar produce alveolar periostitis?

8. How can it be prevented?

9. What should be the procedure in extracting dogs' teeth?

\section{Dental Fistula.-Page 54}

1. What is a dental fistula?

2. What is osteomyelitis purulenta?

3. In abscesses of the upper molars in dogs where do they usually open? 

4. For what might such fistulous tract be mistaken?

5. How is dental fistula differentiated from bone fistula?

6. How should the former be treated?

i. What is periostitis alveolaris ossificans?

8. What effect may it have on the removal of a tooth?

9. How should it be treated?

\section{Neoplasms of the Gums and Alveoli.-Page 57}

1. What is an epulis?

2. What varieties are noted?

3. What is the prognosis?

4. What would be the treatment?

\section{Diseases of the Nose and Nostrils.-Page 59}

1. How may wounds to the alae occur?

2. How should they be treated?

$\therefore$ What would be the result if the cartilage is involved?

4. How may the nasal bones be fractured?

5. How may such fractures cause permanent defects?

6. How should they be treated?

7. Under what circumstances would it be necessary to trephine in such cases?

\section{Foreign Bodies and Tumors in the Nostrils.-Page 6I}

1. How may foreign bodies obtain entrance to the nose of herbivora?

2. What form of new growth is most common?

3. What is a fibroma?

4. What is a myxoma?

5. From what parts of the nostrils do tumors usually grow?

6. Do they ever extend from the brain and maxillary sinuses into the nose?

7. In what form has strongylus armatus been found here?

$\therefore$ What fungi have been found in the nostrils?

9. Are the discharges from such growths bi-lateral or unilateral?

11. If the right side was affected, what would be the effect of closing the left nostril?

11. What might be determined by the use of a sound? 

12. Is a roaring sound ever present?

1:). If so, what is the sound called?

14. How may tumors cause an overflow of tears?

15. Do they ever produce bulging of the facial bones?

16. Do such growths in the sinuses ever protrude into the mouth?

17. Do they ever protrude from the anterior naries?

1S. What are the symptoms of tumors in dogs and cats?

19. What parasites in dog's' noses produce attacks resembling rabies?

21). What classes of such new growths are amenable to treatment?

21. How may polypi be removed?

22. Is trephining ever resorted to in their removal?

23. What would be the prognosis if the turbinated bones were diseased?

24. How might excessive hemorrhage accompanying such operations be controlled?

:J. Is tracheotomy ever necessary in this operation?

26. Does inflammation from these growths. or following operations, ever extend to the brain?

\section{Edema of the Head.-Page 64}

1. What are the causes of extensive edema of the head?

2. What treatment would be required?

\section{Diseases of the Facial Sinuses.-Page $6+i$}

1. How many of these sinuses in the horse?

2. How many divisions of the maxillary?

3. What divides it into anterior and posterior chambers?

4. What divides it into internal and external chambers?

5. What bounds the frontal sinus antero-inferiorly?

6. What bounds the anterior chamber of the maxillary sinus internally?

7. What four abnormal conditions are said to prevail in these cavities?

8. What disease of the teeth might affect these sinuses?

9. How may foreign bodies gain access to these sinuses?

11. What larvae are sometimes found in the facial sinuses of horses? 

11. What parasites are found here in sheep?

12. What is the character of the discharge in catarrhal accimulations of these sinuses?

13. How would the discharge from a catarrhal accumulation differ from that resulting from purulent alveolar periostitis?

14. Do these conditions ever cause enlargement of the submaxillary glands?

15. What might be determined by percussing over the sinuses?

16. Do diseases of the teeth ever cause bulging of the facial bones?

17. Do they ever cause brain lesions in cattle?

18. What are the terminations?

19. Is recovery ever spontaneous?

20. How should such cases be treated?

21. How should a case of nasal catarrh without accumulations in the sinuses be treated?

22. How could the internal chamber of the anterior division of the maxillary sinus be drained?

23. How long should the trephine hole be kept open?

24. How should the parts be dressed, and how often should the dressing be repeated?

\section{Trephining the Maxillary and Frontal Sinuses.-Page 67}

1. For what purposes is this operation performed?

2. What is a trephine?

3. What are elevators and for what are they used in this connection?

4. What is a bone gouge, and when would it be useful in this connection?

5. What is a lenticular knife, and what is its use?

f. Where should the opening be made to empty the frontal sinuses?

7. How should the operative field be prepared?

8. Where should the opening be made to open both anterior and posterior divisions of the maxillary sinus?

9. How should the age of the animal modify the location?

10. How should the animal be secured?

11. What vessels might be injured in trephining the maxillary sinus? 

12. How can too rapid closing of the trephine hole be prevented?

13. How should the contents of the sinus be removed?

\section{Disease of the Turbinated Bones.-Page 72}

1. Do these bones ever become thickened?

2. If so, what effect would it have on the respiration?

3. Why is it difficult to heal the remaining parts of a turbinated bone after removal of a part?

4. What are the symptoms of necrosis of these bones?

5. How should such cases be treated?

6. How should one proceed to remove a turbinated bone?

\section{Epistaxis, (Bleeding at the Nose.)-Page 75}

1. What animal is most often affected?

2. What are the causes?

3. How may it be controlled?

\section{Disease from the Salivary Glands. - Page 76}

1. What is the chief danger in wounds of the salivary glands or their ducts?

2. In what animals is Stenson's duct most exposed?

$\therefore$ How may wounds of these structures be determined?

4. Do such wounds ever heal spontaneously?

5. Is healing of such wounds by first intention desirable?.

6. How should they be treated?

7. Is it advisable to withhold feed and water?

8. How would small doses of atrophine affect such a case?

9. What is parotitis?

11. Is it ever endemic?

11. During the course of what disease is it liable to occur?

12. What part of the structure is primarily affected?

13. What is the appearance of the structure at this period?

14. What is the result of its spreading to the connective tissue?

15. Where does pus formation take place?

16. How do the larger abscesses form?

17. How does this produce necrosis of the gland tissue?

18. What is the appearance of such abscesses when they open spontaneously? 

19. In what other structures does abscess in the region of the parotid gland form?

20. What would be the difference in the appearance of an abscess of a lymph and of a salivary gland after open. ing?

21. What are the symptoms?

22. In what position is the head held?

23. Do abscesses ever interfere with breathing and deglutition?

24. How could they cause facial paralysis?

25. How long will it take such abscesses to heal after being opened?

26. Do they ever terminate in septicemia or pyemia?

27. How could parotitis be distinguished from distention of the guttural pouch?

28. How distinguished from tumors?

2!. If an abscess forms in Wharton's duct where would it open?

30. What does Stockfelt say of inflammation of the submaxillary gland in cows?

31. How can foreign bodies enter these glands?

32. How remove foreign bodies from the ducts of these glands?

33. Is heat or cold most beneficial in treating parotitis?

34. What symptoms indicate that the abscess is ready to open?

\section{Abscosses of the Subparotid Lymph Glands.--Page}

1. What causes these abscesses in horses?

2. What causes them in cattle and dogs?

3. What causes them in swine?

4. What are the symptoms?

5. Is respiration ever interfered with?

6. What other lesions may develop as a result of the difficult deglutition?

7. What complication would be indicated by food escaping externally with the pus?

8. How should such abscesses be opened?

9. What should be the after treatment?

\section{Salivary Calculi,--Page 8I}

1. Where do these formations occur?

2. In what animals are they most frequent?

3. What are the causes? 

4. What are the symptoms?

5. How should they be treated?

6. Why is it best to remove them through the buccal membrane?

\section{Salivary Fistula.-Page 82}

1. What is the cause?

2. Why is it difficult to heal?

3. What is the clinical difference between a fistula of the duct and of the gland?

4. How should each be treated?

5. What is a draw-purse suture?

6. How should an artificial opening into the mouth be made?

7. Under what circumstances might it be necessary to destroy the function of the gland?

8. What is the procedure in ligating Stenson's duct?

9. What pathological lesions follow its ligation?

10. What was the effect of injecting six drachms of ethyl alcohol?

11. Does distention of the duct ever occur?

12. What other methods might be used to destroy the gland?

13. What would be the effect of an abscess formation after injection?

14. How should these injections be made?

\section{Tumors of the Salivary Glands.-Page 86}

1. What form of new growths are found in these glands?

2. What variety is usually found in gray horses?

3. How are tumors of this region diagnosed?

4. How should they be treated?

5. Under what circumstances should extirpation of the gland be performed?

6. What is the technique of the operation for its removal?

\section{Actinomycosis of the Parotideal Region.--Page 87}

1. In what animals is this disease most common?

2. What is the cause?

3. How is infection supposed to take place? 

4. Do these growths have their origin superficial or deep?

5. What are the symptoms?

6. What is the appearance of the wound after opening?

7. What is the prognosis?

8. How should it be treated?

9. What is the technique of its removal?

10. What remedy is useful internally?

\section{Diseases of the Face and Lower Jaw.--Page 90}

1. What bones of the face are most liable to fractures?

2. How should the following fractures be treated: 1st, Transverse of lower jaw through the interdental space; 2nd, Of the nasal bones; 3rd. Of the frontal; 4th, of the lachrymal and malar bones; 5 th, Of the premaxilla; 6 th, of the condyle of the lower jaw?

\section{Dislocation of the Lower Jaw.-Page 97}

1. What animals are most subject to this injury?

2. Why not others?

3. How may it affect the eyeball?

4. What are the symptoms?

5. What disease may it be mistaken for?

6. How should it be treated?

7. Is it of frequent recurrence?

\section{Inflammation of the Articulation of the Jaw.-Page 98}

1. What are the causes?

2. What are the symptoms?

3. How does it affect the general constitution?

4. How may it affect the teeth?

5. Is this articulation liable to be opened?

6. What is the treatment for each of these conditions?

\section{Paralysis of Muscles of Mastication.-Page 99}

1. In what animals is it most liable to occur?

2. In what disease is it often seen?

3. How shouid such cases be treated? 

4. What nerve supplies the masseter and temporal muscles?

\section{Actinomycosis of the Maxillae.-Page I03}

1. In what animals does it occur?

2. What disease has it been mistaken for, in many instances?

3. What form of ostitis does it produce?

4. What are the symptoms?

5. How may it be differentiated from dental fistula?

6. What form of alveolar periostitis does it produce?

7. What is the prognosis?

8. How are the germs supposed to enter the bones?

\section{Inflammation and new Growths in the Submaxillary Lymph Glands.-Page 105}

1. What conditions cause swelling of these glands?

2. What disease is lymphadenitis liable to accompany?

3. Do tumors ever form here primarily?

4. What is the appearance of these glands during the presence of the following diseases: 1st, Glanders; 2nd, Empy. emia of the sinuses; 3rd, Actinomycosis and bothry. omyces; 4th, Strangles; 5th, Influenza?

5. How should they be treated if involved in a new growth?

6. How in cases of abscess formation?

7. How should a new growth be resected?

8. What vessels and nerves are liable to be injured in removing them?

9. What should be the procedure if the sublingual gland be involved?

\section{Diseases of the Ear and Guttural Pouch.--Page 107}

1. In what ways may the external ears of dogs be injured?

2. How are horses' ears liable to be injured?

3. How may the shaking of the dog's head interfere with healing?

4. How should a split ear of a horse or mule be treated?

5. How are pigs' ears often injured?

6. What is edema of the external ear?

7. In what animals is this liable to occur? 

8. What are the causes?

9. What are the symptoms?

10. How should they be treated?

11. How may wounds of dogs' ears be protected from injury by shaking of the head?

\section{Otorrhea (Otitis Externa,)-Page rio}

1. What is otitis externa?

2. What kind of glands is the lining membrane of the external portion of the ear supplied with?

3. Under what circumstances may the wax become irritating?

4. Is the disease ever parasitic?

5. In what animal is the acute form seen?

6. What is the cause?

7. What two varieties of the chronic form are mentioned by Möller?

8. In what animal is the superficial seen?

9. What is the cause of this form?

11.. What is the character of the discharge?

11. What are the symptoms of the deep form?

12. Do granulations ever close the opening?

13. If the inflammation extends to the middle ear, what constitutional symptoms may be seen?

14. Is this disease ever seen in the horse?

15. What position should the dog be placed in to examine the ear?

16. What is the prognosis of otitis externa?

17. How should it be treated?

18. What is otitis media?

19. What is otitis interna?

20. Can either of the last two forms be recognized during iife?

21. Are tumors ever found in the ears?

2.2. What circumstances might cause paralysis of the ear?

23. What are dentigerous cysts?

24. In what localities are they usually found?

25. How should they be treated? 



\section{Catarrh of the Guttural Pouch.-Page II4}

1. Where are these pouches located?

2. Are diseases of these cavities chronic or acute?

3. When diseased, are the contents solid or liquid?

4. Have tumors ever been found in the guttural pouch?

5. What is the character of the discharge?

6 . When is the discharge most noticeable?

7. Does it necessarily cause external swelling?

8. How may it interfere with deglutition and respiration?

9. How is it that filling the pouches with fluids causes dyspnea while filling them with solids does not?

10. How may the diagnosis be confirmed?

11. What is Gunther's catheter?

12. What is its principal use?

13. What is the prognosis in disease of these cavities?

14. What is hyovertobrotomy?

15. How is it performed?

16. What is Viborg's triangle?

17. What diseases are easily mistaken for accumulations in guttural pouches?

18. What is staphylotomy?

19. What is its object?

20. What is its relation to the opening of the guttural pouches?

21 . What is tympanitis of the guttural pouch?

22. In animals of what age is it usually seen?

23. How is it treated?

\section{Diseases of the Skull.-Page I23}

1. What is the common cause of fracture of the cranial bones?

2. What bones of the skull are most liable to fracture?

3. What are the constitutional symptoms?

4. Do such symptoms always appear at the time of fracture?

5. Is direct injury to the brain necessarily fatal?

6. What is the cause of death when such wounds become infected?

7. What is the prognosis if only the external plate of such bones is injured?

8. Why should the prognosis in all such injuries be guarded?

9. How should simple fractures of these bones be treated? 

10. How should compound fractures of these bones be treated?

11. What should the internal treatment be?

Concussion of the Brain. (Commotio Cerebri.)-Page I26

1. What are the causes?

2. What are the symptoms?

3. What are the clinical indications, if during such an attack

the pulse becomes frequent and wiry and mucous membrane injected?

4. How may fractures of the horn-core be detected?

j. How should such cases be treated?

6. How long may these conditions continue?

\section{Fracture of the Frontal Bones.-Page 126}

1. How does the frontal bone of the ox differ from that of the horse?

2. What is the clinical difference between fractures of the frontal bones and those of the cranial region?

3. How should such fractures be treated?

4. How may fractures of the horn-core be detected?

5. How should they be treated?

6. What is loosening of the horns?

i. What is the prognosis?

8. How should wounds of the soft tissues of the head be treated?

\section{Operations on the Cranial Cavity. In Sheep and Oxen for Parasitic Diseases.-Page I3I}

1. What tapeworm larva is found in the brain of sheep?

2. Is it ever found in the brain of other animals?

3. How large do the cysts become?

4. What is the common name for the disease?

5. At what age does it usually appear?

6. What are the symptoms?

7. Is treatment other than surgical of any avail?

8. What instruments are necessary for a successful operation?

9. Where is the cysticercus usually located?

10. What may be learned by percussion? 

11. What by palpation?

12. If these symptoms are wanting, how may the cysticercus be located?

13. Are the abnormal movements of the animal reliable symptoms for its location?

14. In the absence of positive knowledge of its location, where should the opening be made?

15. What harm might be done by trephining nearer than $3-16$ of an inch to the middle line?

16. Is it necessary to open over the center of the cyst?

17. What antiseptic precautions should be taken?

18. What after treatment should be applied?

19. What is Möller's favorite method?

20. Are these operations usually successful?

\section{Diseases of the Neck.-Page 137}

1. What tissues of the neck are liable to become necrotic from wounds?

2. How does necrosis of these tissues cause fistulous tracts?

3. How may this be prevented?

4. In wounds of the jugular, why is it necessary to ligate hoth ends of the vein?

5. How may wounds of the jugular be distinguished from wounds of the carotid?

6. If the carotid is injured, how should it be treated?

7. In ligating the carotid, what nerve trunks are in danger of being included?

8. Why is it necessary to ligate both ends of the carotid?

9. Why cut the vessel in two after ligating?

10. Under what circumstances may blood from the carotid flow in a steady stream?

11. What would be the physiological effect of division of the vagus?

12. What of dividing the recurrent?

13. How should such wounds of the neck be treated?

14. In what ways may wounds of the trachea be fatal?

15. What three symptoms would indicate perforation of the trachea?

16. How should such perforations be treated? 

17. In what conditions of wounds of this region would tra. cheotomy ve indicated?

18. In what part of the neck are wounds most liable to involve the esophagus?

19. What symptoms would indicate its perforation?

20. What kinds of wounds are liable to occur in the region of the base of the neck and breast?

\section{Fracture of the Cervical Vertebrae--Page 140}

1. What parts of the bones of the neck are most liable to be fractured?

2. What are the general causes?

3. Do fractures of the vertebrae always cause unfavorable symptoms at the time they occur?

4. What is the prognosis?

5. How should such fractures be treated?

\section{Distortion of the Neck (Torticollis.)--Page $\mathrm{I}_{42}$}

1. Does rheumatism ever cause this condition in horse and dog?

2. On which side of the curved neck would the affected muscle be located in rheumatism?

3. On which side, if the disease was paralysis?

4. What are the causes of paralysis in this region?

5. Is luxation of the cervical vertebrae probable?

6. What conditions might be mistaken for luxation?

7. What kind of accidents may lead to this condition?

8. How could these conditions cause edema of the head?

9. How may fracture, subluxation, rheumatism and paralysis of this region be differentiated?

10. What would be the prognosis if due to: 1st, Rheumatism: 2nd Paralysis; 3rd, Dislocation; 4th, Fracture?

11. What should be the treatment in each of the above conditions?

\section{Goitre or Struma.-Page I49}

1. What organs are involved?

2. What animals are most susceptible?

3. Does acute inflammation ever occur? 

4. During the course of what disease does temporary enlargement of these glands occur?

8. How could these conditions cause edema of the head?

6. Upon what does real goitre (struma follicularis) depend?

7. Does this condition necessarily affect all the gland?

8. What tissue is involved in fibrous goitre?

9. What vessels are involved and how affected in varicose goitre?

10. What is cystic goitre?

11. Is sarcoma of these glands ever noted?

12. What per cent of old dogs is said to be affected with goitre?

13. What is cretinism and what relation does it bear to goitre?

14. Is goitre ever inherited?

15. Is the normal gland always of the same relative size?

16. What are the symptoms of goitre?

17. Where may the enlarged gland be located in dogs?

18. What is the prognosis?

19. What is cachexia strumipriva?

20. How can these symptoms be averted?

21. How does the blood supply to these glands compare in quantity with that of the brain?

22. How should goitre in general be treated?

23. How should one proceed in the removal of the gland?

24. What is the dose of thyroid extract?

\section{Inflammation of the Bursa of the Ligamentum Nuchae.-Page I54}

1. Where is this bursa located?

2. What kind of bursa is it?

3. What muscle covers it on each side?

4. What relation does inflammation of this bursa have to poll-evil?

5. What are the causes of inflammation of this bursa?

6. What are the earlier symptoms?

7. What is the first pathological change?

8. What is the condition of the swelling in paribursitis?

9. Can recovery occur at this stage?

10. If infection takes place, what is the result?

11. How are such infections liable to occur?

12. What are corpora oryzoidea, and how are they formed? 

13. If the inflammation becomes chronic, what course does the disease pursue?

14. How does purulent exudate affect the ligament?

15. Does necrosis of the vertebrae occur?

16. What is the cause of stiff neck that sometimes follows?

17. How should the bursitis be treated in the early stages?

18. How if chronic inflammation has resulted?

19. How if the exudate has become purulent?

20. What is gained by dividing one branch of the ligamentum nuchae?

21. Why is it best to liberate the pus early?

22. If pus burrows down along the neck, what course should be pursued?

23. What treatment will be indicated if necrosis of the bone is present?

24. Of what advantage are long continued antiseptic irrigations?

\section{Jugular Phlebitis.--Page I57}

1. What are the causes?

2. What would be the result of an infected blood clot beneath the skin?

3. What would be the appearance of the wound, on removing: the suture, if it had become infected?

4. How may the extension of the disease to the lumen of the vein be determined?

5. What does a round, hard ridge along the course of the vein indicate?

6. What is the danger of manipulating such wounds?

7. If an embolus were detached from the jugular, where would it be liable to lodge?

8. What causes the final occlusion of the vein?

9. How is circulation reestablished?

10. What is the prognosis?

11. How does obliteration of the vein affect the animal while grazing?

12. Why is it not best to put a collar on the horse for twentyfour hours after phlebotomy?

13. If on removing the suture, the wound is oozing but the vein is unobstructed, how should it be treated?

14. What should be done in case of secondary hemorrhage from the vein? 

Foreign Bodies in the Pharynx and Esophagus.-Page I62

1. In what animals is this most common?

2. What kinds of foreign bodies are liable to be found there?

3 . What is the cause of their lodging?

4. What parts of the tube are most liable to obstruction?

5. What are the symptoms?

6. Why do cattle bloat when choked?

7. How should such bodies be removed from the pharynx?

S. How should they be removed from the anterior end of the esophagus?

9. How may pilocarpine be used in treating choke?

10. How may chloroform be used in such cases?

11. Is spontaneous recovery liable to take place?

12. What dangers are to be encountered in passing the probang?

13. How should the tympanites accompanying choke of cattle be treated?

14. How may the obstruction be reduced in size?

15. Is their extraction by instruments advisable?

Esophagotomy.-Page I66

1. What is esophagotomy?

2. For what purpose is it performed?

3. Where is it performed?

4. How is it performea?

5. Should the wound be sutured?

6. What is the after treatment?

7. Of what should the diet consist after the operation?

\section{Foreign Bodies in the Pharynx and Esophagus of Carnivora.-Page 170}

1. What are the symptoms of these obstructions?

2. How should they be treated if in the pharynx?

3. How should they be treated if in the esophagus?

4. How may apomorphine be useful in this condition?

5. Is treatment effective in the dog? 



\section{Impaction of the Crop in Birds.-Page I7o}

1. What is the crop?

2. What are the causes of its impaction?

3. What are the symptoms?

4. Does it ever become chronic?

5. In what way does it destroy life?

6. How should it be treated?

7. How should an operation for its removal be performed:

8. What is the prognosis?

\section{Dilatation of the Esophagus - Page I73}

1. What is ectasia?

2. What is diverticula of the esophagus?

3. What are the causes of such dilatation?

4. Where do such dilatations usually occur?

5. What are the symptoms?

6. Does rupture of the mucous coat ever occur?

7. How should such dilatations be treated?

8. Is operative procedure liable to be successful?

9. What is the best advice to the owner under such circumstances?

Stenosis and Compression of the Esophagus.-Page I 76

1. What is stenosis?

2. What is the cause?

3. How may stenosis tend to produce dilatation above the point so affected?

4. What conditions of the mucous membrane may lead to its contraction?

5. How could stenosis be distinguished from choke?

6. Can it be diagnosed positively during life?

7. Why do bovines show tympanities during stenosis of the esophagus?

\section{Paralysis of the Pharynx and Esophagus.-Page 176}

1. What nerve energizes the pharynx and upper two-thirds of the esophagus?

2. What one supplies the lower third? 

3. What are the symptoms of paralysis of these organs?

4. Can paralysis be positively distinguished from stenosis?

5. Might such paralysis be unilateral?

6. What treatment is indicated when they are paralyzed:

7. What is the prognosis?

8. How may they be fed under such circumstances?

\section{Tumors in the Pharynx and Esophagus.--Page 178}

1. What form of tumors is most frequent in the pharynx of cattle?

2. How may tumors in this region affect the larynx?

3. What is the general effect of tumors in the esophagus?

4. How can they be diagnosed?

5. How may staphylotomy be of service here?

6. How can they be removed through the larynx?

\section{Diseases of the Larynx and Trachea.-Page I 82}

1. What is the rhino-laryngoscope?

2. Is it of practical utility?

3. Does the larynx ever suffer from external injuries?

4. If chronic inflammation is present what is its probable termination?

5. What is perilaryngitis chronica fibrosa?

6. What effect would this be liable to have on respiration?

7. How may chronic inflammation be induced in laryngeal op. erations?

8. How may the vocal cords be affected by chronic inflammation?

9. How would a change in them affect respiration?

10. What are the symptoms of chronic laryngitis?

11. How would you distinguish conditions of this kind from paralysis?

12. Are the changes in the larynx visible externally?

13. How could ossification of the larynx be prevented?

14. What are the symptoms of chronic inflammation of the mucous membrane?

15. How does whistling differ from roaring?

16. What is aphonia?

17. What is the cause? 

18. What is the effect of new growths in the larynx?

19. How do purulent and exudative chronic inflammation of the larynx differ in their results?

20. What is the prognosis of each variety?

21. How may such conditions be palliated?

\section{Nervous Diseases of the Larynx.-Page 187}

1. What is neurosis?

2. What are spasms?

3. What is hemiplegia?

4 . What is diplegia?

5 . What is apnoea?

6. What is spasm of the larynx?

7. What organs are involved?

8. What are the causes?

9. What is the prognosis?

10. What is the treatment?

11. When would tracheotomy be indicated?

12. Is excitement injurious?

13. How may chloral hydrate be used in this connection?

14. What is myopathic paralysis?

15. What is neuropathic paralysis?

16. What is hemiplegia laryngis?

17. What muscles act upon the vocal cords?

18. What nerve energizes them?

19. If the constrictors of the larynx are in a state of spasm, which act of respiration would be affected?

20. If they were paralyzed, would the breathing be disturbed?

21. If the crico-arytenoideus posticus was paralyzed, how would it affect the vocal cords, and which act of respiration would be disturbed?

22. What organ could force the arytenoid toward the opening of the glottis?

23. How could the inspired air do this?

24. How can whistling be differentiated from roaring?

25. How might nerve grafting remedy roaring? 



\section{Fracture, Deformity and Stenosis of the Trachea.-Page 189}

1. What is fracture of the trachea?

2. What are the symptoms?

3. How could tracheotomy cause stenosis of the trachea?

4. How could it be produced by pericarditis?

5. In what ways may the tube be narrowed?

6. What are the symptoms?

7. How could fracture of the trachea cause emphysema of the neck?

8. What is the prognosis of tracheal stenosis?

9. Are these conditions ever congenital?

10. What is meant by congenital?

11. How can stenosis of the trachea be treated?

12. When would a tampon canula be useful?

13. How could tracheotomy be performed below the stenosis, and the tube dilated above the point of operation?

\section{Foreign Bodies. Tumors and Parasites in the Trachea.-Page 192}

1. Why do foreign bodies rarely gain access to the trachea?

2. What conditions of the pharynx and larynx might allow foreign bodies to enter the trachea?

3. Why is it particularly dangerous for foreign bodies to enter the trachea?

4. How may foreign bodies enter the trachea during trache. otomy?

- 5. Are new growths ever found in the trachea?

6. What varieties of worms infest it?

7. What are the symptoms of the various foreign bodies in the trachea?

S. How could their presence be distinguished from obstruction of the larynx?

9. How might abscesses on the wall of the trachea produce mechanical pneumonia?

10. Is it possible for the feed to be forced into the trachea from the rumen after death?

11. What prophylactic measures might prevent foreign bodles from entering the trachea? 



\section{Tracheotomy.-Page 194}

1. What is tracheotomy?

2. What four reasons are given for performing it?

3. What animals is it most often performed upon?

4. What part of the trachea offers the most convenient point for operation?

5. In what ways are incisions of the trachea made?

6. What tube is most practical for temporary use?

7. What one for permanent use?

8. What may be used in the place of a tube in case of an emergency

9. What is said of tracheotomy through the crico-tracheal ligament?

10. How is the use of the tube in this way said to affect roaring?

11. In what way is the tampon canula useful?

12. What unfavorable conditions are liable to follow tracheotomy?

13. What are the causes of stenosis following it?

14. How might it be relieved?

Laryngotomy. Laryngo-Fissure.-Page 205

1. What is thyroidotomy?

2. What is cricotomy?

3. What is crico-tracheotomy?

4. What is crico-thyroidotomy?

5. What instruments are necessary to perform these operations?

6. How should the animal be secured?

7. How should the field of operation be prepared?

8. How should the incision be made?

9. Why is it necessary to control all hemorrhage before dividing the mucous membrane?

10. How could blood be prevented from entering the lungs without the tampon canula?

11. How may the cartilages be injured?

12. What is the technique of the removal of the arytenoid cartilage?

13. How may the operative field be kept free from blood?

14. How should spurting vessels be treated?

15. How should the mucous membrane be sutured? 

16. What is the after treatment?

17. How much rest should the animal be given before it is returned to work?

18. Are the effects always immediate or may they be dedelayed?

\section{Diseases of the Thorax.-Page 217}

1. What is the thoracic cavity?

2. What bones form its frame work?

3. What forms its postero-inferior boundary?

4. What bounds its anterior aperture?

5. What lines it internally?

6. What organs does it contain?

7. What organs are covered by the pleurae?

8. What blood vessels supply its walls with blood?

9. On which border of the rib is the intercostal artery and vein located?

10. Where does the external thoracic vein cross its walls?

11. What are the boundaries of the space occupied by the heart?

12. On a line with which ribs are the posterior borders of the olecranon tuberosities?

\section{Fracture of the Ribs.--Page 217}

1. How are such fractures usually produced?

2. What is a contused iracture?

3. Which rib is sometimes fractured by hard pulling?

4. Why are hogs' ribs so often fractured?

5. What is a subperiosteal fracture?

6. What is a compound fracture?

7. What complications of costal fractures are most serious?

8. Why is union of the posterior ribs most difficult?

9. Does union, by cartilage only, impair the health of the animal?

10. What is the chief danger in compound fractures, involving the skin?

11. What is sequestrum?

12. What are the chief dangers from injuries to the pleurae and lungs? 

13. What blood vessels are liable to be injured?

14. How are costal fractures diagnosed?

15. What would be the symptoms of injury to the lungs and pleurae from costal fractures, without a skin wound?

16. What similarity is seen in the symptoms of fracture of the first rib and radial paralysis?

17. How should simple fractures of the ribs be treated?

18. How should they be treated if complicated?

\section{Costal Sinus.-Page 2 I9}

1. What is a costal sinus?

2. What are the causes?

3. What are the symptoms?

4. How should it be treated?

5. What is the prognosis?

\section{Sternal Sinus.-Page 220}

1. What are the causes of a sternal sinus?

2. What is the treatment?

3. What is the prognosis?

Wounds ann Bruises of the Soft Parts of the Chest Wall Wounds without Perforaions.-Page 222

1. Of what do the above wounds consist?

2. What vessels are liable to be injured?

3. What are the chief dangers from punctured wounds of this region, that do not reach the thoracic or abdominal cavities?

1. What constitutional sjmptoms would indicate serious com plications?

5. How might emphysema develop from such wounds?

6. What would lameness, when accompanying such wounds indicate?

7. What would coldness and loss of pulsation about the foot indicate?

8. How should such wounds be treated? 



\section{Wounds of the Pleura.-Page $22+$}

1. What is pneumothorax?

2. In what two ways may air enter the pleural sac?

3. What forms of wounds are liable to open it?

4. How may it be determined?

5. What effect does opening it have on respiration?

6. What becomes of air when introduced into it?

7. What is haemothorax?

$\delta$. Injury to what vessels would allow blood to enter the pleural cavity?

9. In what way would hemothorax be dangerous to life?

10. In what ways may the pleurae become infected from such wounds?

11. What damage may be done by probing such wounds?

12. What knowledge may be gained by examining the body that made the wound?

13. How determine whether the dyspnoea is the result of penumothorax, hemothorax, pleurisy, or injury to the muscles?

14. What kind of sound would percussion yield in the following cases: 1st, Penumothorax; 2nd, Hemothorax; 3rd, Pleurisy?

15. What would a blood stained discharge from the nose or mouth indicate?

16. Why should the prognosis in such cases be guarded?

17. In what animals are such wounds most serious?

18. What is the most important principle to be observer in treating them?

19. When is it advisable to suture them?

20. When would drains and counter-incisions be indicated?

21.- How should they be bandaged?

22. What would indicate necessity of redressing?

23. How should pneumothorax be treated?

24. How should hæmothorax be treated?

25. How should septic pleuritis be treated?

26. What strength of bicloride solution may be used for irrigating the pleural sacks? 



\section{Shoulder Abscesses.-Page 228}

1. What are shoulder abscesses?

2. In what tissues do they develop?

3. What relation do they bear to the levator humeri muscle?

4. What is their appearance?

5. Are they of slow or rapid development?

6. What are the causes?

7. What germ is said to produce them?

8. Why should they be opened early?

9. What is the result of leaving them too long without opening?

10. What is the effect of setons upon them?

11. How may the swelling be treated before opening?

12. How may fibrous growths be destroyed after they are opened?

13. How may they be dissected?

14. What blood vessels are in danger of being wounded?

15. What effect does their dissection have on the levator hu. meri muscles?

16. What after treatment is necessary?

17. What are pillar reins and where are they useful?

\section{Sadale and Collar Galls.-Pase 233}

1. What is hygroma?

2. How may undue pressure on a part produce one?

3. What is the difference in the appearance of a cyst when superficial and when beneath the fascia?

4. How would the superficial and deep forms differ clinically?

5. How might undue pressure produce necrosis of the skin?

6. How could such injuries cause necrosis of the bone?

7. How may necrosis of fascia or ligament be produced?

8. How are such injuries liable to terminate?

9. How do such injuries to the withers act to produce fistulous withers?

10. Why are abscesses in the region of the withers so difficult to heal?

11. Does necrosis of the ribs, bodies of the vertebrae, or scapula ever occur?

12. What is the prognosis? 

13. How do the above conditions differ from eczema of the same region?

14. What is the important principle in fitting a saddle or collar to prevent injury to the tissues?

15. Why are side saddles particularly injurious to the parts?

16. How may double girt saddles prevent such injuries?

17. What is the primary cause of all fistulous withers?

18. How may such injuries occur independent of the saddle and collar?

19. Is this disease endemic; if so, what is the cause?

20. How should cutaneous injuries of this region be treated?

21. How does cold affect the extravasation?

22. Why do some bruises cause hygroma and others abscess?

23. What should be the treatment if necrosis is present?

24. What three principles should always be observed in treating fistulous withers?

25. Of what does a perfect drainage consist?

26. How does a dry surface prevent the development of bacteria?

27. How could hygroma be distinguished from an abscess?

28. How should each be treated?

29. If a hygroma is to be aspirated, what antiseptic precautions are necessary?

3). What was Portal's experience in removing the cartilage of prolongation?

31. Where should an incision be made to drain the region internal to it?

32. How may pads be arranged to protect a bruised spot beneath collar or saddle?

33. How should fibroma and granuloma resulting from injuries by collar or saddle be treated?

\section{Tapping the Thoracic Cavity.-Page 244}

1. What is paracentesis?

2. What is the operation called when applied to the thoracic cavity?

3. For what purpose is it performed?

4. What sized trocar should be used?

5. How should the field of operation and instruments be prepared? 

6. How may entrance of air to the cavity be prevented?

7. Where should the puncture be made in the horse, measuring from point of elbow?

8. How tell when the trocar has reached the thoracic cavity?

9. At which border of the rib should the puncture be made?

\section{Surgical Diseases of the Abdomen.-Page 25I}

1. What organs and tissues compose the abdominal walls?

2. By what vessels are they supplied with blood?

3. What organs are contained within this cavity?

4. What vessels supply them with blood?

5. Through what system of veins is it returned to the heart?

6. What are the natural openings to the abdominal cavity?

7. Where is each situated?

8. What is a hæmatoma?

9. How could one be produced by a bruise?

10. What is the principal danger from punctured wounds of this wall, that do not penetrate the cavity?

11. How should they be treated?

12. How should incised wounds of these walls be treated?

13. How should bruises of this region be treated?

\section{Wounds of the Abdomen.--Page 258}

1. What four classes of these wounds are mentioned by Möllen?

2. How do these compare from a clinical standpoint?

3. How are wounds that penetrate this cavity usually made?

4. What are the principal dangers from such wounds?

5. How should they be treated?

6. What symptoms would indicate peritonitis?

7. In wounds with prolapse, what is the first important step in their treatment?

8. How may the prolapsed organs be kept in position?

9. What general line of treatment should be adopted with all such wounds? 



\section{Bowel Fistula.-Page 259}

1. What is anus preternaturalis?

2. How may these fistulae be formed?

3. In what way may they be of detriment to the animal?

4. How should they be treated?

5. How could the purse-string suture be used in their treatment?

\section{Paracentesis Abdominis.-Page 26r}

1. Of what does this operation consist?

2. For what purpose is it performed?

3. At what point may the puncture be made?

4. How should the field of operation and instruments be jrepared

\section{Hernia.--Page 263}

1. What is hernia?

2. How does it differ from prolapse?

3. What is incarceration?

4. What kind of herniae are caused by congenital defects?

5. At what period of life do they usually appear?

6. What is intra-abdominal pressure?

7. How does it affect hernia?

8. What is the hernial ring?

9. What is the hernial mass or swelling?

10. What is the hernial sac ?

11. What is the hernial content?

12. What may be in the sac?

13. What is the difference between reducible and irreducible herniae?

14. What conditions would cause them to be irreducible?

15. How may they be diagnosed?

16. How do they differ from inflammatory swellings?

17. What does the existence of the hernia opening prove?

18. How could the trocar be of service in diagnosing hernia?

19. When does a hernia become dangerous?

20. Which is the most dangerous, the large or small hernial ring? 

21. What constitutes strangulated hernia?

22. When strangulation takes place, which set of blood vessels becomes obstructed first?

23. What effect does the venous obstruction have upon the contents of the bowel?

24. What causes the pain in strangulated hernia?

25. How does faecal stasis add to the disturbance?

26. What causes necrosis of the contents?

27. Where is it first visible?

28. What is the appearance when in its first stage?

29. Is the color of the tissues a positive guide?

30 . What is the cause of strangulation?

31. What are the symptoms?

\section{Umbilical Hernia.-Page 273}

1. How is the umbilical ring formed?

2. What is an umbilical hernia?

3. What viscera are liable to protrude?

4. What are the causes?

5. What are the symptoms?

6. How may the open umbilicus be found?

7. What other diseases might be mistaken for it?

8. How can they be differentiated?

9. What would result if the cord was not severed close enough?

10. What animals are subject to umbilical hernia?

11. Why is incarceration of umbilical hernia rare?

12. What effect does the size of protruding organs have on spontaneous recovery?

13. Is spontaneous recovery common?

14. If so, what is the cause?

15. Prior to what age does it occur, if at all?

16. Upon what does the prognosis depend?

17. What is the prognosis, if strangulation has taken place?

18. How may common salt be used in the treatment of hernia?

19. How may trusses be used?

20. What is the object in using caustics?

21. How does their effect differ from the actual cautery? 

22. What is the relative value of the above means as curative agents?

23. What constitutes radical treatment?

24. How is the operation of simple ligation performed?

25. In what sized hernial rings is this method effective?

26. How is the multiple ligature applied?

27. How is the operation performed by clamps?

28. How could a wood clamp be used?

29. How long should clamps or ligatures be left on?

30. In what sized hernix are ligatures and clamps always of service?

31. What is herniotomy?

32. Under what circumstances should it be performed?

33. What is the technique of the operation?

34. Should the peritoneal sac be opened?

35. What would be the probale result if catgut sutures were used?

36. How does adhesion of the peritoneum interfere with the operation?

37. How would a large oval ring affect the results?

38. Why are ligatures, clamps, and irritants unsuitable for dogs and other small animals?

\section{Inguinal and Scrotal Hernia.-Page 280}

1. Through what natural opening do they occur?

2. What forms the hernial sac?

2. Is either sex exempt?

4. Why are quadrupeds less susceptible than man?

5. What species of the lower animals are most susceptible?

6. What organs are liable to enter the sac?

Inguinal Hernia in the Horse.-Page $28 I$

1. What is the inguinal canal?

2. What forms its anterior and posterior boundaries?

3. What forms its external opening?

4. What is its shape?

5. Has it an internal opening? 

6. By what is it occupied in the normal male?

7. By what is it occupied in the female?

8. What is its length in the horse?

9. What is the processus vaginalis?

10. Of what is it composed?

11. From what is the infundibuliform fascia derived?

12. What is the relative strength of the structures forming the testicular sac?

13. What forms the abdominal ring?

14. What is the cause of inguinal hernia?

15. At what age is it most likely to appear?

16. At what age is spontaneous recovery likely to occur?

17. Are geldings exempt?

18. What are the symptoms?

19. What is the difference between inguinal and scrotal heruia?

20. What is the condition of the spermatic cord, in incomplete inguinal hernia?

21. How can a diagnosis be confirmed by manual examination?

22. What effect does strangulated inguinal hernia have on the gait?

23. How do the symptoms differ from those of colic?

24. Why is it advisable to examine the scrotal region in all cases of colic?

25. How can it be differentiated from sarcocele?

26. How can it be differentiated from hydrocele and hematocele?

27. What is the prognosis of non-strangulated hernia?

28. What of strangulated?

Treatment of Inguinal and Scrotal Hernia.-Page 285

1. What is the object to be sought in their treatment?

2. How does it differ when the horse is to be kept entire or gelded?

3. How can reduction be assisted per rectum?

4. How may clamps be used?

5. How may ligatures be serviceable?

6. To what tissues must either clamps or ligatures be applied?

7. How long should they be left on?

8. How should the operation be modified in the gelding?

9. What is the procedure, if omentum is found in the processus? 

10. How does the treatment of strangulated hernia differ from the above?

11. What methods should be tried to reduc it without operating?

12. How may hot applications be of service?

13. How can the abdominal ring be enlarged?

14. What vessels are liable to be injured?

15. How may the cavity of the processus vaginatis be obstructed to prevent a recurrence?

16. Why is immediate operation necessary in strangulation?

\section{False Inguinal Hernia.-Page 292}

1. How does this differ from the true inguinal hernia?

2. Could they be differentiated without an operation?

3. How would the treatment differ?

4. In what position should the horse be placed, and how restrained for such operations?

5. How should adhesion be treated?

\section{Inguinal Hernia in Ruminants.-Page 294}

1. Is this of common occurrence?

2. Why is it less serious than in the horse?

3. In what ways, if any, would the treatment differ from that for the horse?

\section{Inguinal Hernia in Swine.-Page 295}

1. Is this of common occurrence?

2. How does it differ from that of the horse?

3. How should it be treated?

4. How should the animal be restrained?

\section{Inguinal Hernia in Dogs.-Pagr 297}

1. In which sex is it most common?

2. What organ is usually found in the hernial sac?

3. Are bitches that have never had puppies subject to it?

4. How does parturition predispose them to it?

5. Is strangulation liable to occur? 

6. How is inguinal hernia diagnosed?

7. Would strangulation be liable to produce vomiting?

8. What is the technique of the radical operation for it?

9. At what periods should such operations be avoided?

\section{Crural Hernia. - Page 298}

1. Where is the crural ring?

2. What bounds it?

3. By what is it occupied?

4. What divides it from the peritoneal cavity?

5. What structures must be distended or ruptured to allow viscera to enter it?

6. What are the symptoms of this form of hernia?

7. Is a rectal examination of any service in diagnosing it?

8. What are the causes?

9. How should it be treated in diagnosing it?

10. Is the disease common?

\section{Perineal Hernia.-Page 299}

1. What is the excavatio recto-vesicalis?

2. In which sex is it found?

3. Where is the excavatio recto-uterina?

4. Where is the excavatio vesico-uterina?

5. What is perineal hernia?

6. What animals suffer most from this accident?

7. What organs are usually found in the sac in the male?

8. What in the female?

9. Where does the tumor of this hernia form?

10. How can it be diagnosed?

11. What are the causes?

12. Does strangulation ever occur?

13. What is the technique of the operation for its cure?

14. Under what circumstances is it best to operate?

\section{Ventral Hernia.-Page 301}

1. What is ventral hernia?

2. How does it differ from umbilical?

3. What are the causes? 

4. Is the sac of ventral hernia usually lined with peritoneum?

5. What organs are liable to be in it?

6. Where are ventral herniae usually located?

7. What are the symptoms?

S. How does the diagnosis differ from that of umbilical?

9. How does the treatment differ?

10. Why are the clamp and ligature not successful in treating it?

11. In what kind of ventral herniae is incarceration most liable to occur?

12. What other forms of hernia are liable to be met with?

\section{Surgical Diseases of the Stomach and Bowels, Foreign Bodies in the Digestive Tract.- Page 3 Io}

1. How do foreign bodies reach the digestive tract?

2. What species of animals are most frequently affected?

3. What class of foreign bodies is liable to be found in the digestive tract of oxen?

4. Have horses ever been known to be so affected?

5. What foreign substances are most liable to reach the intestinal tract of dogs?

6. What is the chief danger of them in bovines?

6. From what organ can they reach the pericardium?

7. How may they cause peritonitis?

8. Do they ever penetrate to the exterior of the body?

9. Are sheep and goats ever so affected?

10. What would be the probable result if a dog swallowed a solid rubber ball one inch in diameter?

11. If a bone swallowed by a dog reaches the stomach, where is it liable to lodge?

12. What are the symptoms of a foreign body passing from the reticulum to the pericardial sac in cattle?

13. What are the symptoms of obstruction of the digestive tract of dogs by foreign bodies.

14. How may palpation be of service in this connection?

15. Are the X-rays of service here?

16. What is the technique of the operation for the removal of such bodies in cattle?

17. How should dogs be treated if known to have recently swallowed harmful bodies? 

18. What is the meaning of the prefix,-laparo?

19. What is the meaning of the suffix,-tomy?

20. What is laparotomy?

21. What is laparo-gastrotomy?

22. What is laparo-hysterectomy?

23. What is laparo-enterotomy?

24. What is laparo-colostomy?

25. How is Gely's bowel-suture made?

26. How is Lembert's?

27. How is Wolfler's?

28. What is the principle of all bowel sutures?

29. What of the Murphy button?

30. How is it used?

31. How is the Connell suture made?

32. What is the technique of laparo-gastrotomy, and laparoenterotomy for the removal of a foreign body?

33. What antiseptic precautions should be taken?

34. How should the abdominal wound be closed?

35. What should be the after treatment?

36. Why is the prognosis of laparatomy in the horse so unfavorable?

\section{Puncture of the Bowel in Horses.-Page 315}

1. What is punctio-intestini?

2. For what purpose is it performed?

3. What organs are punctured?

4. Where is the field of operation?

5. What are the necessary antiseptic precautions?

6. How determine the necessity of puncturing at a certain point?

7. What points of the abdomen can be punctured?

8. What is the prognosis?

9. What of puncture from the rectum?

10. What causes the most serious abscesses following puncture?

11. How should an abscess following this operation be treated?

12. Should the skin be incised before the trocar is inserted?

13. What sized trocar is preferable ?

14. Is it advisable to puncture more than once in the same. place? 

15. Is it ever advisable to puncture the same animal in more than one place?

16. When is the stomach tube of service?

\section{Puncture of the Rumen.-Page 321}

1. What instruments are necessary for this operation?

2. Under what circumstances is it necessary to periorm it?

3. Where is the ficld of operation?

4. Is antisepsis as essential as in the horse?

5. Why is it necessary to use so large a canula?

6. What feeds are most liable to cause fermentation in the rumen?

7. Is the stomach tube of service in this condition?

8. How should it be used?

\section{Rumenotomy.-Page 325}

1. What is rumenotomy?

2. When is it indicated?

3 . Where is the field of operation?

4. What are the necessary antiseptic precautions?

5. What are the necessary instruments?

i. How should the animal be secured?

7. What is the technique of opening the rumen?

8. What precautions are necessary to prevent ingesta from entering the peritoneal cavity?

9. After the rumen is opened, how should the contents be removed?

10. How should the incision in the rumen be closed?

11. When should the rumen be loosened from the abdomiual wall?

12. How should the incision in the abdominal wall be closed?

13. What is the after-treatment?

Intussusception or Invagination of the Bowel.--Page 328

1. What is intussussception?

2. What are its symptoms in the horse?

3. What in the ox? 

4. What in the dog?

5. Is medicinal treatment of any value?

6. What is the surgical treatment?

7. How does it differ from that for the removal of foreign bodies?

\section{Twist or Rotation of the Colon.-Page 330}

1. Of what does it consist?

2. What part of the colon becomes displaced?

3. According to Jellimann, what percentage of fatal cases of colic examined, resulted from this condition?

4. What class of horses is most susceptible?

5. How do the symptoms differ from those of ordinary colics?

6. What is the normal direction of the longtitudinal bands of the colon?

7. Can these be detected per rectum?

8. What is their direction in twist to the right?

9. What is their direction in torsion to the left?

10. What is the appearance of the rectal mesentery?

11. What is the difference in the direction of caecal and colic bands?

12. How can these points be demonstrated on the cadaver?

13. What is the prognosis, if not reduced?

14. What is the modus operandi of their reduction?

15. Is it advisable to evacuate the gas by puncture?

16. Is it not possible that this condition often exists and reduces spontaneously after puncturing?

\section{Surgical Diseases of the Posterior Portion of the Rectum and Anus.-Page 335}

1. How much of the rectum of the horse is without a serous covering?

2. What portion is so arranged in the smaller animals?

3. What supports it in its position?

4. How do the gland structures about the anus of the dog differ from those of other animals? 

Diseases of the Urinary Organs. Congenital Malformations. Fissures of the Male Meatus Urinarius.-Page 356

1. What constitutes hypospadia?

2. What is epispadia?

3. What are the causes?

\section{Pervious Urachus.-Page 356}

1. What is the urachus?

2. What is its function in ioetal life?

3. What becomes of it after birth?

4. What happens when it remains open?

5. How should it be treated?

6. Is it of importance to note if the urethra is normal?

\section{Urinary Calculi.-Page 357}

1. What are calculi?

2. Where do urinary calculi form?

3. From what are they formed?

4. How do they form?

5. How may catarrhal inflammation of the tract cause them?

6. How may they be caused by retention of urine?

7. Are they usually single or multiple?

\section{Urinary Calculi in the Horse.--Page $35^{8}$}

1. In what part of the urinary tract are calculi liable to form?

2. What are the symptoms?

3. How can they be diagnesed through the rectum or through the vagina?

4. How may the catheter be of service in the diagnosis?

5. If these bodies lodge in the urethra, at what point are they liable to be?

6. Where is the fossa navicularis?

7. What is lithotomy?

8. What is the technique of this operation?

9. In what position should the animal be placed?

10. How should it be restrained? 

17. If reposition fails, what operative procedure may be resorted to?

18. How is the wooden ring used?

19. How are multiple ligatures applied in amputating it?

20. What is the cobbler's stitch, and how is it applied?

21. What aftertreatment is necessary?

\section{Dialatation. Stenosis and Paralysis of the Rectum and Anus.-Page 349}

1. What is stenosis?

2. What are the causes of stenosis of the anus?

3. What of the rectum?

4. How may each be prevented?

5. How may each be treated after once contracted?

6. What is dilatation of the rectum?

7. How does it differ from paralysis?

8. How should each of these conditions be treated?

\section{Anal and Recto-Vaginal. Fistula.-Page 353}

1. What constitutes complete anal fistula?

2. What incomplete anal fistula?

3. What recto-vaginal fistula?

4. What is the cause of the former?

5. What of the latter?

6. How are they diagnosed?

7. What is the treatment for anal fistula?

8. What for recto-vaginal?

9. What is the prognosis?

\section{Tumors in the Rectum and Anus.-Page 354}

1. What kind of tumors has been found in the perirectal connective tissue of dogs?

2. What kind of tumors is found in the same region of the horse?

3. What class is most common in the rectum?

4. How are they diagnosed?

5. Upon what does the prognosis depend?

6. How should they be treated? 

9. What are the symptoms?

10. Is it liable to cause pruritus?

11. How should it be treated?

\section{Inflammation of the Surrounding Rectal Connective Tissue.-Page $34 \mathrm{I}$}

1. What is paraproctitis?

2. What are the causes?

3. What is purulent cellulitis?

4. How may it affect these tissues?

5. What would be the effect of an abscess of this kind npon the movement of the bowels?

6. What would be the result of its opening into the peritoneal cavity?

7. What is the prognosis, if it opens or is opened into the rectum?

8. What if external?

9. How should such conditions be treated?

\section{Prolapse of Rectum and Anus.-Page 343}

1. Of what does this consist?

2. When is prolapsus ani a physiological condition?

3. In what animal is this condition most marked?

4. What animals are subject to an abnormal prolapse?

5. What tissue would necessarily be ruptured in complete prolapsus recti?

6. What is prolapsus recti cum invaginatione?

7. What is the usual cause?

8. How can prolapsus be distinguished from invagination?

9. What causes the twisted appearance of an inverted bowel?

10. How can it be reduced?

11. What medicinal agents may be used to prevent its return?

12. In what position should the animal be kept?

13. What effect would distention of the bowel with liquid have, if the hind quarters were raised?

14. What effect does the length of time it has existed have on reposition?

15. What methods may be employed to prevent a relapse?

16. How should sutures be applied for this purpose? 



\section{Congenital Malformations.-Page 335}

1. What is atresia ani?

2. What is atresia recti?

3. What is cloaca?

4. How is the anus formed?

5. At what period does this occur in the horse and ox?

6. When in sheep, goats and swine?

7. When in carnivora?

8. How does it happen that the anus is not always formeil?

9. What are the symptoms of imperforated anus?

10. What animals are most liable to be so affected?

11. How should they be treated?

12. How can stenosis be prevented?

13. What is the prognosis?

Injuries to the Rectum and Anal Region.--Page 338

1. How may the rectum be injured?

2. How may the injuries vary in extent?

3. How are they diagnosed?

4. What are mares that receive such injuries during parturition commonly called?

5. How should such cases be treated?

6. Is it necessary to give special attention to the condition of the bowels during the treatment?

7. Would division of the sphincter ani on the opposite side be of service?

\section{Inflammation of the Mucous Membrane of the Rectum and Anus.-Page 340}

1. What is proctitis?

2. What are the causes?

3. What is pruritus ani?

4. What is tenesmus?

5. What are the symptoms of proctitis?

6. Of what does the local treatment consist?

7. What internal treatment is indicated?

8. What glands about the anus of dogs are subject to inflammation? 
L. of C 


\section{Inflammation of the Urinary Bladder.-Page 380}

1. What are the usual causes of cystitis?

2. What is pericystitis?

3. What are its surgical causes?

4. What are the symptoms?

5. What is the treatment if due to a traumatism?

6. What if from a foreign body?

7. What if from irritating drugs?

8. What if from alkaline fermentation?

\section{Prolapse and Inversion of the Bladder. - Page $3 S_{2}$}

1. Which sex is subject to this condition?

2. Which species are most subject to it?

3. If the lower vaginal wall were ruptured and the bladder pushed through, would the condition constitute ;rolapse or eversion?

4. Which condition would exist, if the outer surface of the protruding body were a serous membrane?

5. Which if the outer surface were a mucous membrane?

6. Would any tissue necessarily have to rupture to permit eversion of the bladder?

7. How does eversion take place?

8. For what might prolapse vesicae be mistaken in parturition?

9. Could the prolapsed bladder contain urine?

10. Could the everted one?

11. In the latter case, where would the uterus be found?

12. In eversion where is the protruding organ found?

13. Why is prolapse more dangerous than eversion?

14. How should recent cases of prolapse be treated?

15. If the serous coat had become ulcerated, what would be the prognosis?

16. How should the vaginal wound be treated after reposition?

17. In prolapse, what part of the urethra is liable to become obstructed?

18. How should eversion be treated?

19. What would be the prognosis of eversion if the mucous membrane had become diseased?

20. How should reposition be accomplished? 

19. Why should cicatricial tissue be reduced to the minimum?

20. Is surturing of the urethral wound advisable?

21. Why should the skin wound be left open and larger than that of the urethra?

22. Why is it necessary to wash frequently urethral wounds of $\operatorname{dog}_{\mathrm{S}}$ with a saline solution?

23. How should stenosis be treated?

24. Under what circumstances might an artificiary urinary meatus be established?

25. What is the technique of the operation?

26. What are the causes of urethral fistula?

\section{Paralysis of the Urinary Bladder.-Page 377}

1. What is cystoplegia?

2. How does this affect urination?

3. What effect would paralysis of the sphincter vesicae have on urination?

1. What conditions may produce paralysis of the bladder?

5. What are the symptoms of paralysis of its muscular coat?

6 . What if both the detrusor, urinae, and sphincter vesicae are paralyzed?

7. What is ischuria?

8. What is enuresis?

9. What is the prognosis?

10. How should retention be treated ?

11. How should catheterization be performed on the horse and mare?

12. How on male and female bovine?

13. How on the dog?

14. What danger is there of producing infection of the bladder?

15. What complications might result from decomposition of the urine?

16. What is cystitis?

17. What is nephritis?

18. What is pyelitis?

19. What is pyelo-nephritis?

20. Under what circumstances should the bladder be irrigated?

21. How should the operation be performed? 

S. How is it performed upon the dog?

9. How is the wound in the bladder closed?

10. Why would it be better to stitch the incision in the bladder to that of the abdomen?

\section{Puncture of the Bladder.-Page 373}

1. In what animals does the over-distended bladder reach the floor of the abdomen?

2. From what point is puncture of the bladder most easily performed in herbivora?

3. From what point in dogs?

4. What is the technique of this operation?

5. Under what circumstances should it be performed?

\section{Injuries, Inflammaiion and Stenosis of the Urethra.-Page 375}

1. How is the urethra of the horse liable to be injured?

2. What are the causes of stenosis of it?

3. What is urethritis?

4. What are the causes?

5. What animals suffer from chronic, purulent, urethral catarrh?

6. What is stricture.

7. How is perforation of the urethra recognized?

8. What would be the probable result of a small puncture of the urethra?

9. What effect does urethritis have on urination?

10. What are the symptoms of simple catarrhal urethritis in horses?

11. What is the treatment?

12. What are the symptoms of stricture?

13. How do these differ from those of urethral calculus?

14. What are the symptoms of purulent, catarrhal urethritis in dogs?

15. How should it be treated?

16. What is the prognosis of injuries and stenosis of the urethra?

17. How should injuries of the urethra be treated?

18. Why is it important to prevent cellular-tissue becoming infiltrated with urine? 

11. What would be the procedure if the calculus were too large to pass the urethra?

12. What is the after treatment?

13. How much time may be required to dilate the urethral muscles?

14. Is an anesthetic necessary?

\section{Urethral Calculi in Ruminants.-Page 365}

1. How does the urethra of other male animals differ from that of the horse?

2. In what part of the urinary tract are calculi most liable to lodge?

3. Which sex is troubled most?

4. What are the symptoms?

5. What condition is the upper part of the urethra and blad: der liable to be in?

6. Is rupture of the bladder liable to occur?

7. What is urethrotomy?

8. In which curve of the penis is the calculus most liable to be?

9. In what position should the animal be placed to operate?

10. Can the location of the stone be determined by palpation?

11. Where should the incision be made?

12. How avoid opening the testicular sac?

13. How is the stone removed after the incision is made?

14. What after treatment should the wound receive?

15. If there were danger of rupture of the bladder, how could it be evacuated?

16. How could the animal be relieved?

\section{Urinary Calculi in the Dog.-Page $37 \mathrm{I}$}

1. How does the penis of the dog differ from that of other animals?

2. Where are urinary calculi most liable to lodge?

3. What are the symptoms?

4. How may a diagnosis be confirmed?

5. What is the technique of the operation for their removal?

6. What sequelae are liable to follow?

7. What is laparo-cystotomy? 

21. What treatment would be indicated if the mucous membrane were necrotic?

22. What is the technique of the operation of amputating the bladder?

\section{Tumors in the Urethra and Bladder.-Page 386}

1. What kind of tumors is liable to form in the uretira?

2. What forms of new growth are liable to form in the bladder?

3. What are the symptoms?

4. What is the prognosis?

5. How should they be treated?

Diseases of the Male Organs of Generation.-Page 389

1. What is balanitis?

2. What is the prepuce?

3. How is it formed in the horse?

4. What constitutes the preputial ring?

5. What is the glands penis?

6. Where is the urethral fossa?

7. What kind of glands is found in the preputial tissues?

8. What is smegma preputii?

9. How may an excess of smegma affect the sheath?

10. How may it affect urination?

11. How will urinating in the sheath affect it?

12. What is the effect of such accumulations in the urethral fossa?

13. What conditions would tend to cause oedema of the sheath?

14. What is the treatment?

15. How should the penis be grasped to pull it down?

16. How should stenosis of the sheath be treated?

17. How can a horse be prevented from urinating in the sheath?

18. How should excoriations of the prepuce be treated?

\section{Inflammation of the Prepuce in Oxen.-Page 391}

1. How is the prepuce of the ox formed?

2. What are the causes of its inflammation? 

3. How does the accumulation of smegma interfere with urination?

4. What are the symptoms?

5. What complications are liable to ensue?

6. How should the hairs about the prepuce be treated?

7. What treatment is required if the prepuce is swollen from accumulations within?

8. What, if necrosis is present?

Inflammation of the Prepuce in Carnivora.-Page 393

1. What are the symptoms of chronic preputial catarrh in dogs?

2. Has the disease any relation to gonorrhoea of man?

3. What is the treatment?

\section{Phimosis, Paraphimosis, Paralysis of the Muscles of, and Injury to, the Penis.-Page 394}

1. Of what does phimosis consist?

2. How may this interfere with urination?

3. What kind of abnormal connection between the sheath and prepuce could interfere with copulation?

4. How should phimosis be treated?

5. What constitutes paraphimosis?

6. What are the causes?

7. Why are dogs subject to this condition?

8. How does paraphimosis differ from paralysis?

9. Is thrombosis of the vessels of the penis ever met with?

10. How could injury to the penis cause paraphimoris?

11. How can paralysis and paraphimosis be differentiated?

12. Why do these conditions sometimes occur during severe disease?

13. How should paraphimosis of the dog be treated?

14. How should the same condition of the horse be treated?

15. How stenosis of the sheath?

16. How can the elastic bandage be used?

17. Of what benefit is scarification?

18. What medicinal treatment would be indicated in paralysis of the penis?

19. Where should such agents be injected? 

20. How could the penis be protected from injury?

21. How is it liable to be injured in the horse or bull?

22. What constitutes its so-called fracture?

23. How may the penis of the dog be injured during coition:

24. How may such injuries produce stricture?

25. How may they affect urination?

\section{Tumors of the Sheath and Penis.-Page 398}

1. What kind of tumors is common to the sheath of horses?

2. Are dogs exempt?

3. What kind of new growths is common about the penis of bulls?

4. How should such growths be treated?

\section{Amputation of the Penis.-Page 399}

1. Where is the corpus cavernosum?

2. The corpus spongiosum?

3. What structure penetrates its entire length?

4. What forms the glauds penis?

5. What constitutes the crura?

6. What muscle empties the urethra?

7. What muscle elevates and retracts the penis?

8. What other muscle retracts it?

9. What structure surrounds the corpus cavernosum?

10. Through what vessels does the blood enter and return from the penis?

11. Where are they situated?

12. What three factors are to be considered in amputating the penis?

13. What conditions make the operation necessary?

14. How should the animal be restrained?

15. At what point should the penis be amputated?

16. How can it be held down during the operation?

17. What principles must be observed to prevent stenosis?

18. How can hemorrhage be controlled?

19. Why is it more difficult to control in the entire horse than a castrated one?

20. What is the technique of the operation by ligation?

21. What by cautery? 

22. What by simple section?

23. What by the ecraseur?

24. What by the elastic ligature?

25. How is the operation performed in carnivora?

\section{Disease of the Prostate.-Page 403}

1. Where is the prostate gland located?

2. Of how many lobes is it composed?

3. What is the size of the lobes?

4. How is it developed in the ox and swine?

5. Is it present in the dog?

6. What form of disease of this gland is met with in the lower animals?

7. What species are most often affected?

8. What are the symptoms of disease of this gland?

9. How differentiated from calculi?

10. When abscesses form, where do they discharge?

11. What effect does castration have on the disease in man?

12. How may the inflammation be relieved?

\section{Diseases of the Scrotum.-Page 405}

1. To what class of wounds is the scrotum subject?

2. What kinds are most dangerous?

3. How should they be treated?

4. What animals are liable to have the scrotum frozen?

5. What are the symptoms?

6. What disease of the skin attacks the scrotum of dogs?

\section{Diseases of the Testicle. Castration of Cryptorchids.-Page 407}

1. What is a cryptorchid?

2. Where is the testicle developed during foetal life?

3. How is it drawn into the scrotum?

4. By what is it supported while in the abdominal cavity?

5. What is the processus vaginalis?

6. Of what is it composed?

7. How is it formed?

8. Does it exist in an abdominal cryptorchid? 

9 At what points are hidden testicles liable to be?

10. What animals are affected?

11. What is the necessary preparation of the subject for the operation?

12. What are the necessary instruments?

13. How should the horse be secured?

14. In what position should he be placed?

15. What antiseptic precautions should be taken?

16. Where should the incision be made?

17. What tissues are to be cut through?

18. How should the inguinal canal be opened?

19. If the testicie is found in the canal, how is the operation completed?

20. If it is not found there, how is the peritoneal cavity opened?

21. Where should this opening be made?

22. Where should the attachment of the testicular ligament be found?

23. How many fingers should enter the peritoneal cavity?

24. What should be sought for there?

25. When any part of the organ is found, how may it be sesecured?

26. How is the operation completed?

27. What after treatment is necessary?

28. What would be the procedure if both are hidden?

\section{Inflammation of the Testicle and Epididymis.-Page $4 \mathrm{I} 3$}

1. What is orchitis?

2. What is the meaning of the prefix, peri-?

3. What is periorchitis?

4. What is epididymitis?

5. What are the causes of these conditions in the lower animals?

6. What are the symptoms?

7. How does an infectious disease of these organs affect the body temperature?

8. How does periorchitis affect the scrotum?

9. What is the prognosis, if from bruises?

10. Are calcification and ossification ever seen?

11. What is the chief danger from abscess formation?

12. What is the common result of periorchitis?

13. How should inflammation of the testicles be treated? 



\section{Tumors of the Testicle.-Page 4 I4}

1. What is sarcocele?

2. What form of tumors is met with in the testicle?

3. What are the symptoms?

4. What is the treatment?

\section{Hydrocele, Hematocele and Varicocele.-Page 415}

1. What is hydrocele?

2. What is haematocele?

3. What is varicocele?

4. What are the causes of these conditions in the lower animals?

5. What are the symptoms?

6. What is the treatment for such lesions?

7. How may these conditions be differentiated from hernia?

8. Which of these conditions sometimes follows castration?

9. How should it be treated?

\section{Inflammation of the Spermatic Cord.-Page 417}

1. What is scirrhus cord?

2. What is champignon?

3. How does scirrhus cord differ fiom champignon?

4. What are the causes of these conditions?

5. What is their appearance when extra-scrotal?

6. When intra-scrotal?

7. When inguinal?

8. What are the symptoms when intra-abdominal?

9. What causes the acute attacks of cellulitis?

10. Are they slow or rapid in their development?

11. Is the omentum ever involved in these growths?

12. What preventive measure should be observed?

13. What internal treatment might be of service?

14. What is the technique of the operation for the removal of scirrhus cord?

15. What is the prognosis?

16. What is the after treatment? 

Diseases of the Female Organs of Generation.-Page 424

1. How may the vulva be wounded?

2. How should recent wounds of this kind be treated?

3. What additional treatment is needed if the edges have cicatrized?

4. How may wounds of the mucous membrane lead to stenosis or occlusion of the vulva?

5. What would be the probable result of an occlusion of the vagina, with fluid accumulations anterior to it?

6. What is meant by primipara?

7. How may the vagina be wounded during coition?

8. What tissues are liable to be injured?

9. What is the principal danger from perforation of the peritoneum?

10. How may air enter the peritoneal cavity from such wounds?

11. What would be the probable result of blood entering it?

12. How should such injuries be treated?

13. How are these parts sometimes injured during parturition?

14. How should such wounds be treated?

15. In what animals are wounds of the peritoneum most serious?

16. How should injuries of the uterus be treated?

17. What is infectious vulvitis?

18. How is it transmitted?

19. How should it be treated?

\section{Eversion of the Vagina.-Page 423}

1. What is the difference between prolapse and eversion?

2. What displacement of the uterus occurs in these diseases?

3. How is it favored by tympanitis?

4. How by stall feeding on distillers' grain?

5. How by severe straining?

6. How by standing in sloping stalls?

7. Why is it most common in pregnant subjects?

8. Why does it appear when the animal lies down, and disappear when it gets up?

9. What is the appearance when the eversion only reaches the vulva?

10. In complete eversion of the vagina, what organ is visible in its center? 

11. In this condition, where would the urinary meatus be?

12. How differentiate between a recent case and one of long standing?

13. How may the organ be injured?

14. How may over-fat cause prolapse?

15. What precautions can be taken to prevent it?

16. In what position should the animal be placed for reposition?

17. In replacing the organ, over what part of it should pressure be applied?

18. Is it important that the uterus be forced into the abdominal cavity?

19. How should sutures be inserted to prevent relapse?

21. How may the tail be used as a truss?

21. In what position should the smaller animals be placed for reposition?

22. How may swelling of the prolapsed organ be reduced?

\section{Eversion of the Uterus.-Page 43I}

1. How does eversion of the uterus differ from that of the vagina?

2. What is the appearance of the surface of the everted uterus of the cow?

3. What condition must the cervix be in, to permit eversion of the uterus?

4. At what period does it occur?

5. How may intussusception of one horn occur?

6. Is this liable to remain after reposition?

7. What are the causes of eversion?

8. What is the prognosis in mares?

9. What in cows?

10. What in bitches?

11. In what way does its treatment differ from that for eversion of the vagina?

12. What medicinal agent may be given to prevent straining?

13. How may uterine contractions be encouraged?

14. How may the hind quarters be raised to assist in replacement, or to prevent relapse? 



\section{Amputation of the Uterus.-Page 434}

1. What conditions indicate amputation of the uterus?

2. At what point should the organ be amputated?

3. How is the operation performed by single ligature?

4. How by multiple?

5. Why is the single preferable?

6. How is it performed by elastic ligature?

7. How may it be performed with the ecraseur and ligature?

8. What is the prognosis?

\section{Tumors in the Vagina and Uterus.-Page 436}

1. Are tumors of these organs as prevalent in the lower animal as in the human?

2. How are they diagnosed?

3. How should they be treated?

4. What instruments are necessary?

5. How may such growths interfere with impregnation?

\section{Diseases of the Mammary Gland - Page 439}

1. Of what does the mammary gland consist?

2. What is the formation of the parenchymatous tissue?

3. What shaped spaces are found in the connective tissue of the stroma?

4. By what are they lined?

5. What do they secrete?

6. By what do they open?

7. To what do these gland ducts lead?

8. In what animals do the milk ducts lead direct to the exterior?

9. To what do they lead in herbivora?

10. Where are the galactophorous sinuses located?

11. How many do the ruminants possess?

12. How many sinuses does the udder of the equine possess?

13. How many ducts does each teat possess in ruminants?

14. How many in the mare?

15. How many teats does each gland have in herbivora?

16. How many milk ducts lead from each gland to the surface of its teat? 

17. Of what does the stroma consist?

18. Do these surround the udder?

19. How is the parenchyma separated?

\section{Wounds and Bruises of the Udder.-Page 440}

1. What animals are most subject to wounds of udder and teat?

2. How are such wounds usually made?

3. How should superficial wounds of this region be treated?

4. What is a teat fistula?

5. How is it formed?

6. How may injuries to the teat permanently interfere with milking?

7. How may bruises cause bloody milk?

8. How should wounds penetrating the milk duct or sinus be treated, during the lacteal stage?

9. How should teat fistula be treated during this period?

10. How is the milk tube of benefit?

11. How can adhesive plasters be used?

12. How can collodion or wound gelatine be of service in treat. ing them?

13. When are teat fistulae most easily treated?

\section{Lactic Calculi.--Page 440}

1. Where do these calculi form?

2. In what way are they troublesome?

3. How can they be removed?

\section{Acute Inflammation of the Udder. - Page $+4 r$}

1. What is the meaning of: 1st, Mastitis; 2nd, Mammitis; $3 \mathrm{rd}$, Garget?

2. How does Fleming classify mastitis?

3. What animals suffer most from mammitis?

4. At what periods of lactation is it most prevalent?

5. At what seasons of the year?

6. Are virgin animals ever affected?

7. What four etiological classifications does Möller give?

8. What are the mechanical causes?

9. What the chemical causes? 

10. What the thermal causes?

11. What the specific causes?

12. How does the mill favor the development of bacteria?

13. By what three paths may they enter the udder?

14. How may they enter through the skin?

15. How may infection occur through the teat duct?

16. How would delay in milking assist bacterial development?

17. How may over-distention with milli produce mammitis?

18. What forms of infection may take place through the blood?

19. What four clinical classes of acute mammitis are given by Möller?

20. What are the four clinical classes of chronic mammitis?

\section{Phlegmonous Mastitis - Page 445}

1. What tissue does this form involve?

2. Is it generally circumscribed or diffused?

3. What is the appearance of the udder?

4. What is the color of the skin?

5. Is the swelling hard?

6. How does it affect the milk?

7. How is the body temperature affected?

8. What may be the terminations?

9. How are the abscesses of this form distinguished from those of the parenchymatous?

10. Does this form ever lead to gangrene?

11. How does it differ from œdema of the udder at time of parturition?

12. Does such œdema ever terminate in phlegmonous mammitis?

13. What is the prognosis?

14. Is phlegmonous mastitis ever contagious?

15. How should it be treated?

\section{Catarrhal Mastitis.-Page 447}

1. What structures of the udder are involved?

2. Is the quantity of milk altered?

3. How does it affect the quality of the milk?

4. Does it usually involve the entire udder?

5. What is the appearance of the milk? 

6. What is the appearance of the udder?

7. What are the causes?

8. Does the catarrhal form ever become chronic?

9. What is the prognosis?

10. What quarantine measures are said to be necessary to prevent its spreading?

11. Is medical treatment of any avail?

12. When are antiseptic injections indicated?

13. What is the prognosis?

\section{Purulent Mastitis.-Page 449.}

1. Where does this form of mammitis originate?

2. To what tissues does it spread?

3. How does it differ from the catarrhal form?

4. How does Franck's experiment prove its mode of infectinn?

5. Does it spread from the quarter first infected?

6. How does it affect the epithelium of the ducts and sinues?

7. What are the causes?

8. How does the attack being confined to one quarter prove that it is infectious?

9 . Is the attack sudden and painful?

10. Where does the swelling originate?

11. Does it spread to the skin?

12. How does it differ from the phlegmonous form in this particular?

13. How does it affect the secretion?

14. What causes the yellowish appearance of the milk?

15. What causes its red appearance?

16. What causes it to curdle?

17. What occludes the milk ducts?

18. How does it affect the body temperature?

19. How does it affect the appetite?

20. How may it affect the gait?

21. What is the cause of such complications as paraplegia and arthritis?

22. What does microscopic examinatin of the milk show?

23. What changes are found by chemically testing the milk?

24. Does normal milk contain any organized ferments?

25. How late in an attack of purulent mastitis is resolution likely to occur? 

26. Is it ever complete?

27. What are the symptoms of this disease?

28. When is the lacteal flow likely to be reestablished?

29. What is a retro-mammary abscess?

30. Where are they liable to develop?

31. Where do they usually open?

32. What is the prognosis?

33. How may conditions of this kind cause septic pneumonia?

\section{Gangrenous In flammation of the Udder.-Page 45I.}

1. What is mastitis gangrenosa?

2. What animals are most subject to it?

3. How did Nocard's experiment with it prove its infectious nature?

4. How did the germ act on other animals than sheep?

5. What does this fact tend to prove?

6. How does mastitis gangrenosa begin?

7. How does it afect the animal's appetite?

8. How does it affect the animal's strength?

9. How does it affect the animal's gait?

10. What is the appearance of the udder?

11. By what are these spots surrounded?

12. Do they ever extend to the surrounding parts?

13. What generalized disease becomes apparent?

14. Does this condition ever prove fatal?

15. If the necrotic process is limited, what is the result?

16. Is septic metritis ever a complication?

17. What is the prognosis of gangrenous mastitis?

18. What steps should be taken to prevent spreading of the disease?

19. When is the disease said to be peracute?

20. How does it affect the body temperature?

21. Why should the udder be kept empty?

22. Of what does the oxygen treatment consist?

23. When would injections of disinfecting fluids be indicated?

24. What agents are suitable for this purpose?

25. How are hot fomentations best applied?

26. How can camphorated mercurous-iode ointment be used?

27 . At what stage is it indicated?

28. How should abscesses be treated?

29. When is amputation indicated? 

30. When would partial amputation be sufficient?

31. What is the technique of the latter?

32. How does complete amputation differ from partial?

33. How can hemorrhage be best controlled during the opera-

34. What after treatment should the wouni receive? ¿uo!

3.5. What is the prognosis?

\section{Chronic Catarrhal Mammitis.-Page 455.}

1. What is the common termination?

2. What is the cause?

3. Is it infectious?

4. What is the clinical appearance?

5. How is it diagnosed?

6. What is the prognosis?

7. What is the treatment?

Tuberculosis and Actinomycosis of the Udder.-Page 455

1. What are the symptoms of each?

2. How are they diagnosed?

3. What animals are subject to actinomycosis?

4. In what two forms does it appear?

5. What is the difference in the clinical appearance of actinomycosis and tuberculosis of the udder?

6. What is the effect upon the milk?

7. How should they be treated?

8. What animals are subject to bothromycosis of the udder?

9. What is the clinical appearance?

10. How can the diagnosis confirmed?

11. What is the prognosis?

12. What is the technique of amputation of the mare's udder?

Stenosis and Closure of the Mammary Duct.-Page 457.

1. What prevents the involuntary escape of milk from the cow's teat?

2. How is the meatus formed?

3. How far from the end of the teat is the sphincter?

4. What causes stenosis or closure of the milk duct? 

5. Is it ever congenital?

6. Is it ever due to tumor formation?

7. How do occluding membranes from in the upper part of the teat?

8. How are these conditions diagnosed?

9. What is a teat catheter or siphon?

10. How are they made self retaining?

11. What sterilization is necessary in their use?

12. What is the teat bistoury. and how is it used?

13. What is the result of amputating the end of the teat?

14. When is this operation indicated?

15. When will the involuntary milk flow cease?

\section{Tumors of the Udder.-Page 460.}

1. What animals suffer most from tumors on the teats and udder?

2. What class of tumor is most common?

3. On what part of the udder do polypi form?

4. In the udders of what animals has sarcoma been found?

5. In the udders of what animals has carcinoma, enchondroma, and adenoma been found?

6. In the udder of what animals are melonotic tumors seen?

7. How should tumors of the udder be treated?

8. What is the prognosis?

Diseases of the Spinal Column and Pelvis.-Page 463.

1. What forms of fracture of the vertebrae are seen in the lower animals?

2. How do they occur?

3. Are they always manifested at the time the injury occurs?

4. How does muscular contraction cause them?

5. What conditions of the vertebrae predispose them to fracture?

6. What are the symptoms?

7. Are fractures of this region easily detected?

8. Why do they generally cause paralysis?

9. How are they differentiated from haemoglobinuria?

10. What is the prognosis of vertebral fracture with paraylegia? 

Fractures of the Sacral and Caudal Vertebrae.-Page 468.

1. What parts of these vertebrae are liable to fracture?

2. What is the cause?

3. What are the symptoms?

4. How should they be treated?

Curvature of the Spine.-Page 470.

1. What is the most common form in the horse?

2. What is the cause?

3. What is lordosis?

4. What is kyphosis?

5. What is skoliosis?

6. What is kypho-skoliosis?

7. What are the common causes of lardosis developing after birth?

\section{Fracture of the Pelvis.-Page 472.}

1. How may the pelvis of horses be fractured?

2. What constitutes the pelvic girdle?

3. At what points may fracture occur without its division?

4. At what one of these points is fracture most common?

5. Do fractures without division of the girdle ever cause lame. ness?

6. What points of the pelvis are liable to be fractured that would divide the girdle?

7. How may such fractures cause serious hemorrhage?

8. How are they diagnosed?

9. How does division of the girdle afiect the position of the foot?

11. How may crepitation be detected?

11. What function of the leg is interfered with, if the fracture is in front of the cotyloid cavity?

12. What if behind?

1:. What form of lameness is present, when the fracture involves the cotyloid cavity?

14. In what kind of fractures of the pelvis is deformity noted?

15. How may this form be diagnosed?

16. In what part of the pelvis could fracture cause swelling in the region of the udder? 

17. How would fracture of the pelvis cause swelling of the vulva?

18. Unusual mobility of the thigh is caused by fracture of what paits of the osinnominatum?

19. How can the diagnosis be confirmed?

20. What is the prognosis in the various pelvic fractures?

21. How should they be treated?

22. When are slings indicated?

23. What condition may follow that will affect brood mares and cows?

24. What is the probable time required for recovery?

\section{Diastasis or Luxation of the Sacro-iliac Articulation.} Page 480 .

1. By what bones is this articulation formed?

2. What kind of articulation is it?

3. What ligaments hold it in position?

4. Why is this accident rare in the horse?

5. What is the difference in the ligamentous structure of this joint in the horse and ox?

6. What physiological act is liable to produce luxation of this joint?

7. How does it favor it?

8. What are the symptoms?

9. What effect is complete luxation liable to have on future delivery and defecation?

11. What is the prognosis?

11. What effect does luxation of the symphysis pubis have upon luxation of this joint?

12. How is this luxation diagnosed?

13. What is hygroma of the ischial tuberosity?

14. What animals are subject to it?

15. How should it be treated?

\section{Paralysis of the Hind Extremities.-Page 483.}

1. What is paralysis?

2. What is paraplegia?

3. What three sets of organs, either of which being diseased, may cause paralysis?

4. How does undue pressure on a part cause paralysis?

5. What pathological conditions may cause such pressure on 

the brain or cord?

6. What form of paralysis is seen in haemoglobinuria?

7. Do diseases of the kidneys ever primarily produce paralysis?

8. What is pachymeningitis?

9. What is leptomeningitis?

10. What are the symptoms of complete paraplegia?

11. What of incomplete?

12. Why is it that reflex idditability is lost when the lesion is in or behind the lumbar but maintained if in front?

13. What is ataxia?

14. In incomplete paralysis, if atrophy of muscle appears, where would it indicate the lesion to be?

15. Upon what does the prognosis depend?

16. What would it be if due to concussion?

17. What is the treatment?

\section{Diseases of the Tail.-Page 491.}

1. What animals are subject to accidental injuries to the tail?

2. How are dogs' tails liable to be injured?

3. How are oxen's?

4. How are such injuries detected?

5. How should they be treated?

6. How if necrosed?

7. What is rat-tail?

8. How should it be treated?

9. How does fracture of the sacrum and coccygeal bones canse paralysis of the tail?

10. What other causes are given for such paralysis?

11. How should tumors of the tail be treated?

12. What is the technique of its amputation by shears?

13. What by the tiap operation?

14. How may the hemorrhage be controlled in each?

15. What is the after treatment in each?

Necrosis of the Lumbo-Dorsal Fascia.-Page 497.

1. Where is this fascia located?

2. What are the causes of its becoming necrotic?

3. How should it be treated?

4. What is the prognosis? 



\section{Diseases of the Fore Limb. \\ Fractures of the Scapula.-Page 498.}

1. What are the causes?

2. What part of the bone is most liable to be injured?

3. What is a comminuted fracture?

4. What is a subcutaneous fracture?

5. What is a simple fracture?

6. What is a compound fracture?

7. How may each be diagnosed?

8. Is crepitation usually distinct in fracture of the scapila:

9. What part of the bone might be broken without causing supporting-leg lameness?

10. Why would swinging-leg lameness be pronounced, in fracture of scapular spine?

11. Why is fracture of the neck of the scapula attended with excessive mobility of the foot?

12. What is the prognosis of fracture of the scapula in horses?

13. What in cattle?

14. What in small animals?

15. How should fracture of the scapular spine be treated?

16. How should fracture of its neck be treated?

17. How may the ribs be used as a splint?

18. How may a new scapula be formed after necrosis of the original?

\section{Fractures of the Humerus.-Page 50r.}

1. What animals are subject to fractures of this bone?

2. What part of the bone is liable to be broken?

3. What is the diaphysis of a bone?

4. How may fractures of the diaphysis of the humerus be recognized?

5. In what direction does displacement occur, in fracture of the external condyle of the humerus of dogs?

6. In what direction does the displacement occur if the internal one is fractured?

7. What is the prognosis in fractures of the humerus?

8. How would shortening of the humerus in quadrupeds affect the length of the leg?

9. How should animals suffering from fracture of this bone be treated? 



\section{Diseases of the Shoulder Joint.-Page 503.}

1. To which class of articulations does the shoulder joint belong?

2. How many ligaments hold it in position?

3. What other structures act as binding ligaments to it?

4. Is luxation of this articulation common in the lower animals?

5. What are the symptoms?

6. What is the prognosis?

7. How should they be reduced?

8. How are anesthetics valuable in reducing fractures and dis. locations?

9. What treatment should follow reduction?

10. What are the symptoms of inflammation of this joint?

11. What is the prognosis?

12. How may it be wounded?

13. Under what circumstances do we find spontaneous inflam. mation in the shoulder-joint?

14. What is omarthitis?

15. What is synostosis?

16. How are wounds of the capsular ligament diagnosed?

17. What is the prognosis of omarthritis?

18. What is the prognosis of open shoulder-joint?

19. How should the former be treated?

20. What treatment is indicated if the joint is open?

\section{Inflammation of the Biceps Bursa.--Page 507.}

1. What is bursitis intertubercularis?

2. Where is this bursa situated?

3. What groove and tendon does it supply?

4. In what animals is it continuous with the shoulder-joint?

5. What are the causes of its inflammation in horses?

6. What is the probable termination of such bursal inflammation?

7. What are the symptoms?

8. What is the prognosis?

9. What are the symptoms of the chronic form?

10. What is the prognosis?

11. How should the acute form be treated?

12. How should the chronic form be treated? 



\section{Inflammation of the Tendon and Bursa of the Postea Spinatus Muscle.--Page 5 ro.}

1. Where is this bursa located?

2. What is the name of the projection of bone that it lubricates?

3. What is the action of the muscle?

4. How is this tendon and muscle usually injured?

5. What kind of lameness does it produce?

6. Does it cause adduction or abduction?

7. Is there pain and pressure over the region?

8 . Are heat and swelling often present?

9 . How should the inflammation be combated?

10. In what stage should irritants be used?

11. What kinds are indicated?

12. How much rest should the horse have?

13. What is the prognosis?

14. Where is the suprascapular nerve located?

15. What muscles does it energize?

16. How may it be injured?

17. What are the symptoms?

18. What is the prognosis?

19. How should such paralysis be treated?

20. What conditions are liable to cause atrophy of the muscle?

21. What treatment is then indicated?

\section{Paralysis of the Radial Nerve.-Page $5 \mathrm{I} 3$.}

1. Where is this nerve situated?

2. What muscles does it inervate?

3. What kind of lameness does paralysis of the radial nerve cause?

4. Why is the supporting function deranged?

5. Can weight be borne if the leg is passively extended?

6. How does fracture of the first rib cause similar symptoms?

7. What are the symptoms of incomplete radial paralysis?

8. How does myopathic paralysis of the caput muscles correspond with radial paralysis?

3. How does the faulty action of the shoulder-joint differ from that seen in suprascapular paralysis?

10. What is the prognosis of radial paralysis?

1. What is the treatment? 



\section{Paralysis of the Brachial Plexus.-Page 5Ig.}

1. What muscles are supplied by this plexus?

2. What are the causes of its paralysis?

3. What are the symptoms?

4. Would the leg support weight if placed in position?

5. Upon what must the prognosis be based?

6. Of what should the treatment consist?

7. What would be the symptoms of cramp of the triceps muscles?

\section{Shoulder Lameness.-Page $52 \mathrm{I}$.}

1. What is understood by shoulder lameness?

2. What structures are usually involved?

3. What form of lameness is usually present?

4. What are the chief points to be ascertained in making this kind of a diagnosis?

5. Upon what does the prognosis depend?

6. What treatment would be indicated?

\section{Diseases of the Elbow and Fore Arm.-Page 526.}

1. What animals are subject to fracture of the ulna?

2. What are the causes?

3. Why are the symptoms of fractures of the olecranon like those of radical paralysis?

4. What are the symptoms if the fracture extends to the elbow joint?

5. What is the prognosis if the fracture is above the radioulnar arch?

6. How should fractures of this bone be treated?

7. Why should the elbow be kept extended?

\section{Fractures of the Radius.-Page 528 .}

1. What are the causes of fracture of the radius?

2. In what animals is diagnosis difficult on account of the ulna?

3. What are the symptoms?

4. What is the prognosis in the horse? 

5. What in cattle?

6. What in dogs?

7. Why is a fracture of the diaphysis of the radius of the horse the most favorable fracture of the front leg to treat?

8. What is the technique of reducing such fracture and of retaining these bones in position?

9. In fractures of the radius of a six year o!d ho: se, how long should the splints be kept on?

10. How long on a six months' old dog?

11. What is supination?

12. How should large animals be kept quiet during treatment?

13. How may the splints be prevented from slipping down?

\section{Luxation of the Elbow Joint.-Page 529.}

1. Can the elbow joint of the horse be disiocated without rupture of a lateral ligament?

2. How is it diagnosed?

3. How should it be treated?

4. What is the prognosis?

Inflammation of the Elbow Joint.-Page 530.

1. What animals are subject to this disease as a sequela to navel-ill?

2. What other causes are there for it?

3. How may injuries to the sheath of the flexor metacarpi externus affect it?

4. What symptoms indicate that the joint is open?

5. What is the prognosis of inflammation of this joint?

6. What treatment is indicated if the joint is not opened?

7. What if it is?

\section{Capped Elbow in the Horse.-Page 531.}

1. What form of bursa is found at the posterior surface of the elbow?

2. What animals have this bursa?

3. In what way is it often injured?

4. What is the result of a bruise of this bursa?

5. What is the result of inflammation of the bursa? 

6. What is the result if hemorrhage occurs?

7. What is the result if cocci enter it?

8. How may parabursitis be established?

9. What is the appearance if recently bruised?

10. What is the appearance if the bursa be distended?

11. What is the appearance if liberal plastic infiltration, with organization in the surrounding tissues, has taken place?

12. If there be no infection or further bruise, what will become of the bursal fluid?

13. If absorption takes place, what will become of the parabursitis?

14. In what condition would reabsorption leave the skin?

15. That would be the result if repeatedly bruised?

16. How may such bruises be inflicted?

17. How may they be prevented?

18. How should fresh injuries of this kind be treated?

19. After inflammation has subsided how may thickenings be absorbed?

20. When is opening indicated?

21. What are the symptoms of purulent infection?

22 . How does the lining of the bursal sac prevent granulation?

23. How may this membrane be destroyed?

24. How may the tumor be removed by ligature?

25. How by the elastic ligature?

26. How should the surface be treated while the ligature is in position?

27. How may the ligature be prevented from slipping off on account of the tumor having a large base?

28. How should the wound be treated after the tumor has fallen off?

29. What is the technique of enucleation of these tumors?

30 . What is the atter-treatment?

31. How is this condition developed in dogs?

32. How do the symptoms in the dog differ from those in the hor'se?

33. What is bursitis sero-fibrinosa?

34. Why is it difficult to apply a ligature to this kind of a tumor on a dog?

35. What is the technique of removal of this bursa in the dog?

36. Is it essential that all the bursal membrane be removed? 

37. What is the after treatment?

38. What is the prognosis in the horse?

39. What is the prognosis in the dog?

40. What blood vessels are liable to be injured in operating at this point?

41. How should the hemorrhage be controlled?

Wounds and Bruises of the Fore Arm.-Page 536.

1. What constitutes the forearm?

2. If a cross section of the forearm was made at the middle of the radius, what structures would be cut through?

3. Why is a horizontal wound of the forearm more troublesome than a vertical one?

4. Which is liable to leave the worst blemish?

5. Why are wounds that penetrate the fascia of the forearm particularly troublesome?

6 . Why is a punctured wound more dangerous than an incised one?

7. What kind of a muscle wound is likely to be followed by a gap in the muscle?

8. When is suturing indicated in wounds of the forearm?

9. What line of treatment is best adapted to prevent formation of scar-tissue?

10. How should punctured wounds of this region be treated?

11. Why is the removal of a piece of fascia or a cross section of its fibres essential?

12. How should bruises of this region be treated?

13. How should abscesses of this region be treated?

14. How may the median nerve be injured?

15. What are the symptoms?

16. How should such an injury be treated?

\section{Diseases of the Knee.-Page 538 .}

1. What bones form the frame-work of the carpus?

2. What sets of articulations are formed by the carpal and adjacent bones?

3. What ligaments bind these bones together?

4. What bursae supply these articulations with synovia?

5. What synovial sheaths are connected with the tendons about the joint? 

6. Where is each located?

7. What fascia is continued over the knee?

8. To what does it attach externally?

9. How is it arranged on the anterior surface?

10. To what does it attach on the internal side?

11. Where are subcutaneous bursae found?

12. How may knowledge of the presence of these bursae modify the diagnosis of wounds to this region?

13. In what articulation does the principal flexion of the knee take place?

14. Over what surface of the knee do the principal blood vessels pass?

\section{Fractures of Bones of the Knee.-Page 539.}

1. What bone of the knee is liabie to be fractured from muscular contraction?

2. Are the ligaments of this bone ever ruptured?

3. How may other bones of this group be fractured?

4. What are the symptoms of such fractures?

5. What is the prognosis?

6. What is the treatment?

Injuries to the Anterior Surface of the Knee.- Page 540.

1. To what kind of injuries is the anterior surface of the horse's knee subject?

2. What is meant by broken knee?

3. What is the usual result of bruises of this region, without rupture of the skin?

4. In an examination for soundness, of what significance are scars on the front of the knee?

5. How may hygroma of the knee be produced?

6. What kind of a discharge would indicate a serious complication?

7. What constitutional symptoms would be indicative of open bursa or joint?

8. How should wounds of the knee, without complication of the bursa, be treated?

9. What line of treatment would be indicated if the sheaths or joints be open? 

10. How does limiting the movement of an open joint hasten recovery?

11. How should hygroma of the knee be treated?

12. How should abscesses about the knee be opened?

13. What is the prognosis of broken knees?

14. What is the technique of the operation for the removal of scar tissue from the knee?

\section{Tumors of the Knee in Cattle.-Page 546 .}

1. What three forms of enlargement are met with in the knees of cattle?

2. How may such diseases be caused?

3. In the cutaneous form, how are layers of horny tumors formed?

4. What is the synovial form like?

5. What is tendovaginitis chronica serosa?

6. The tendons of what muscles are liable to be involved?

7. What other tissues are involved?

8. What specific disease is often the cause of the tendinous form?

9. What is hygroma proliferum?

10. What is tumor albus?

11. In the articular variety, what tissues are involved?

12. How does it effect the articulation?

13. Are these tumors of slow or rapid growth?

14. How should the cutaneous form be treated?

15. How the synovial form?

16. How the articular or hard form?

17. What is the prognosis in each?

\section{Chronic Inflammation of the Knee Joint.- Page 549.}

1. What animals are most subject to chronic carpitis?

2. What bones are likely to be involved in knee spavin?

3. What class of horses are most susceptible?

4. What are the symptoms?

5. What are the symptoms shown in the gait?

6. How is this form of lameness differentiated from shoulder lameness?

7. Upon what does the prognosis depend? 

8. How should it be treated?

9. What neurectomy would relieve this kind of lameness?

\section{Inflammation of the Bursa of the Flexor Pedis.-Page $55^{\circ}$.}

1. Where is this bursa located?

2. What is the cause of acute inflammation of it?

3. What is the cause of the chronic form?

4. What is the result of the chronic form?

5. What is the appearance of the distended sheath?

6. Is lameness present in the chronic form?

7. What is the technique of aspirating the sheath?

8. What fluids may be injected into it?

9. Of what value are compresses after aspirating?

10. How should they be applied?

11. How should the chronic thickening that remains be treated?

12. What are the symptoms of the acute form?

13. How should it be treated?

14. What is the prognosis?

15. What is the usual termination of purulent synovitis?

\section{Enlargement of Articular and Tendinous Synovial Cavi- ties in the Fore Limb.--Page 5.52.}

1. What three classes are mentioned?

2. What are knee-galls?

3. What articular capsule of the knee is liable to be distended?

4. Where does the swelling appear?

5. Where do fetlock galls appear?

6. What structure is distended?

7. Why do they disappear when the foot is raised?

8. What sheath within the hoof can be so distended?

9. Where is this distension manifested?

10. What flexor tendon sheath may be distended at the knee?

11. What are wind galls of the fetlock?

12. What sheath is distended?

13. Where do they appear?

14. At what point below the fetlock may they appear?

15. Where does distension of the following extensor tendons of the carpus occur: 1st, suffraginis; 2nd, pedis; 3rd, metacarpi mangus; 4th, metacarpi obliquus? 

16. Describe the appearance and location of the distended bursa of the extensor pedis, at the fetlock.

17. What is chronic synovitis?

18. Does it cause lameness?

19. Why is it accompanied by dropsy?

20. What are the causes?

21. What treatment is indicated?

22. How do compresses affect a distended bursa?

23. How are they assisted by aspiration?

24. How is such chronic inflammation affected by cold applications?

25. How may it be treated by the cautery?

26. How does blistering affect it?

27. What is the radical treatment?

28. Under what antiseptic precautions must the operation be performed?

29. Where is the opening made?

30. How can it be treated by setons?

31. How by drainage tubes?

32. What are the objections to the two last methods?

33. How long should the bandage be left on after it has been opened?

\section{Diseases of the Metacarpus.-Page 560}

1. What tissues would be cut through in amputating a horse's leg three inches below the carpus?

2. How many metacarpal bones in the ox?

3. How many in swine?

4. How many in dogs?

Fractures of the Metacarpus.-Page 56 r.

1. In what animals are all the metacarpal bones usually involved in a fracture?

2. How do such fractures generally occur?

3. How are the metacarpals of the smaller animals usually fractured?

4. How should these fractures be treated in the horse?

5. How in the dog?

6. How in the ox?

7. What is the prognosis in each? 

Wounds and Bruises of the Metacarpus.--Page 562.

1. Why are wounds of this region hard to treat?

2. When is suturing of such wounds indicated?

3. How should they be disinfected?

4. When are adhesive plasters serviceab!e?

5. How do compresses act to cause absorption, or to prevent formation of excessive granulation?

6. What dry dressings are suitable for wounds of this region?

7. What liquid dressings are serviceable?

8. What condition of the dressing would indicate the necessity of a redressing?

9. How should wounds of this region involving tendinous sheaths be treated?

10. What dry dressing is indicated in open jo:nts and sheaths?

11. When should such dressings be changed?

12. How should bleeding be controlled?

13. If bleeding be serious and horse restless, how can the hemorrhage be temporarily controlled?

14. In what part of this region are the flexor tendons enclosed in synovial sheaths?

15. What special treatment does division of these tendons require?

16. How would a high heeled shoe and brace be serviceable?

\section{Rupture of the Flexor Tendons, and Suspensory Liga-} ment.-Page 565 .

1. What animals are liable to this accident?

2. Under what circumstances does it usually occur?

3. What condition of a tendon acts as a predisposing cause?

4. By what structures are the perforatus and perforans converted into ligaments?

5. What constitutes an inhibitory structure?

6. What structures act in this capacity at the knee?

7. What constitutes this apparatus at the fetlock?

8. What are passive agents of support?

9. What are active agents?

10. What effect does rupture of the suspensory ligament have upon the fetlock and toe?

11. How does rupture of the inferior sesamoidean ligaments affect them? 

12. How are they affected in rupture of the perforatus tendon?

13. What would be the result if the perforans alone were ruptured?

14. What would be the result if all three of these structures were ruptured?

15. What is paratendineum?

16. Why do tendons not unite so well when bisected through a synovial sheath?

17. Under favorable circumstances, how long would it take for a ruptured perforans to unite?

18. How may divided enảs of tendons be approximated by shoeing?

b9. How would even pressure to parts be of service in wounds of the tendons?

20. How may a brace be applied from the shoe to the leg, to prevent undue dorsal flexion?

21. Would rupture of the suspensory call for different treatment?

22. What is the prognosis, in rupture of these, if the tendon tissue be not diseased?

23. How should they be treated?

24. How is the iron splint of service here?

25. How does division of the extensors correspond with the flexors, in gravity?

Inflammation of the Flexor Tendons.-Page 570.

1. What is tendinitis?

2. What is a strain?

3. What are the common causes of tendinitis?

4. What form of tendon predisposes to it?

5. Is the large size of the tendon positive assurance of its strength?

6. What is the appearance of a strong tendon on palpation?

7. How does prolonged rest affecttendons?

8. How do severe constitutional diseases sometimes affect them?

9. What form of fetlock increases the strain on the flexor tendons?

10. How do low heels and long toes affect them?

11. How does stepping on an elevation with the toe affect the flexors? 

12. Why do race horses and jumpers suffer most from this accident?

13. Why do draft horses suffer from this condition most in the hind leg?

14. Why are the front limbs of riding and driving horses more liable to this accident than the hind ones?

15. What strains are classed as passive strains?

16. What ones are classed as active?

17. Which flexor tendon is most likely to suffer from the former?

18. Are the check ligaments ever involved in strain?

19. Which tendon sometimes suffers from bruises?

20. What portion of a tendon is usually involved in tendinitis following constitutional disease?

21. What parasite has been found in the suspensory ligament of the horse?

22. What form of tendinitis causes the most severe lameness?

23. How severe is lameness from inflammation of the suspensory ligament?

24. Is lameness always present at the time of the accident?

:5. What form of lameness does it cause?

26. In this disease, what position is the fetlock usually placed in during rest?

27. What are the local symptoms?

28. Is the swelling perceptible?

29. In what shape should the leg be held to examine the tendons?

30. What effect does chronic inflammation have upon the length of a tendon?

31. What effect does contraction of the inhibitory apparatus of the fetlock have upon the position of tlıat joint?

:2. How may contraction be differentiated from inflammation without contraction?

33. How does contraction of the perforans affect the position of the fetlock?

34. How does it affect the position of the heel?

35. How does contraction of the suspensory ligament affect the fetlock?

36. How does it affect the heel?

37. How does contraction of the perforatus affect the fetlock?

38. How does it affect the heel? 

39. How differentiate between contraction of the perforatus and suspensory ligament?

40. Do these structures ever stretch without rupture of fibres?

41. How does inflammation of a tendon cause it to contract?

42. How does the direction of the fibres in a contracted tendon differ from those of the normal?

43. What is the prognosis of such inflammation, if properly treated before contraction occurs?

44. Do the ruptured fibres ever regain their normal strength?

45. If resorption completely removes the swelling, will the tendon be normally strong?

46. At what point of the flexors is strain the most serious?

47. How does contraction of the perforatus affect the animal's usefulness?

48. Why are the chances of recovery lessened when the disease is bilateral?

49. What pathological condition can be benefited by tenotomy?

50. What is the cause of a tendinitis that frequently changes its location?

\section{Treatment.-Page 576 .}

1. Is rest important?

2. When are cold applications indicated?

3. How may they be applied?

4. How should warm applications following the cold be applied?

5. How is pressure beneficial?

6. How should it be applied?

7. How often should warm, moist compresses be changed?

8. Is it necessary to have the pressure even over the entire surface?

9. When should massage be used?

10. Why should the diseased tendon be rubbed upward?

11. When would such rubbing be contra-indicated?

12. How does the success of this method compare with the former antiphlogistic methods?

13. How may adhesive blister plasters be used?

14. When are blister ointments indicated?

15. How should they be applied?

16. When is firing indicated?

17. What form of firing is best suited here? 

18. How long should the animal rest?

19. What form of shoe is indicated in these conditions?

20. What part of the inhibitory apparatus is relieved by highheeled shoes?

21. When is tenotomy indicated?

22. Does contraction of the perforans and perforatus ever cause buck knees?

23. What is the cause of buck knees?

24. Where is the field of operation for tenotomy of the perforans?

25. How should it be prepared?

26. Why is antisepsis of particular importance in tenotomy?

27. What is the technique of this operation on the perforans?

28. How should the wound be dressed?

29. When should the dressing be removed?

30. If adhesions are present, how may they be broken down?

31. How long does it require new tendon tissue to form, and be strong enough to support the weight of the animal?

32. Can this operation be performed under local anaethesia, without casting?

33. Is it important that the fetlock descend to its normal position?

34. Is it important that weight be kept on the limb after tenotomy?

35. What attention should the foot receive?

36. When both tendons are divided, how may injury to the supensory ligament be prevented?

37. When would median neurectomy be indicated in tendinitis?

\section{Knuckling Over in Foals.-Page 582.}

1. Foals of what age are subject to this condition?

2. What is the cause?

3 What are the results, if not remedied?

4. What are the symptoms?

5. What is the prognosis?

9. How should such conditions be treated?

7. What is pes equinus of man?

8. How should knuckling over in colts, not congenital, be treated? 



\section{Splints.-Page 586.}

1. What are splints?

2. How are the splint bones attached to the great metacarpal?

3. By what process do they unite?

4. At what age does this bony union usually occur?

5. What circumstances tend to hasten it?

6. Is the union of these bones a physiological or a pathological condition?

7. Does their union always cause lameness?

8. What two stages of splints are recognized?

9. In what stage is lameness present?

10. Where does the inflammatory process start?

11. What causes the exostosis to form?

12. Why is it so largely confined to the internal side?

13. Why is it more frequent in the fore than the hind leg?

14. When appearing in the hind leg, why is it usually on the outside?

15. Why are only perissodactyla affected?

16. Under what circumstances will splint lameness remain, after the inflammatory stage has subsided?

17. Why is splint lameness rare after horses are seven years old?

18. What two etiological classes are recognized?

19. How may they be differentiated?

20. According to Möller, what three conditions cause splint lameness?

21. Does the exostosis ever cause lameness by interfering with the suspensory ligament?

22. In what gaits is splint lameness most marked?

23. What form of lameness does it cause?

24. Why is the first half of the stride shortened?

25. Why is it more manifest in a trot than a walk?

26. How does the tension of the fascia of the forearm affect it?

27. How does this affect the advancement of the opposite foot?

28. When is abduction and circumduction most marked?

29. What is the cause of the circumduction?

30 . What is revealed by local examination?

31. Is a visible splint positive evidence of splint lameness?

32. Is the absence of a splint positive evidence that the lameness is not due to a splint? 

33. How can a defferentiation be made?

34. How should the leg be held to examine the splint seat?

35 . On what kind of roads is splint lameness most manifest?

26. When is the prognosis unfavorable?

37. How should splint-lame horse be shod?

38. When would cold applications be indicated in its treatment?

39. When is blistering indicated?

40. When is firing indicated?

41. How should the actual cautery be applied?

42. Is spontaneous recovery common?

43. When would splints constitute unsoundness?

44. How does a lead compress produce resorption of an exostosis?

45. What are sore shins?

46. What are the causes?

47. What are the symptoms?

48. What is the treatment?

49. What is a speedy bruise?

50. How should one be treated?

Diseases of the Phalanges.-Page 592.

1. What constitute the phalanges in solipeds?

2. Of what do they consist in ruminants?

3. Of what in the pig?

4. Of what in the carnivora?

5. What ligaments unite the bones that form the fetlock in the horse?

6. How are its synovial structures arranged?

7. What ligaments unite the bones that form the pastern joint?

8. Where is the glenoid cartilage located?

9. What ligaments insert to it?

10. How is the synovial structure of the pastern joint arranged?

11. What ligaments bind the bones of the distal phalangeal articulation together?

12. How is the synovial apparatus of this joint arranged?

13. What is the plantar aponeurosis?

14. What constitutes the navicular sheath?

15. What the sesamoidean sheath? 

16. What are the locations and distributions of the plantar nerves?

17. What is their relation?

18. How are the arteries of the metacarpal region arranged?

19. How are the veins arranged?

20. How are the arteries arranged from the fetlock to the foot?

21. What is the venous arrangement of that region?

\section{Luxation of the Phalanges.-Page 594.}

1. Does luxation of these articulations of the larger animals ever occur without rupture of ligaments?

2. What is the prognosis of such dislocations with extensive rupture?

\section{Sprain of the Coronary Joint.-Page 596.}

1. What defective formations favor this accident?

2. How do slips tend to cause such strains?

3. What are the symptoms?

4. Does lameness appear suddenly?

5. What inflammatory symptoms are present?

6. What may be learned by rotating the foot?

7. What form of lameness is it likely to produce?

8. How can injuries to the pastern and pedal joints be differentiated?

9. What is the probable course of such strains?

10. How does strain differ from rupture?

11. How are strains liable to affect a part permanently?

12. How may strain of ligaments lead to exostosis?

13. What is hydrops articuli?

14. How can this condition be caused by a strain?

15. What is hemarthrosis?

16. What peculiar sound is heard on motion, when hemarthrosis is present?

17. What is the common termination of hemarthrosis?

18. What is the prognosis?

19. What is the fundamental principle in the treatment of strains?

20. What is the usual outcome of a strain when marked symptoms of pain immediately follow? 

21. Why is the condition usually serious when the pain and sweling are severe at the end of the first or second day?

22. How may rest of a single joint be enforced?

23. Of what should the dressing consist for the first three days?

24. Under what circumstances should this application be continued?

25. When are absorbents, such as mercury, indicated?

26. When are warm, moist applications indicated?

27. When and why is pressure serviceable?

28. When is firing needed?

\section{Fractures of the Phalanges.-Page 599.}

1. What is the difference between fissure and fracture of bone?

2. Which of the phalanges of the horse are most liable to be broken?

3. Where more than one bone is fractured at once, what is the probable predisposing cause?

4. What is the usual cause of fissures?

5. What of fractures?

6. How are complete fractures diagnosed?

7. How are fractures of one side of the articular end determined?

8. How may fissures be differentiated from strains?

9. In what position should the limb be held to examine this region?

10. What are the causes of fracture of the os pedis?

11. How are these fractures diagnosed?

12. How soon after fractures of the bones within the hoof could increased pulsation of the digital arteries be noticed?

13. What is the prognosis of fissure of these bones?

14. What of fracture?

15. What form of fracture is most favorable?

16. In what aged animals are fractures most likely to recover?

17. Could such accidients be said to recover when permanent lameness follows?

18. In what class of horses are such fractures most amenable to treatment?

19. How does the prognosis of fractures of the os coronae compare with those of the suffraginis?

20. Why are fractures of the os pedis more favorable? 

21. What is the chief danger to the opposite foot, during the treatment of such disease?

22. What is the prognosis of compound fractures of these bones?

23. How should fractures of this region be treated?

24. How are plaster bandages prepared?

25. How are paste or starch bandages applied?

26. What advantages has the starch over the plaster?

27. What is the formula for Stolz' ointment dressing?

28. How may lameness following fracture be relieved?

29. Under what circumstances are s'ings indicated?

30. Why is it often better to permit horses to lie down than to keep them in slings?

\section{Ring-Bone.-l'page 605.}

1. What is ring-bone?

2. What is articular ring-bone?

3. How does arthritis chronica differ from arthritis chronica deformans?

4. What is periarticular ring-bone?

5. How may strain of ligaments produce this form?

6. What is rachitic ring-bone?

7. Does this form cause lamieness?

8. What is traumatic ring-bone?

9. What kind of traumatisms is liable to produce it?

10. Why is the coronet joint so subject to disease?

11. Is ring-bone always confined to the region of the inter-phalangeal articulation?

12. Is exostosis ever hereditary?

13. What are the symptoms of ring-bone?

14. How does the periarticular form differ from the articular in appearance?

15. What causes the lameness in the periarticular form?

16. What normal conditions of the os corona may be mistaken for ring-bone?

17. At what part of the step is the pain most manifest in the weight bearing leg?

18. What can be determined by passive rotation and flexion?

19. What is the best position from which to inspect this region for enlargements? 

20. What is the prognosis of articular ring-bone?

21. What of the periarticular?

22. What of an exostosis entirely removed from the joint?

23. What form of ring-bone would be liable to develop from strain of the posterior ligaments of the pastern joint?

24. How should a horse afflicted with ring-bone be shod?

25. How do long toes affect ring-bone?

26. Why is it important to keep an even distribution of weight on the foot?

27. When would lowering the heels be detrimental?

28. When would blistering be indicated?

29. When would firing be indicated?

30. What form of firing would be suitable?

31. When would neurectomy be indicated?

Plantar Neurectomy.-Page 6I. (Williams, Page 137.)

1. What two important points should be determined before resorting to neurectomy?

2. What is neurectomy?

3. What is neurotomy?

4. Should either of these operations be performed during a febrile condition of the parts, beyond the point of nerve ảivision?

5. What conditions of the foot would contra-indicate neurectomy?

6. From what kind of service should a neurectomised horse be exempt?

7. What is plantar neurectomy?

8. What is digital neurectomy?

9. How do they differ in effect upon the foot?

10. What is the necessary preparation of the field of operation?

11. Where should the incision be made in plantar neurectomy?

12. How should it be made?

13. What antiseptic precautions should be taken?

14. How should the hemorrhage be controlled during the operation?

15. How can the nerve be distinguished from neighboring vessels?

16. How should it be secured after it is exposed?

17. Why should the nerve be divided on the central side of the incision, first? 

18. How much of it should be removed?

19. How should the wound be closed?

20. How should it be treated after the operation?

\section{Digital Neurectomy.-(Williams, Page 132.)}

1. Where is the incision made to divide the digital nerve?

2. Why is this a safer operation than plantar neurectomy?

3. What bad effects are liable to follow complete permanent anaesthesia of the foot?

4. What is the cause of degeneration of the tissues after neurectomy?

5. How should the animal be secured for this operation?

6. How may it be performed without casting the animal?

7. How can local anaesthesia be obtained without injecting the drug at the point of operation?

8. Is complete cessation of lameness always manifest immediately after the operation?

9. When is digital neurectomy indicated?

Median Neurectomy.--Page 616. (Williams, Page Ifr.)

1. When is median neurectomy indicated?

2. From what source is the median nerve derived?

3. What is its course?

4. What is its distribution?

5. What are the relaxations of the median nerve at the proximal end of the radius?

6. What is its direction as it passes this point?

7. When it is divided on a level with the elbow, how much of the sensation of the foot is destroyed?

8. Where should the incision be made in median neurectomy?

9 . In which direction does it lie, from the radial tuberosity to which the lateral ligament of the elbow joint is attached?

10. How should the animal be secured for this operation?

11. How should the leg be kept in position?

12. How large an incision should be made through the skin?

13. What muscle must be cut through beneath the skin?

14. What kind of an incision should be made in the antibrachial fascia? 

15. How may the nerve be located by palpation, both before and after the skin incision?

16. How should the hemorrhage be controlled?

17. How should the nerve be secured?

18. What veins are liable to be injured?

19. What kind of an instrument should be used to raise the nerve, to avoid piercing the veins?

20. How should the nerve be divided?

21. How should the wound be closed?

22. What after-treatment should it receive?

23. How much rest should the horse have after the operation?

Ulnar Neurectomy.-Page 621. (Williams, Page 147.)

1. What is ulnar neurectomy?

2. What is the source of the ulnar nerve?

3. What is its course?

4. What are its relaxations in the antibrachial region?

5. What is its distribution?

6. What tissues would be anaestehtized if the ulnar nerve were cocained six inches above the trapezium?

7. What tissues would be anaesthetized by cocaining the median at the elbow, and the ulna at the above mentioned point?

8. Where should the incision be made in ulnar neurectomy?

9. What tissues would be cut through, to reach this nerve?

10. What is the technique of the operation after the incision is made?

11. How should the animal be controlled?

12. If cocained, where should it be injected?

13. What strength of cocaine is required?

14. What vessels are liable to be injured at this point?

15. What after-treatment does this operation require?

\section{Inflammation of the Posterior Ligaments of the Coronet Joint.-Page 622.}

1. What forms the inhibitory or limiting apparatus of the pastern joint?

2. What similarity in function exists between the suspensory ligament and posterior ligaments of the pastern?

3. How may the posterior ligaments of the coronet joint be injured? 

4. What are the symptoms of their injury?

5. How can these injuries be differentiated from diseases of other limiting structures of the phalangeal articulations?

6. How does this lesion compare in frequency with others of this region?

7. How may it be differentiated from navicular disease?

8. How would it affect the pulsations of the digital arteries?

3. Which feet are most often involved?

10. Is the lameness of sudden origin?

11. How showld it be treated?

12. What kind of treatment do the feet need?

13. When would blistering be indicated?

14. When would firing?

15. What kind of firing would be suitable?

16. What is the prognosis?

Fractures of the Sesamoid Bones.-Page 625 .

1. How may these bones be fractured?

2. In what direction does the fracture usually occur?

3. What conditions predispose to such accidents?

4. What are the symptoms of such fractures?

5. What is the prognosis?

6. If treatment is attmepted, along what lines should it be directed?

Sesamoid Lameness.-Page 624.

1. What parts of the sesamoids are subject to inflammation?

2. What disease of the flexors may produce it?

3. What pathological changes may occur?

4. What are the causes of the acute form?

5. What are the causes of the chronic form?

6 . What are the symptoms of the acute?

7. What are the symptoms of the chronic?

8. In the latter, in what position is the fetlock joint held?

3. How is it affected by work and rest?

10. Is it liable to terminate in ankylosis?

11. What is the prognosis?

12. How should it be treated? 

Ossification of the Lateral Cartilage.-Page 628.

1. What consttutes side-bones?

2. Where are the lateral cartilages located?

3. To what bone are they attached?

4. What is their function?

5. What animals possess them?

6 What are the causes of their ossification?

7. How can pathological changes in them be detected?

8. In what part of the cartilage does ossification begin?

9. Do both cartilages always become involved?

10. What form of lameness does it cause?

11. Which feet are usually involved?

12. What class of horses are most often affected?

13. How may the diagnosis be proven by palpation?

14. At what period of the ossification is the lameness most marked?

15. How do dry, hard hoofs affect the lameness ?

16. Does ossifcation of these cartilages constitute unsoundness?

17. What are the causes?

18. What is the prognosis?

19. What causes the lameness after ossofication is complete?

20. How may they be treated to relieve pressure?

21. How should the horse be shod?

22. When would firing and blistering be indicated?

Fractures of the Navicular Bone.-Page 632.

1. What are the causes of fracture of the navicular?

2. What disease of this region predisposes to its fracture?

3. What kinds of traumatisms are liable to fracture it?

4. What are the symptoms?

5. How is it differentiated from navicular disease?

6. What is the prognosis?

7. How should fracture of the navicular be treated when due to nail prick?

\section{Navicular Disease.-Page 633.}

1. What is podotrochilitis?

2. Where is the bursa podotrochlearis?

3. Is navicular disease an acute or chronic disease? 

4. Where is its seat?

5. What structures are affected?

6. In which of these structures does the disease originate?

7. What pathological changes occur in the bone when it is involved?

8. What form of ostitis does it cause?

9. How does rarefying inflammation affect a bone?

10. How does the inflammation affect the ligaments attached to it?

11. Is the upper surface of the bone ever affected?

12. Is this disease ever an arthritis?

13. What is the appearance of the synovial structures when the disease originates in the bursa podotrochlearis?

14. What are the pathological changes in the tendon, when it is the primary seat of disease?

15. Why is it so easily injured beneath the bone?

16. In what way may the disease be hereditary?

17. What class of horses are most susceptible to it?

18. Why are the front feet most often attacked?

19. How does an upright pastern cause increased pressure on the navicular bone?

20. What point in the flexor tendons receive the increased strain caused by the foot being kept back of a perpendicular line?

21. What effect do low heels, high toes, or stepping on an an elevation with the toe have upon the navicular region?

22. How may rheumatism affect these structures?

23. How would frequent raising and lowering of the heels in shoeing be liable to affect them?

24. What kind of roads tend to produce navicular disease?

25. Is it ever caused by bruises?

26. When it follows such disease as influenza what is its nature?

27. Is it often bilateral?

27. Is the lameness manifested suddenly or gradually?

29. Is it continuous or intermittent?

30. . In traveling, what part of the foot is brought to the ground first?

31. Which part of the stride is shortened?

32. If bilateral, what kind of a gait is produced?

33. Which does it cause, supporting or swinging leg lameness? 

34. In what position is the foot held when standing?

35. What effect does long rest have on it?

36. How does pressure over the joint affect it?

37. How would it be affected by a bar shoe?

38. How by a high-heeled shoe?

39. How can it be differentiated from inflammation of the posterior ligaments of the coronet joint?

40. How would the pulsations in the digital arteries be affected?

41. Why is atrophy of the frog and contraction of the heels accompanying symptoms?

42. What is the characteristic shape of the foot in cases of long standing?

43. Why does the coronary band seem swollen?

44. Why does the pastern become upright?

45. How does it produce muscular atrophy?

46. In cases of long standing, what group of muscles becomes atrophied?

47. How is the shape of the feet and atrophy of the muscles affected by neurectomy?

48. How may cocaine be used to advantage in diagnosing this disease?

19. What would be the probable result of ankylosis of the tendon and navicular bone?

50. Why does the perforans tendon frequently rupture after neurectomy?

\section{Differential Diagnosis and Treatment of Navicular Disease.-Page 64I.}

1. How does navicular disease differ from contracted sole?

2. How from curving in of the heels?

3. How from sprain of the posterior ligaments?

4. How may it be distinguished from lameness caused by thrush?

5. How does is differ from sesamoidean lameness?

6. Upon what does the prognosis depend?

7. What antiphlogistic treatment can be applied to advantage?

8. What kind of pasture is recommended?

9. How should the feet be pared?

10. How should they be shod?

11. Are frog setons of any value? 

12. How are they applied?

13. Through what tissues are they passed?

14. Is rest essential?

15. Is destruction of the bursa podotrochlearis ever followed by complete recovery?

16. What form of neurectomy is indicated in navicular disease?

17. When should neurectomy be resorted to?

\section{Dermatilis in the Fetlock Region. Mud Fever. Cracked} Heels. Grease.--Page 644 .

1. What three characteristics are common to all of these dis eases?

2. What four varieties are mentioned by Möller?

3. What are the general characteristics of the three first?

4. Which form is recognized in England as true grease?

5. What is dermatitis?

What is dermatitis erythematosa?

6. In what colored animals is erythema most perceptible?

7. What kind of skin is most likely to be affected?

8. What is the apearance of the parts in this condition?

9. What portion of the skin becomes involved ?

10. What are the causes?

11. What is the prognosis?

12. What treatment is indicated?

13. What would be the probable termination if neglected, or irritation continued?

14. What is eczema?

15. What is dermatitis eczematosa?

16. Why is it sometimes called mud fever?

17. Is this condition always associated with redness and swelling?

18. Does it always produce lameness?

19. When is the lameness most marked?

20. What is the character of the discharge?

21. What is the cause of the brownish crusts on the parts?

22. Why does the horse raise the leg so high when made to move?

23. What constitutes the papillary stage?

24. What the vesicular stage?

25. What the weeping stage?

26. What the squamous stage? 

27. What does the squamous stage indicate?

28. What time is required for a typical case to pass through all the stages to recovery?

29. What complication may arise during this time?

30. What are the causes?

31. What three forms of irritation may produce it?

32. How may shoeing act as a mechanical cause?

33. How may washing the legs cause it?

34. How may the sun produce it?

35. How may muddy roads cause it?

36. What chemical irritants are liable to cause it?

37. What is the prognosis if properly and timely treated?

38. What is the prognosis if masses of horny scar-tissue form?

39. Why is it necessary to rest the animal during treatment?

40. What amount of washing is useful?

41. What astringent wash should be used?

42. How may thoform, dermatol and other formic acid preparations be used?

43. What form of mercurial ointment is useful?

44. How may oxide of mercury ointment be used?

45. How should blue ointment be used?

46. How can excessive inflammation be best controlled?

47. How may excessive granulations be reduced?

48. After these are destroyed, how should the wound be treated?

49. How may excessive cicatricail tissue be removed by operation?

\section{Dermatitis Gangrenosa.-Page 649.}

1. What is the nature of this form?

2. What kind of weather is most favorable for it?

3. Why do slight injuries about the extremities so often lead to septic processes?

4. What are the general causes?

5. How might the farrier's knife be the means of infection?

6. Is the attack sudden?

7. What are the earlier symptoms?

8. How does the degree of lameness compare with the apparent lesion?

9. What condition of the skin may be found on close examination?

10. What kind of a discharge is seen in moist gangrene? 

11. What parts of the extremities are subject to such attacks?

12. Is extensive sloughing liable to occur?

13. How may the lateral cartilages be involved?

14. In what way may serious hemorrhage be developed?

15. How may the disease affect the tendinous sheaths and joints?

16. What is septic intoxication?

17. What are its symptoms?

18. How does it differ from generalized septicæmia?

19. How does it cause loss of hoof?

20. When is prognosis favorable?

21. What is the prognosis, if tendinous sheaths or joints are involved?

22. What if septic intoxication is present?

23. What general line of treatment is indicated?

24. How should charcoal be prepared and applied to such wounds?

25. When is actual cautery indicated?

26. How should it be applied?

27. What does pus around the edges of a gangrenous wound indicate?

28. How should fistulous tracts following slough be treated?

29. What treatment should the wounds receive after the dead tissue has sloughea away?

30. What is the prognosis?

Dermatitis Chronica Verrucosa.-Page 652 .

1. What condition of the skin does this name signify?

2. What is the general appearance?

3. What kind of odor is always present in grease?

4. In the rete mucosum proliferation, does the cell become horny?

5. When the proliferation is less rapid, what kind of mass is formed on the skin?

6. What is the result of cell proliferation in the papillæ?

7 . What is the result of subcutis infiltration?

8. How does the disease affect the hair follicles?

9. Which legs are most often involved?

10. What breed of horses is most often affected?

11. Does the eczematous form ever develop into the verrucous?

12. Is it ever due to specific organism? 

1.). Which of the two forms, dry or moist, offers the most favorable prognosis?

14. What line of treatment should be followed?

15. How should large warts be removed?

16. What may be gained by antiseptic poultices?

17. How should they be made?

18. What is Dalrymple's treatment?

\section{Injuries to the Muscles and Faciae of the Quarter. Page 655.}

1. How may the muscles and fasciæ of the quarter be injured?

2. What are the symptoms?

3. Why are punctured wounds of this region dangerous?

4. How should ruptures of muscles and fasciæ be treated?

5. How should punctured wounds of the fasciæ be treated?

6. How many are hematoma, without wound, be treated?

7. How treat hygroma?

8. What treatment should skin wounds of this region receive?

9. What different treatment would a deep one require?

10. How are wounds that cannot be healed by primary union benefited by suturing?

11. What is the prognosis of muscular rupture?

12. What condition is likely to follow rupture of the fasciæ?

\section{Fracture of the Femur.-Page 657.}

1. What are the causes of such fractures in the horse?

2. How may they occur in casting?

3. In what animals is the neck of the femur liable to be fractured?

4. Why is it rare in the horse ana ox?

5. Are the trochanters ever fractured?

6. Are the condyles?

7. What are the symptoms of fracture of the former?

8. What is the prognosis in the horse?

9. What in the ox?

10. What in small animals?

11. What effect would the shortening of the femur have upon the length of the leg?

12. How should fractures of the femur be treated? 

Luxation of the Femur.-Page 66r.

1. Is is possible for complete luxation of the femur of the horse to occur, without rupture of ligaments?

2. What are the symptoms of such luxations?

3. What is the prognosis in the large animals?

4. What in the small animals?

5. How may they be reduced?

\section{Inflammation of the Hip Joint.-Page 665.}

1. What is coxitis?

2. What kind of articulation is the hip joint?

3. What are the ligaments of the coxo-femoral articulation?

4. Is disease of this joint common?

5. Are the capsular and round ligaments ever ruptured?

6. What are the symptoms of coxitis?

7. In cattle so affected, how is the diseased limb extended?

8. What kind of gait is present?

9. How is the animal affected, when turning on the diseased limb?

10. What is the prognosis?

11. How should it be treated?

\section{Inflammation of the Tendon and Bursa of the Gluteus Medius Muscle.-Page 666.}

(Gluteus Maximus of Strangeway.)

1. Where do the tendons of the gluteus medius insert?

2. What is its action?

3. Where is the trochanteric bursa?

4. How may this bursa and tendon be injured?

5. How may the bursa be bruised?

6. How may the tendon be injured in rising from a decubital position?

7. If chronic tendinitis exists, what would be the probable termination?

8. If bursitis supervenes, how would it be liable to affect the bone?

9. Upon what does the prognosis depend?

10. What are the symptoms?

11. What kind of gait does it cause? 

12. If the bursa is involved, what is the physical appearance of the region?

13. Where is the seat of the lesion, if there is muscular atrophy?

14. Under what circumstances and how can crepitation be detected?

15. How should recent cases be treated?

16. If atrophy is present, how should it be treateü?

17. When would firing be indicated?

18. What kind would be appropriate?

19. How long should the animal rest?

20. What is the prognosis?

\section{Paralysis of the Hind Limb.-Page 667.}

1. What muscles are supplied by the anterior gluteal nerve?

2. What is its source and course?

3. What muscles are supplied by the posterior gluteal nerve?

4. What by the great sciatic?

5. What are supplied by the anteriar crural (crural by Strangeway)?

6. What is its source and course?

7. What muscles are supplied by the obturator nerve?

8. What are the symptoms of paralysis of the gluteal nerves?

9. In what parts would motor power be lost if the great sciatic was paralyzed?

10. What are the symptoms of paralysis of the external popliteal?

11. Why does this form produce supporting-leg lameness?

12. What are the symptoms of paralysis of the crural nerve?

13. What would be the effect of paralysis of the internal popliteal or tibial?

14. How would the symptoms of paralysis of the tibial and great sciatic differ?

15. What are the causes of paralysis?

16. What is the prognosis?

17. What is the treatment?

18. How is hemoglobinuria said to produce crural paralysis?

19. Is it true that muscular atrophy and loss of function can scarcely be expected to follow a purely muscular disease?

20. How differentiate between crural paralysis, rupture of the crural muscles, fracture of the patella and rupture of its straight ligaments? 

Thrombosis of the Posterior Aorta.-Page 677.

1. What is aneurism?

2. What is thrombus?

3. What is an embolus?

4. How does thrombus of an artery interfere with muscle function?

5. From what vessels are aneurismal products said to float backward and occlude those of the pelvic limb?

6. When arterial supply to a muscle is obstructed, why is the function of the muscle disturbed, only after considerable exercise?

i. What condition would modify the amount of exercise necessary to produce lameness?

8. What are the symptoms of thrombosis of the posterior aorta?

9. What would be the difference in the symptoms if the obstruction were in the external iliac?

10. What if in the femoral artery or its branches?

11. How could a thrombus interfere with copulation?

12. How can the existence of a posterior aortic thrombus be determined by manual examination?

13. How differentiate between thrombus at the aortic quadrification, and abscess or tumor in that region?

14. What is the prognosis of aortic thrombus?

15. What treatment would be indicated?

Displacement of the Biceps Femoris Muscle.-Page 680 . (Triceps Abductor Femoris of Strangeway.)

1. Where is this muscle located?

2. Where does it originate?

3. What is its insertion?

4. What is its relation to the trochanter major?

5. What animals are most subject to displacement of it?

6. On which side of the trochanter does it become fixed?

7. What form of luxation of the patella does it resemble?

8. How can they be differentiated?

9. Is the condition ever momentary?

10. What are the symptoms?

11. What is the treatment?

12. Where should the incision be made to divide the muscle? 

Hip Lameness.-Page 682.

1. What does this term comprise?

2. What structures are liable to be diseased?

3. What kind of lameness is usually present?

4. What is meant by shortening of the forward stride?

5. If the lameness were swinging leg, what structures would be involved?

6. What ones if the lameness were mixed?

7. What ones if the lameness were supporting leg?

8. What kind of an examination would reduce the diagnosis of hip-lameness to a minimum?

9. What is meant by diagnosis by exclusion?

10. What is the etiological indication, when the lameness appears suddenly?

11. What is the prognosis in old cases?

12. What in intermittent lameness?

1:3. What if the disease be articular?

1.4. What is the treatment if the injury be recent?

15. What is the treatment if of rheumatic origin?

16. When would blistering be indicated?

17. When would firing?

18. What kind of firing would be suitable?

19. When would setons be indicated?

20. When and what kind of subcutaneous injections might be indicated?

Disease of the Stifle Joint.-Page 687.

1. What kind of an articulation is the' stifle joint?

2. What ligaments are attached to the patella?

3. What divides the femoro-tibial articulation into two parts?

4. What tendinous sheath communicates with the external division?

5. How long is this sheath?

6. What are the names and attachments of the binding ligaments of this articulation?

7. How are the synovial structures arranged? 

Luxations and Sprains of the Stifle Joint.-Page 687.

1. What animals are subject to luxation of the femoro-tibial articulation?

2. Are strains of this joint common?

\section{Luxation of the Patella.-Page 688.}

1. What animals are most subject?

2. What are the two most common forms of this displacement?

3. In upward luxation, is the patella actually dislocated?

4. In what position must the joint be when this occurs?

5. In what position is the leg supposed to be at this time?

6. Is it not possible for this to occur with all joints extended from the stifle down, and the foot forward?

7. In what position would the stifle have to be to allow the upper margin of the patella to catch on the lower edge of the external lip?

8. In the upward luxation with posterior extension, what form of lameness is present?

9. What is momentary luxation of the patella?

10. What are the symptoms?

11. What part of the step is affected?

12. What are the causes?

13. Why does movement of all the joints of the leg, except the hip, depend upon flexion of the stifle?

14. Why are all of the joints of the leg, from the stifle down, fixed when movement of the patella is arrested?

15. What is straw cramp?

16. What is the pathological condition causing it after influenza?

17. What are the symptoms of fixed luxation of the patella?

18. What conditions tend to relax and elongate ligaments?

19. During fixed luxation, can the leg be passively flexed?

20. What is vertical luxation?

21. Upon what does the prognosis of upward luxation depend?

22. What is the treatment?

23. When would an anesthetic be indicated?

24. What treatment is required after replacement?

25. How much rest should the animal have?

26. How would division of the internal lateral ligament affect upward luxation? 



\section{Lateral Luxation.-Page 691.}

1. In what animals is congenital lateral displacement seen?

2. What constitutes incomplete, outward luxation?

3. What are the predisposing causes of outward luxation?

4. In what animals is the internal ligament less strong than the outer?

5. What is the prognosis of lateral luxation?

6. How does this resemble crural paralysis?

7. What form of lameness does it produce?

8. What is the difference in the position of all the joints of the leg, in outward and upward luxation?

9. What effect does outward luxation have on the function of the crural muscles?

10. Is the animal capable of walking or trotting in either partial or complete luxation?

11. How may it be reduced?

12. How can the leg be kept in outward forward extension?

13. What joints of the hind leg are in a state of extension, when the foot is fully extended in the forward stride?

14. How long should the foot be kept forward after reducing such luxation?

15. What local application to the region would be indicated?

\section{Rupture of the Straight Ligaments of the Patella.--Page 693}

1. How may these ligaments be ruptured?

2. What form of lameness would it cause?

3. How can their rupture be detected?

4. What is the prognosis?

5. Of what should the treatment consist?

6. How may this accident be differentiated from crural paralysis?

\section{Fracture of the Patella.-Page 694.}

1. In what animals has it been seen?

2. What are the principal causes?

3. If caused by muscular contraction, in what direction would the bone be fractured?

4. What are the symptoms? 

5. How can it be distinguished from rupture of the straight ligaments?

6. How from crural paralysis?

7. How from hemoglobinuria?

8. What principles must be followed in its treatment?

9. What is the prognosis?

\section{Injuries and Acute Inflammation of the Stifle Joint.} Page 695.

1. How may such injuries be inflicted?

2. How do injuries to the ensheathed portion of the extensor pedis tendon affect the joint?

3. How is this sheath liable to be injured?

4. What are the symptoms?

5. What is gonitis acuta serosa?

6. Why does septic arthritis usually follow opening of the extensor pedis sheath?

7. What is the prognosis, if the bursa or sheath is open?

8. What is the prognosis of acute, non-septic inflammation of the stifle-joint?

9. How shouid it be treated?

Chronic Inflammation of the Stifle Joint.- Page 696.

1. What is gonitis chronica sicca?

2. What kind of horses are most liable to be affected?

3. Is this disease always unilateral?

4. Which part of the femoro-tibial joint is most often affected ?

5. What are the post mortem apearances?

6. In what position is the affected leg kept when standing?

7. When bilateral, why do the legs appear too straight?

8. What effect does this disease have upon the normal depression in front of the stifle?

9. What is the prognosis?

\section{Bursitis Praepatellaris.-Page 698}

1. Where is the bursa præpatellaris?

2. What percentage of horses is said to have this bursa?

3. How large may it become when injured?

4. Does it produce lameness? 

5. How should it be treated?

6. What is hydrops geni?

Diseases of the Lower Thigh or Leg.-Page 699.

1. What part of the tibia is most exposed to injury?

2. What anatomical arrangement of this region makes wounds particularly dangerous?

3. How is the tibia liable to be injured?

4. What are the probable results of bruises of the periosteum?

5. What kind of lameness would it produce?

6. How may it be diagnosed?

7. What are the probable results of punctured wounds of the fascia?

8. What is subfascial cellulitis?

9. What is its signifcance?

10. How may muscular hernia be produced in this region?

11. Why are wounds of this region slow to heal?

12. What are the symptoms?

13. How should such wounds be treated?

14. How should exuberant granulations be treated?

15. How should fascia be divided, to insure good drainage?

\section{Fracture of the Tibia.-Page 700 .}

1. Is this bone often fractured in the horse?

2. What are the common causes?

3. What is meant by fissured bone?

4. Is facture of the tibia always manifest at the time of injury?

5. What is green stick fracture?

6. How are fractures of the tibia diagnosed?

7. How is fissue of a bone recognized.

8. How can fracture of the tibia be differentiated from rupture of the flexor metatarsi?

9. How should fracture of the tibia be treated?

10. When partial fracture of the tibia is suspected, how should the horse be handled to prevent the fracture becoming complete?

11. What would be the symptoms of fracture of either malleoli? 

12. Upon what does the prognosis depend?

13. How should dressing be applied to fractures of the tibia?

\section{Rupture of the Tibio-Fibular Interosseous Ligament. Page 704.}

1. Is the fibula ever fractured?

2. How could it be torn loose from the tibia?

\section{Rupture of the Flexor Metatarsi Muscle.-Page 704.}

1. Where does this muscle originate?

2. Of how many parts does it consist?

3. Where does each insert?

4. What is the function of each?

5. How may this muscle be ruptured?

6. What are the symptoms of rupture of the tendinous portion?

7. How would bruises of the muscular part affect the action of the limb?

8. What are the symptoms of rupture of the muscular part?

9. How does rupture of the muscular part differ in its symptoms from paralysis of the muscle?

10. How could rupture of this muscle be differentiated from fracture of the tibia?

11. What is the prognosis of rupture of either part?

12. How should each of these conditions be treated?

\section{Rupture of the Tendo Achillis.-Page 708.}

1. What constitutes the tendon of Achilles?

2. What is the action of the muscles, whose tendons form this structure?

3. How does this accident compare in frequency with rupture of the flexor metatarsi?

4. How is this tendon liable to be ruptured?

5. What are the symptoms?

6. What kind of lameness does it produce?

7. How can it be differentiated from paralysis of the great sciatic nerve?

S. What are the symptoms of rupture of the gastrocnemius muscle? 

9. Why does flexion and descent of the tarsus when this tendon is ruptured cause volar flexion of the phalanges?

10. What are the symptoms of partial rupture or injury to the gastrocnemius?

11. What is the prognosis?

12. How would the prognosis differ if the skin and tendon were cut, from rupture of the tendon?

13. How should a rupture or incised wound of the tendon be treated?

\section{Fracture of the Bones of the Hock.-Page 7II.}

1. What bones form the hock?

2. Which is a lever bone?

3. Which assist in forming a ginglymus articulation?

4. How are the lateral ligaments arranged?

5. Where is the calcaneo-cuboid ligament, and what is its function?

6. What is the origin and insertion of the tarso-metatarsal ligament and what is its function?

7. Where is the oblique ligament, and what is its function?

8. How are the capsular ligaments of the tarsus arranged?

9. Where is the posterior annular ligament?

10. How are the anterior annular ligaments arranged, and what pass beneath them?

11. How are the synovial membranes arranged?

12. What tendinous sheath lies posteriorly?

13. What one lies externally?

14. Over what bones are synovial bursae placed?

15. What bones of the hock are most liable to fracture?

16. What are the symptoms of fracture of the os calcis

17. How is this bone liable to be fractured

18. What is the prognosis?

19. What should be the general plan of treatment?

20. What are the symptoms of fractures of other bones of the hock?

21. What is the prognosis?

22. What should be the method of treatment?

Luxation and Strain of the Hock.-Page 713.

1. Is luxation of this joint probable?

2. In what animals has it been seen? 

3. Are the binding ligaments ever ruptured?

4. What are the symptoms of dislocation of the hock?

5. Are strains of the hock of common occurrence?

(i. What are the symptoms?

i. What is the prognosis?

8. What is the treatment?

9. When would blistering be indicated?

10. What form of blister would be suitable?

11. How should it be applied?

12. When would firing be indicated?

13. Under what circumstances would puncture firing be indicated?

14. How much time should elapse after firing before a blister should be applied?

Wounds and Acute Inflammation of the Hock.-Page 714.

1. How may incised or lacerated wounds be produced about the hock?

2. How are punctured wounds of this region often made?

3. Why are such wounds of the periarticular tissue particularly dangerous?

4. How may intracapsular wounds be differentiated from subfascial ones?

5. Why are subfascial wounds of the hock so liable to bebecome septic?

6. In what part of the hock are intracapsular wounds the most serious?

7. Why are skin wounds in front of the hock so liable to produce granuloma?

8. What are the symptoms of subfascial cellulitis of the hock?

9. What of open bursa?

10. What conditions may act secondarily to open the joint?

11. How should subfascial cellulitis of the hock be treated?

12. What general line of treatment should be followed, if the capsular ligament has been punctured?

13. How should incised and lacerated wounds of this region be treated?

14. How should granuloma in front of the hock be treated?

15. What is the prognosis in purulent subfascia cellulitis?

16. How do septic processes of this region produce septic pneumonia? 

17. Upon what does the prognosis depend, in open hock joint?

18. How should periarticular absce ses be treated?

19. Why is laminitis liable to develop in the opposite foot?

Bog Spavin.--Page 717.

1. What is bog-spavin?

2. What are the attachments of the capsular ligament of the true hock joint?

3. What parts of this ligament receive the least reinforcement from other structures?

1. What is the cause of distention of this ligament?

5 . Where does the distention occur?

6. What are the diagnostic symptoms?

7. How can it be differentiated from tendinous thorough pin?

8. Does bog spavin cause lamness?

9. When is distention of the capsular ligament dangerous to life?

10. How should it be treated, if recent and painful?

11. When acute inflammation has subsided and bog spavin still remains, how should it be treated?

12. When chronic synovitis and distention only exist, how should be treated?

13. What form of firing is indicated?

14. What line of treatment should be followed in colts affected with hydrarthrosis?

15. What precautions are necessary in evacuating the sac with trocar?

16. Is evacuation often beneficial?

17. How often should it be repeated?

18. How and when may iodine be injected into the sac?

19. What strength of sublimate solution may be injected?

20. What is Horn's method of treating it?

21. When is blistering indicated?

22. When and what kind of firing is indicated?

23. What is the prognosis?

\section{Bone Spavin.-Page 7Ig.}

1. What is bone-spavin?

2. What parts have been considered as its origin?

3. How could chronic inflammation of a joint cause exostosis? 

4. What bones may be involved in spavin?

5. Is bone spavin always accompanied by a visible exostosis?

6. What are the pathological changes noted on page $720,(1)$, (2), (3), and (4)?-Möller's Regional Surgery.

7. Is the cunean tendon and bursa ever involved?

8. From the changes noted in the above mentioned articles, where would the point of origin appear to be?

9. What is causa interna ?

10. What are the internal causes of spavin?

11. What form of hocks predispose to spavin?

12. How does the screw-like direction of the trochlea of the astragalus predispose to it?

13. If due to this arrangement of the astragalus, where would the lesion originate?

14. How might undue pressure cause it?

15. How might undue pressure be exerted on any one part of the joint?

16. If from undue pressure, where would the lesion originate?

17. Is spavin due to acute injury, or to slight and oft repeated ones?

18. Why is the tibio-tarsal joint rarely involved?

19. When the foot is planted and the astragalus is rotated, what causes rotation of the parts below?

20. Is spavin lameness a characteristic one?

21. Can it be diagnosed without a visible exostosis?

22. If an exostosis is visible, is it positive evidence that the lameness is due to spavin?

23. When is this lameness the most pronounced?

24. In what respect does it resemble stringhalt?

25. How may it best be detected in the stable?

26. If it be suspected, how can the lameness be developed?

27. What is the spavin test?

28. Why is lameness more marked when turning toward the sound, than the lame side?

29. In what stage is the lameness maintained or even increased, during motion?

30. In what aged animals is the spavin test liable to mislead?

31. From what position can a spavin be seen the best?

32. How will wetting the hair over the spavin seat assist in revealing the tumor? 

33. Is a difference in the size of the two hocks positive evi-dence of disease?

34. Is an exostosis more liable to cause lameness when 10cated well forward?

35. Is superficial evidence of inflammation often present?

36. What form of spavin does lameness cause?

37. How may it be differentiated from stringhalt?

38. How from hip lameness?

39. How from chronic gonitis?

40. How from disease of the perforans and its sheath?

41. How from tendinitis below the hock?

42. How from curb?

43. How from foot lameness?

44. What effect does spavin have on the wearing of the toe or shoe?

45. What is its cause?

46. Does the lameness ever disappear spontaneously?

47. How does long rest affect it?

48. How does severe exertion?

49. How would the work the horse was expected to do, affect the prognosis?

50. How would the location affect it?

51. How would the conformation?

52. How would the age of the patient?

53. What does marked muscular atrophy indicate?

54. What is the general prognosis?

55 . What is the principal object sought for in treating spavin?

56. What attention should the foot receive?

57. When is firing indicated?

58. What kind is applicable?

59. How does blistering succeed?

60. What is the general objection to escharotics?

\section{Cunean Tenotomy.-Page 733 .}

1. Where is the cunean tendon?

2. To what does it insert distally?

3. What is its relation to the seat of bone spavin?

4. Under what circumstances may it increase or prolong spavin lameness?

5. Where should the incision be made, to divide this tendon?

6. How should the field of operation be prepared? 

7. How should the horse be controlled?

8. What is the technique of the operation?

9. What after-treatment should the wound receive?

10. In what way does Möller think this operation benefits bonespavin?

11. What is anterior tibial neurectomy?

12. For what purpose is it performed?

13. Where is the incision made?

14. What tissues are in relation to the nerve at this point?

15. What muscular structure separates it from the anterior tibial artery?

16. What superficial nerve is passed in dissecting for it?

17. How should the animal be secured?

18. What is the technique of the operation?

19. What is posterior tibial neurectomy?

20. For what purpose is it performed?

21. What tissues are supplied by this nerve?

22. How should the animal be secured?

23. What are the relations of this nerve at the point of oper. ation?

24. Where should the incision be made?

25. What is the technique of the operation?

26. What after-treatment is necessary?

Enlargements of the Outer Side of fhe Hock.-- Page $7+1$.

1. What pathological conditions does the above include?

2. What are the causes?

3. What is the French term for enlargement of the outer side?

4. Do these condtions ever cause lameness?

5. What are the symptoms?

6. What is the prognosis?

7. When is treatment necessary?

\section{Curb.--Page 742 .}

1. What is curb?

2. What structures are involved?

3. What are the causes?

4. From what position can it be seen the best?

5. What kind of hocks are predisposed to it?

6. Which bone of the hock is a lever bone? 

7. What structure binds it to the metatarus?

8. What are the symptoms?

9. Does curb always cause lameness?

10. What is the prognosis?

11. How should curbs be treated during the acute inflammatory stage?

12. When is blistering indicated?

13. When is firing indicated?

14. What kind of firing is suitable?

15. How should the horse be shod?

Capped Hock.-Page 744 .

1. What is scapped hock?

2. What bursae may it involve?

3. What other structures may also be involved?

4. What are the causes?

5. What are the symptoms?

6. How differentiate as to structures involved?

7. When does it cause lameness?

8. What is the prognosis?

9. Does it ever produce purulent cellulitis?

10. If so, what is the prognosis?

11. How should same be treated?

12. When should the bursa be opened?

13. When is aspiration indicated?

14. When is blistering indicated?

15. What antiphlogistic treatment might be serviceable?

16. When would firing be useful?

17. What is false capped hock?

\section{Luxation of the Perforatus Tendon.-Page $7 t^{8}$.}

1. How is this tendon attached to the summit of the calcanium?

2. How could this attachment be torn loose?

3 . What would be the result of loosening one side?

4. What are the symptoms?

5. What is the prognosis?

6. How should it be treated? 

Stringhalt.-Page 749 .

1. What is stringhalt?

2. What limbs does it usually affect?

3. What kind of lameness does it cause?

4. What is spavin stringhalt?

5. What is false stringhalt?

6. How does it differ from the true?

7. How does Bassi classify it?

8. How does Möller?

9. What are the causes of idiopathic stringhalt?

10. What of symptomatic?

11. What is the usual course of the disease?

12. What is the prognosis?

13. What is peroneal tenotomy?

14. What is the technique of the operation?

15. Is it necessary to resect a piece of the tendon?

16. How should the animal be secured?

17. What is the prognosis?

18. How should it be performed above the hock?

19. Has division of the fascia given beneficial results?

20. What operations have been performed for the relief of stringhalt?

21. What have been the results?

22. What operations have been performed on the nerves, for its relief?

23. What have been the results?

\section{Diseases of the Tendons and Tendino Sheaths in the Tarsal and Metarsal Region.-Page 754 .}

1. Where is the tarsal sheath of the perforans?

2. What is its extent?

3. What are the symptoms of distention of this sheath?

4. What name is usually applied to it?

5. How can it be differentiated from distention of the capsular ligament of the hock?

6. How can it be distinguished from curb?

7. What are the causes?

8. What is the treatment?

7. What is the prognosis?

10. What are the causes of acute inflammation? 

11. What is the prognosis in the latter form?

12. When is blistering needed?

13. When is firing indicated?

14. What kind of shoe would be beneficial?

15. What bursa of an extensor of the foot at the hock is iiable to become distended?

16. What is the appearance, if distended?

17. Does it cause lameness?

18. What is the prognosis?

19. How should it be treated?

20. How does distention of the sheaths in the metatarsal region differ from the same condition in the metacarpal?

\section{Infectious Inflammation of the Lower Synovial Sheath of the Perforans.-Page 760 .}

1. Is there any difference between diseases of these synovial sheaths and of those of the pectoral limb?

2. Why is infectious synovitis more liable to occur in the pelvic than the pectoral limb?

3. What are the common causes?

4. What is the prognosis?

5. How is it diagnosed?

6. How should it be treated?

\section{Injuries Produced by Striking and Their Complica- tions.-Page 763 .}

1. What does striking or interfering include?

2. Where is the injury usually inflicted on the pelvic limb?

3. Where may it be inflicted on the pectoral?

4. By which foot is it done?

5. By what part of the foot may it be done?

7. When do these injuries cause lameness?

8. What is the nature of the lesion, when the supero-internal part of the metacarpus is struck?

9. How should hygroma of this region be treated?

10. What complications are liable to follow repeated bruises of this kind to the fetlock?

11. What complications are liable to follow if the skin is broken?

12. What is the chief danger from purulent cellulitis? 

13. What vessel is liable to become thrombosed from purulent cellulitis of the posterior fetlock region?

14. What is the course, if the wound remains aseptic?

15. What are the symptoms of subfascial cellulitis?

16. Why does it take the abscess from twelve to fourteen days to break?

17. What effect is this liable to have on the fascia?

18. How should subfascial cellulitis be treated?

19. What is the prognosis?

\section{Anatomy of the Foot.-(Strangeway) Page $5+4$.}

1. What constitutes the foot?

2. What are its three divisions?

3. To what tissues of the body do the two last belong?

4. What part of the skin does the horn represent?

5. Of what are the sensitive and non-sensitive tissues composed?

6. What is the keratophyllous tissue?

7. What is the cutigeral groove?

8. What is lodged in it?

9. What is the function of the coronary substance?

10. What forms the white line in the sole?

11. What is the wall?

12. Into what three parts is it divided?

13. What are the bars?

14. From what are they formed?

15. What constitute the heels?

16. What is the periople?

17. What is the spread?

18. What is the sole?

1?. What is the appearance of its uper surface?

20. What are inserted in the numerous openings on this sur. face?

21. From what is the horny sole secreted?

22. What is the frog?

23. What is its cleft?

24. What occupies the small foramina on its upper surface?

25. What is the frog stay?

26. What are the commissures?

27. What are the heels or bulbs of the frog?

28. Where are the lateral cartilages located? 

29. What is their size and shape?

30. What is their function?

31. What is the keratogenous membrane?

32. Why is it so called?

33. What is the villous or papillated portion of this membrane called?

34. What is the laminated portion called?

35. Where is the villous or velvety tissue?

36. How is the podophyllous tissue related to the bone?

37. How is it attached to the horny tissue?

38. What secretes the periople?

39. What the crust or horn?

40. What the horny sole?

41. What the horny frog?

42. If the coronary band be destroyed, how may the horn be formed?

43. What would be the effect of destruction of a considerable part of the sensitive sole?

\section{Arterial Supply of the Foot.}

1. From what are the posterior digital arteries derived?

2. What is their course?

3. What branches are given off by each?

4. What are their relations?

5. What is the termination of either?

6. What is the source, course, and distribution of the perpendicular artery?

7. What is the source, course, and distribution of the transverse?

8. What does the artery of the frog supply?

9. Where does the preplantar ungual artery originate?

10. What is its course and distribution?

11. What branches are given off by it?

12. Where does the plantar ungual originate?

13. What is its course and distribution?

14. Where is the circulus arteriosus?

15. What are the names and distribution of the ascending branches of the plantar circle?

16. What are the names, number and distribution of the descending ones?

17. Where is the circumflex artery? 

18. What branches are given off by it?

19. What structures do they supply?

20. How do the solar arteries terminate?

\section{Venous Arrangement of the Foot.}

1. What effect does absence of valves in the veins of the foot have upon the circulation?

2. Where is the superficial venous plexus?

3. What are its divisions?

4. What is remarkable about the solar plexus?

5. From what source does it receive blood?

6. Into what do these veins flow?

7. What other veins flow into it?

8. Into what does the circumflex empty?

9. What other vein receives blood from the solar veins?

10. Into what does this vein flow?

11. Where is the laminal plexus located?

12. From what source do the laminal veins recerve ilood?

13. Into what do they flow?

14. Where is the coronary plexus located?

15. How is it divided?

16. Where is the middle division located?

17. From what does it receive blood?

18. How are the lateral portions divided?

19. Where is each located?

20. How are the veins of the frog arranged?

21. Into what do they flow?

22. What is the course of the veins formed by those of the frog?

23. What vessels do they receive ?

24. In what do all these veins terminate?

25. What is the arrangement of the interosseous venous plexus of the foot?

26. Into what do these veins flow?

\section{Nerve Supply of the Foot.}

1. What nerves of the hind leg reach to or below the fetlock?

2. From what is each of these derived?

3. What is the termination of each?

4. What is the course and termination of the posterior digital nerve? 

5. What is the course and termination of the middle branch?

6. What is the course and termination of the anterior branch?

7. What effect would their anastomosis have on the results of digital neurectomy?

8. How does the nerve supply of the front feet differ from that of the hind ones?

\section{Diseases of the Foot.-Page 768.}

1. What is pododermatitis?

2. What conditions does Möller include under the head of inflammation of the podophyllous membrane?

3. What are the causes?

4. Why are such inflammations so extremely painful?

5. Why is the tendency to necrosis so great?

6. What physiological condition of the tissues tends to prevent it?

7. What is the stratum mucosum of the podophyllous membrane?

8. Does this tissue show any horn substance?

9. What tissue is involved in pododermatitis superficialis?

10. How is acute inflammation of this tissue brought about?

11. If it is wounded by a nail or other sharp instrument, what term is applied to it?

12. What term is used if the wound is at the white line between the wall and sole?

13. What if it is at the angle of the heels?

14. Under what circumstances may inflammation of this tissue be aseptic?

15. What change in color of the horn tissue is sometimes noticed after aseptic inflammation?

16. What is the cause of this change?

17. Why does the suppurative process of the sept:c form not spread to the deeper tissues?

18. In what direction does the pus spread?

19. What is the physical appearance of the pus?

20. What is the prognosis of the aseptic form?

21. Under what conditions may this form spontaneously recover?

22. What are the common terminations of the aseptic form?

23. How does the parenchymatous form differ from the superficial? 

24. How do the wounds that cause the former differ from those that cause the latter?

25. What is the character of the pus in the parenchymatous form?

26. What would offensive odor from the deep tissues indicate?

27. How may the joints or navicular sheath be opened by secondary process?

28. What would a reddish or wine-colored, bad smelling discharge indicate?

29. What is the indication if synovia be discharged?

30. What relation does the degree of lameness bear to the prognosis?

31. How might an abscess above the perforans tendon and behind the navicular bone cause necrosis of the foot?

32. How can the superficial form be differentiated from the parenchymatous?

33. How may necrosis be caused by infection?

34. What are the results of purulent cellulitis?

35. What is the termination of purulent, sub-coronary cellulitis?

36. How may septic products enter the blood stream from the feet?

37. What are the causes of acute pododermatitis?

38. What would be the effect of inflammation spreading to the periosteum?

39. How are these conditions diagnosed?

40. How should the foot be examined for injuries ?

41. Upon paring a punctured spot in the sole, when is it evident that infection has not taken place?

42. How may the pulsations in the digital arteries be of service in diagnosis?

43. What is the prognosis of the superficial form?

44. How should it be treated?

45. What principle must be adhered to, in the treatment of the parenchymatous form?

46. What treatment is indicated if the navicular sheath is open but not infected?

47. What are the symptoms of its infection?

48. If suppuration is present, what treatment is indicated?

49. What are the symptoms of abscess beneath the hollow of the heel? 

50. Why is early opening necessary?

51. How should it be opened?

52. What after treatment is necessary?

53. How should it be dressed?

54. What is the cause of the soft tissues filling up an opening in the horn tissue?

55. How should such conditions be treated?

56 . When are foot baths indicated?

\section{Pricks in Shoeing.-Page 776.}

1. How may the sensitive structures be injured by nails in shoeing?

2. How may a bent nail injure the tissues?

3. Are such injuries always noticed at the time they are inflicted?

4. How may a split nail injure the parts?

5. What are the symptoms of pricking?

6. How should such cases be treated?

7. What may be determined by inspecting each nail as it is extracted?

8. Upon what does the prognosis depend?

Puncture of the Foot. Perulent Cellulitis of the Fibro -Fatty Frog.--Page 778.

1. What is the plantar cushion?

2. In what part of the sole or frog are nail pricks most dangerous?

3. Upon what does the suppurative process depend?

4. How should such wounds be treated when first inflicted?

5. What tissues are liable to be injured?

6. Why is purulent cellulitis of the plantar cushion particularly dangerous?

7. How may the plantar aponeurosis become involved?

8. How do such injuries correspond in their pathology and treatment with those mentioned by Möller under acute pododermatitis?

9. In the treatment of such wounds, when is a poultice indicated?

10. After paring out the horn to drain a wound how can it be protected from dirt? 

11. How may packings be retained in the bottom of the shod foot?

12. Why is decomposition of wound discharge dangerous?

13. When is a dry dressing indicated?

14. When may a wound of the sole or frog be safely covered with tar, oakum and a leather pad?

15. When is curetting indicated?

16. When is zinc chloride indicated in such wounds?

17. What course must be followed when the perforans tendion becomes necrotic?

Resection of the Plantar Aponeurosis.-Page $78 \mathrm{i}$.

1. When is this operation indicated?

2. What preparation of the subject is necessary on the previous day?

3. How should the animal be secured?

4. How may local anesthesia be secured for foot operations?

5. How should hemorrhage be controlled?

6. What instruments are necessary for this operation?

7. What is the technique of the operation?

8. What complications are liable to occur in partial resection?

9. How much of the frog and sole should be removed, if complete resection is desired?

10. Where should the fibro-fatty cushion be divided transversely?

11. How is the resected portion removed?

12. How should the wound be dressed to prevent hemorrhage?

13. When should this dressing be removed?

14. What is the after treatment?

15. If the posterior part of the fibro-fatty frog or the navicular sheath be involved, what further operative procedure is indicated?

16. If bone necrosis is present how should it be treated?

17. In what class of horses is the prognosis most favorable?

18. How much time is required for convalescence?

Treads and Injuries to the Coronet.-Page 783 .

1. What is understood by calk wounds?

2. Where are they usually inflicted?

3. How is the coronary region liable to be injured? 

3. What kind of injuries to this region are liable to cause ring-bone?

5. What are the chief dangers from calk wounds to the coronet?

6. If they penetrate behind the hoof, what surgical procedure is necessary?

7. If purulent cellulitis has developed, what treatment is indicated?

8. If cellulitis has not reached the purulent stage, how should it be treated?

9. How may such wounds affect the coronet joint?

10. How may the extensor pedis tendon be involved?

11. Upon what does the prognosis depend?

12. What treatment is indicated if distortion of the horn occurs?

\section{Inflammation of the Subcoronary Connective Tissue.}

Page 787 .

1. How is this tissue related to the fibro-fatty frog?

2. What venous plexus does it contain?

3. How is this disease liable to affect the pedal-joint?

4. What are the common causes?

5. What part of the coronet is usually involved?

6. What is the prognosis?

7. When are antiseptic baths of service.

8. How may the lateral cartilage become involved?

\section{Corns.-Page 790.}

1. What constitute corns in horses' feet?

2. Where are they located?

3. What causes the red streaks in the horn at this region?

4. How may these parts be bruised by the shoe?

5. How by the quarter?

6. Does inflammation in this region ever develop without in. fection?

7. If infection takes place, what is the result?

8. Under what circumstances would necrosis be liable to occur?

9. Where would the necrotic tissue be located?

10. Under what circumstances is the fibro-fatty frog liable to become involved? 

11. If this extension takes place, what condition is liable to follow?

12. What is the result of the infection extending to the perichondrium?

1:). What condition may cause a yellow staining of this region?

14. Why are the heels more liable to be bruised than other parts of the foot?

15. Which heel is most predisposed?

16. In which feet are they most common?

17. What form of foot is most subject?

18. What three conditions in shoeing are liable to produce corns?

19. What kind of shoes protects this region from bruise?

20. How are corns diagnosed?

21. What form of lameness do they produce?

22. How do they affect the pulsations of the digital arteries?

22. How may pododermatitis from corns be distinguished from that caused by injuries to other parts of the foot?

24. What treatment is indicated if infection has not taken place?

25. What if superficial pododermatitis is present?

26. What if pododermatitis parenchymatosa has developed?

27. What if necrosis is present?

28. What is the prognosis in each of these forms?

\section{Quittor.--Page 793.}

1. What is meant by the term quittor in veterinary practice?

2. What tissues are liable to be involved?

3. What terms are used to indicate the particular tissues involved?

4. What is the perichondrium of the lateral cartilages?

5. To what other structures is the perichondrium in close relation?

6. How are abscesses of the perichondrium liable to affect the cartilage?

7. Is direct injury to the cartilage a common cause of quittor?

8. How may corns cause it?

9. How may a quarter crack lead to quittor?

10. What is the physical appearance of necrotic cartilage?

11. Why is the prognosis of necrotic cartilage or ligament so unfavorable?

12. Are these conditions acute or chronic? 

13. Under what circumstances does spontaneous recovery occur?

14. Which cartilage is most often involved?

15. Which end is usually attacked first?

16. What ligaments in this region are liable to become necrotic from the same cause?

1i. How may the pedal-joint be opened during the course of quittor?

18. How may nail pricks cause quittor?

19. What are the symptoms?

20. Is the location of the abscess outside of the cartilage assurance that the cartilage is not necrosed?

21. What condition of the hoof indicates the duration of the disease?

22. What are the indications, if the lameness is severe?

23. What is the prognosis of quittor?

24. Of what does the prophylactic treatment consist?

25. How should acute inflammation of this region be treated?

26. What steps must be taken, if abscess has already formed?

27. If necrosis has occurred but not yet penetrated the cartilage, what treatment is indicated?

28. When are mildly caustic injections indicated?

29. What agents may be used for this purpose?

30. What can be profitably used to remove the pus before such injections are made?

31. How often should such caustics be injected?

32. How should drainage be secured, if sinus extends below the top of the hoof?

33. Why should the coronary band not be divided?

34. How may drainage be maintained?

35. How and when may the cautery be used in the treatment of quittor?

36. What is Ligniere's treatment?

37. How is curetting beneficial?

38. When is radical operation necessary?

39. Of what does it consist?

40. How should the field be prepared?

41. How secure the animal?

42. How control the hemorrhage?

43. What instruments are necessary?

44. How should the hoof be removed? 

45. Where should the incision through the horn be made?

46. How should the superposed tissues be separated from the cartilage?

47. How should the cartilage be separated from the bone and underlying tissues?

48. How should it be removed?

49. How should the wound be dressed?

50. When should it be redressed?

51. What is the after treatment?

52. What is the prognosis?

53. How much time is required for convalescence?

54. What is Bayer's method?

\section{Laminitis.-Page 805.}

1. What kind of foot is predisposed to it?

2. How does this disease differ from acute pododermatitis?

3. What tissues are involved?

4. In what parts of the foot is it most severe?

5. What animals are subject to it?

6. Why is it so extremely painful?

7. What is its common name?

8. Which feet are most often affected?

\section{Etiology of Laminitis.--Page 806.}

1. What kind of feet are predisposed?

2. What are the dietetic. predisposing causes?

3. How may driving on hard roads be an exciting cause?

4. How does drinking, when hot, cause it?

5. How may standing too long on the feet produce it?

6. Why do long voyages sometimes cause it?

7. How does a chill tend to produce it?

8. Why are heavy, rich grains liable to cause it?

9. How do new grains and hay produce it?

10. Why are sudden changes in diet likely to cause it?

11. Why is it often seen after attacks of influenza and other debilitating diseases?

12. Is it common in connection with parturition? 



\section{Symptoms of Laminitis.-Page 807 .}

1. What conditions are usually forerunners of laminitis?

2. What are the primary symptoms?

3. How does it affect the body temperature?

4. What is the character of the pulse?

5. How are the digital arteries affected?

6. How is the cellular tissue of the pedal region affected?

7. How does it affect the muscular system?

8. If confined to the front feet, what position does the animal assume in standing?

9. What are the actions, if made to move?

10. How are the loins apparently affected?

11. Why are the front feet kept forward of a perpendicular line?

12. Why are the hind ones placed under the center of the body?

13. How are these positions and actions modified if all four feet are involved?

14. How are these positions and actions modified when the the disease is confined to the hind feet?

15. What symptoms of laminitis assimilate those of nephritis?

16. For what reason might it be mistaken for spinal meningitis?

17. Upon what does the prognosis depend?

\section{Termination of Laminitis.-Page 674. (Liautard.)}

1. In what ways may it terminate?

2. What is the course if it terminates in resolution?

$\therefore$ How long after the attack can such termination be expected?

4. What is the course, if it terminates in effusion or hemorrhage?

5. How is the podophyllous tissue separated from the keratophyllous?

6. When these tissues are separated, what tends to rotate the os pedis on its transverse axis?

7. If such rotation occurs, what effect does it have on the toe?

8. What on the sole?

9. How would it affect the animal's gait after soreness had disappeared?

10. What fills the space between the toe of the os pedis and wall after inflammation has subsided? 

11. How does this affect the toe of the hoof?

12. What effect does it have upon the anterior part of the wall?

13. What are the symptoms if hemorrhage occurs?

14. How may this condition terminate and leave the animal useful?

15. What are the symptoms of such termination?

16. What is the prognosis?

17. What is the cause of suppuration?

18. What is the course when it terminates by suppuration?

19. What are the symptoms?

20. What is the prognosis?

21. Is this termination common?

22. What is the cause of its terminating in gangrene?

23. What are the symptoms?

24. What is the prognosis?

Treatment of Laminitis.-Page rog.

1. What prophylactic measures should be observed?

2. When is bleeding indicated?

3. From what vessel should blood be extracted?

t. What quantity should be taken?

5. What vessels of the foot and leg might be opened?

6. How would ligation of the digital arteries affect it?

7. When are hot foot baths indicated?

S. When cold ones?

9. When would cold packs serve better than cold baths?

10. What is to be gained by laying the animal down, if it persistently stands?

11. How long should cold applications be continued?

12. When is blistering of the coronary region indicated?

13. How may cold packs be prepared?

14. When is a physic indicated?

15. When are febrifuges and sedatives indicated?

16. What agents of each class should have the preference?

17. How is a rocker shoe serviceable?

18. When should the patient be exercised?

19. What is the prognosis? 



\section{Chronic Laminitis.-Page $81 \mathrm{I}$.}

1. What are the causes of this form?

2. Under what conditions does it originate from the acute?

3. Is it ever associated with descent of the sole?

4. In exudative laminitis with organization, how are the sensitive structures affected?

5. What are the symptoms?

6. How is the circulation affected?

7. In traveling, what part of the foot is brought to the ground first?

8. What part of the shoe is most worn?

9. How would a bar shoe affect it?

10. How can it be differentiated from navicular disease?

11. What is the prognosis?

12. What is the treatment?

13. When is neurectomy indicated?

14. Which of the neurectomies is best suited?

15. When is blistering indicated?

16. When are foot baths indicated in the chronic form?

17. How does the rheumatic form differ from the above?

18. How can it be differentiated from muscular rheumatism?

Keratoma.-Page SII.

1. What is the nature of this affection?

2. What are the causes?

3. How do these horny tumors cause lameness?

4. Where do they form?

5. What are the common causes when they originate near the coronet?

6. What is liable to cause their development when they originate in the sensitive lamina?

7. What form of inflammation causes such growths?

8. At what point may they show externally?

9. When can they be diagnosed ante mortem?

11. How might percussion be of service?

11. Upon what does the prognosis depend?

12. When is treatment indicated?

1:. How should these tumors be removed?

14. Do they ever affect the sole? 



\section{Canker of the Sole and Frog.-Page 815.}

1. What is canker?

2. What is the nature of canker of the foot?

3. What tissues are involved?

4. How are the papillæ affected?

5. How are the cellular elements of the rete affected?

6. What effect does this have upon horn production?

7. If horn is not produced, what becomes of the epithelium?

8. How does this condition compare with grease?

9. Of what does it really consist?

10. Is either of these conditions liable to cause the other?

11. What are the symptoms?

12. At what point does it usually commence?

13. What is its appearance at this time?

14. How do the papillæ appear at this stage?

15. Does it then cause lameness?

16. How does it differ in this respect from acute. inflammatory diseases?

17. In what tissue does it spread?

18. How far may it extend?

19. What are the causes?

20. Upon what does the prognosis depend?

21. How does the nature of the growth affect the prognosis?

22. How does the area involved affect it?

23. Is treatment tedious?

24. Along what general lines must it be directed?

25. What are the best agents for destroying the excessive growths?

26. When would cautery be indicated?

27. Why is it necessary to remove all of the loose horn?

28. Should the horn be removed over any of the sound tissue?

29. How should the animal be.controlled?

30. How should nitrate of lead be used?

31 . When would formalin be indicated?

32. How should it be used?

33. What is the effect of pressure upon such conditions?

34. How may it be applied?

35. How often should the dressings be renewed?

36. When can the disease be said to be cured?

37. What is Iminger's treatment? 

Diseases of the Claws in Cattle and Sheep.-Page 820.

1. Why are the soles of cattle's feet more easily bruised than those of the horse?

2. What feature of the divided hoof renders it particularly susceptible to injuries from dirt?

3. What are the symptoms of inflammation of the claws and interdigital spaces?

4. What symptom of this diseases may lead to the belief that the loins are affected?

5. How may the animal be secured to examine the foot?

6. What condition of the foot would denote inflammation?

7. What condition of the interdigital space would denote disease?

8. How may traveling in stiff mud cause disease of this kind?

9. What is the cause of purulent, subcoronary inflammation in bovines?

10. What are the common causes of inflammation in these tissues?

11. How should it be treated?

12. How does ergotism affect this region?

13. How should it be treated?

14. When are caustics indicated in inflammations of the digits?

\section{Bruises of the Sensitive Sole and Bulbs.-Page 823.}

1. How do such injuries to the feet of artiodactyla differ from similar lesions to the perissodactyla?

2. How would the treatment differ from that applicable to the horse?

3. How do pricks in shoeing in cattle differ from same lesion in the horse?

\section{Laminitis in Cattle.-Page 826.}

1. Is this condition common in cattle?

2. What are the causes?

3. Are they subject to both acute and chronic forms?

4. What are the symptoms?

5. What is the prognosis?

6. What is the treatment?

7. In serious lesions to these animals, how can the financial loss be modified? 



\section{Whitlow or Joint Felon.-Page 826 .}

1. Of what does this consist?

2. How does it differ from purulent inflammation of the subcoronary, connective tissue in the horse?

3. What are the causes?

4. What are the symptoms?

5. What is the course?

6. How does it compare with the septic condition often seen in horses' feet?

7. How should it be treated?

\section{Abnormalities of the Horny Claw.-Page 83T.}

1. Of what do these consist?

2. What are the causes?

3. What is the effect?

4. What is the treatment?

\section{Amputation of the Claws in Cattle.-. Page $8_{3} \mathrm{t}$.}

1. What conditions render this operation necessary?

2. How should the animal be secured?

3. How should the hemorrhage be controlled?

4. What portions of the hoof should be removed?

5. What is the technique of the operation?

6. How should future hemorrhage be prevented?

7. What steps are necessary to insure a covering for the remaining bone?

8. How should the parts be dressed?

9. Why are such operations serviceable in cattle, but not in horses?

\section{Foot Rot in Sheep.-Page 835 .}

1. How does the disease referred to by Möller under this head differ from infectious foot rot in sheep?

2. How from panaritiun of cattle?

3. What are the symptoms?

4. What tissues are first involved?

5. How does it affect the deeper tissues? 

6. What effect does it have upon the horn?

7. How are the ligaments and bones affected?

8. What is the prognosis?

9. How should it be treated?

\section{Diseases of the Claws in Carnivora.-Page 836.}

1. What are dew claws?

2. In what way do they become troublesome?

3. How should they be treated?

4. What treatment is required when a claw is torn off at the matrix?

5. What is the technique of removing the entire phalanx of carnivora?

6 How should the claws of birds be treated when overgrown? 



\section{INDEX}

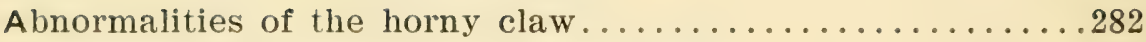

Abscesses of the subparotid lymph glands.............. 32

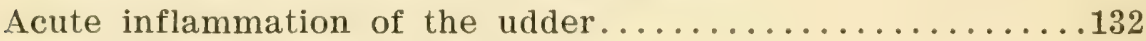

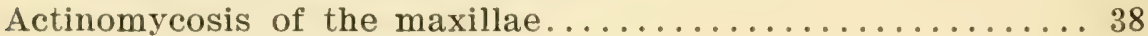

Actinomycosis of the parotideal region............... 34

Actinomycosis of the tongue...................... 14

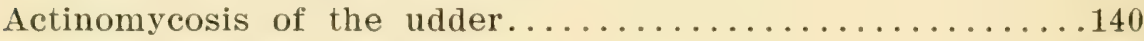

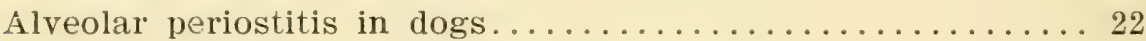

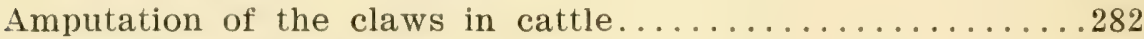

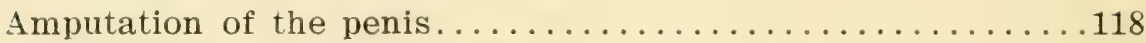

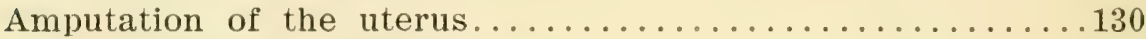

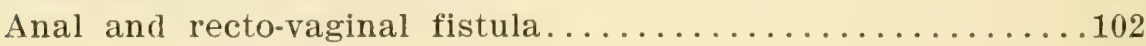

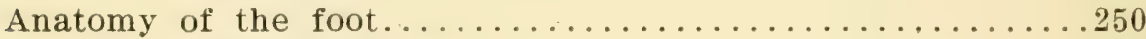

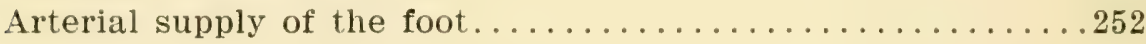

Bleeding from the nose....................... 30

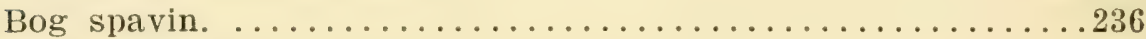

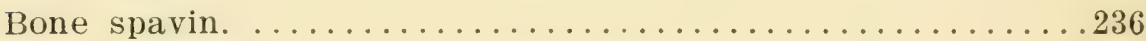

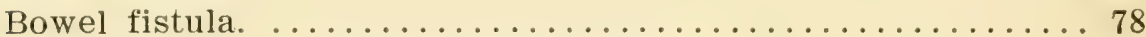

Bruises of the sensitive sole and bulbs................... 280

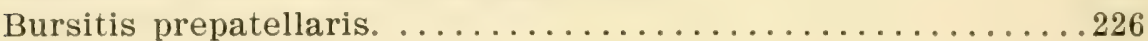

Canker of the sole and frog.......................... 278

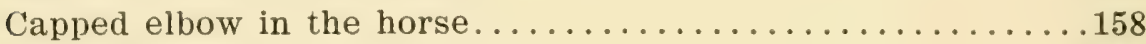

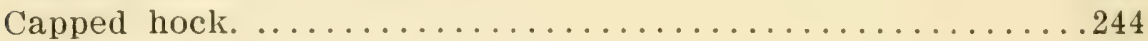

Castration of cryptorchids. ....................... 120

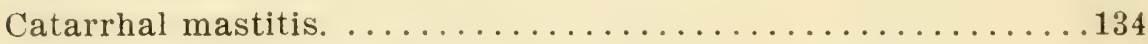

Catarrh of the guttural pouch................... 42

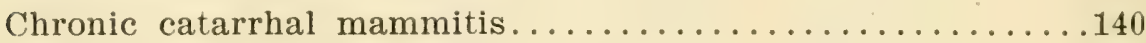

Chronic inflammation of the knee joint............... 166

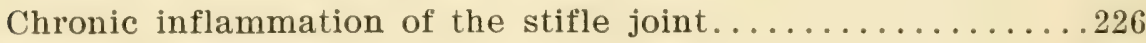

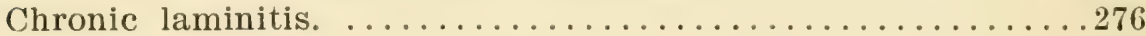

Commotio cerebri. ..........................44

Concussion of the brain........................44

Congenital malformations of the rectum and anus........ 98

Corns. ..................................264

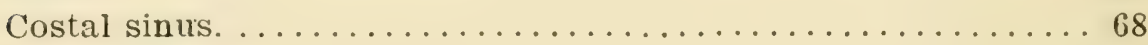

Cracked heels. ............................206

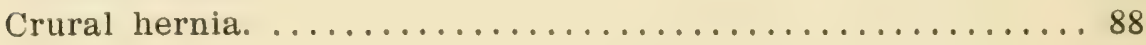




\section{INTERROGATORY SURGERY.}

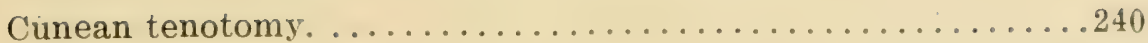

Curb.

Curvature of the spine.

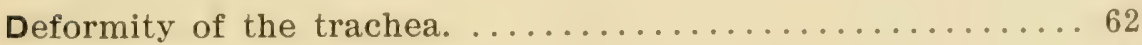

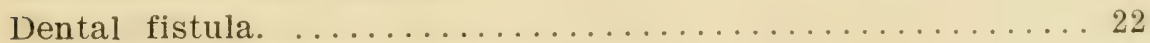

Dermatitis chronica verrucosa....................... 210

Dermatitis gangrenosa. . . . . . . . . . . . . . . 208

Dermatitis in the fetlock region...................206

Differential diagnosis and treatment of navicular disease...204

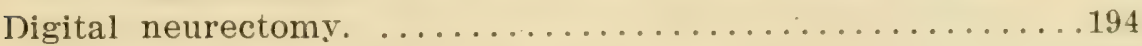

Dilatation of the esophagus..................... 56

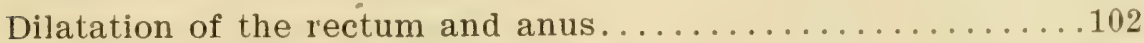

Diseases of the alveoli. ......................... 18

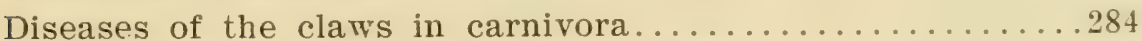

Diseases of the claws in cattle and sheep.............280

Diseases of the ear and guttural pouch.............. 38

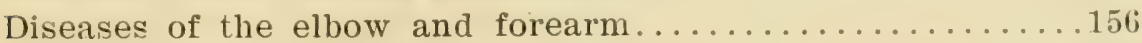

Diseases of the face and lower jaw .................. 36

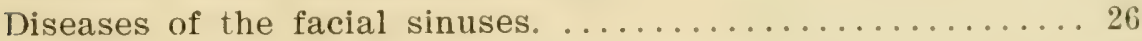

Diseases of the female organs of generation........... 126

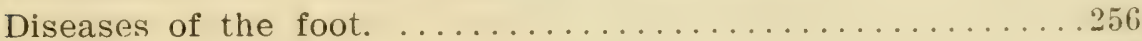

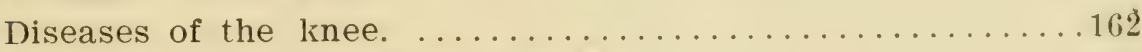

Jiseases of the larynx and trachea................. 58

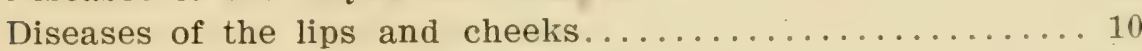

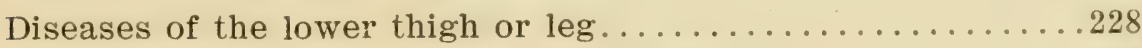

Diseases of the male organs of generation............114

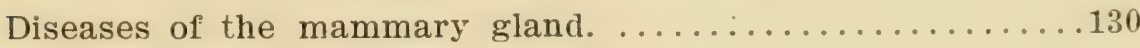

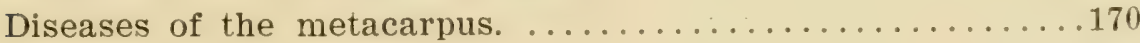

Diseases of the neck. ........................... 46

Diseases of the nose and nostrils................... 24

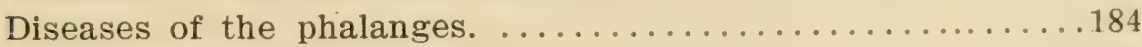

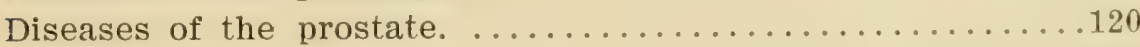

Diseases of the salivary glands. ................. 30

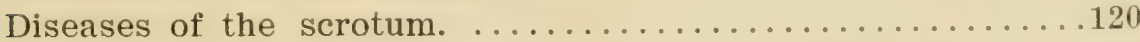

Diseases of the shoulder joint. .................... 152

Diseases of the skull. ......................... 42

Diseases of the spinal column and pelvis. ............... 142

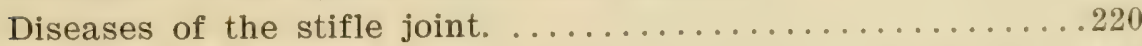

Diseases of the tail. ............................

Diseases of the tendons and tendinous sheaths in the tarsal and metatarsal region. 


\section{INTERROGATORY SURGERY}

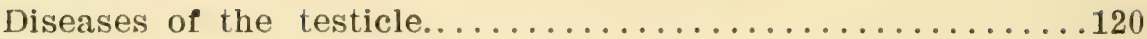

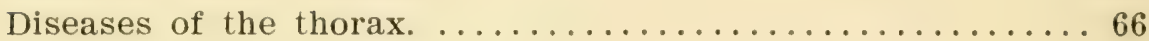

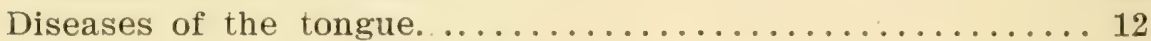

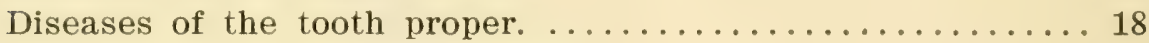

Diseases of the turbinated bones. .................... 30

Diseases of the urinary organs. ................... 104

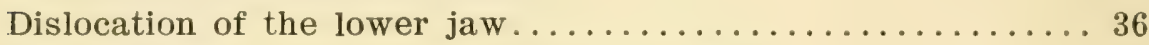

Displacement of the biceps femoris muscle............. 218

Distortion of the neck. .................... 48

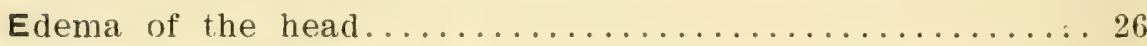

Enlargement of articular and tendinous synovial cavities in

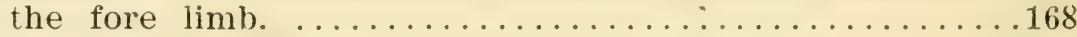

Enlargement of the outer side of the hock............242

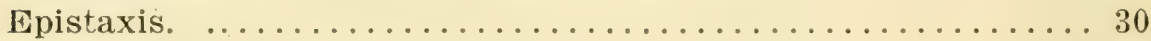

Esophagotomy. ........................ 54

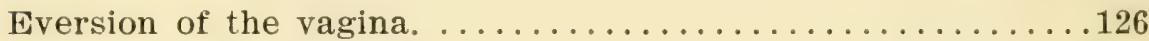

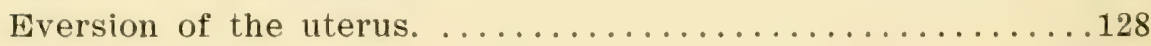

False inguinal hernia. .................... 86

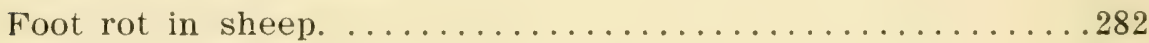

Foreign bodies and tumors in the nostrils............ 24

Foreign bodies in the digestive tract............... 90

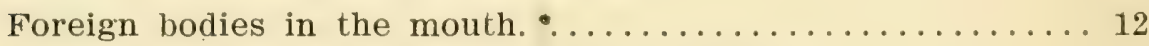

Foreign bodies in the pharynx and esophagus........... 54

Foreign bodies in the pharynx and esophagus of carnivora.. 54

Foreign bodies in the trachea...................62

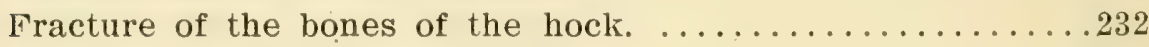

Fracture of the bones of the knee. .................. 164

Fracture of the cervical vertebræ. ............... 48

Fracture of the frontal bones...................... 44

Fracture of the femur. . . . . . . . . . . . . . . 212

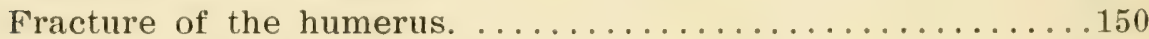

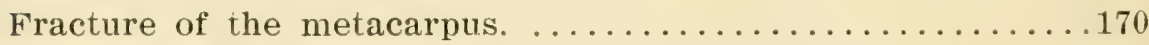

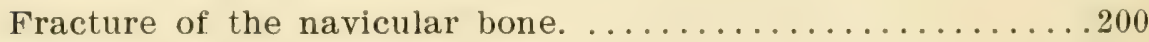

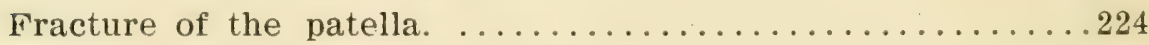

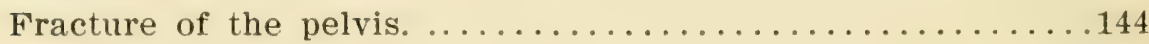

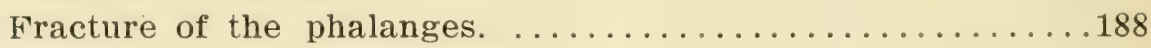

Fracture of the premaxillary. ................. 14

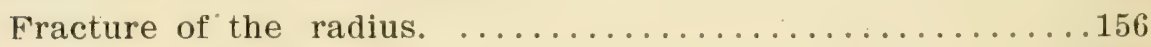

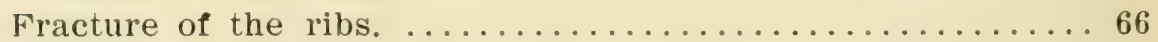

Fracture of the sacral and caudal vertebræ.............. 144 


\section{INTERROGATORY SURGERY.}

Fracture of the scapula. ........................

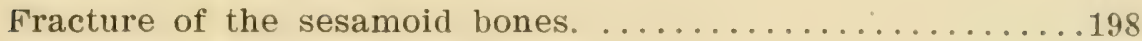

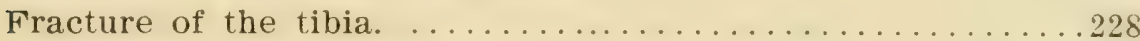

Fracture of the trachea. .......................62

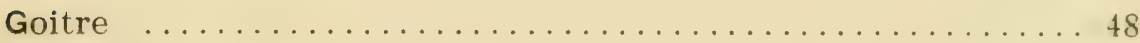

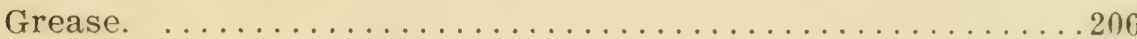

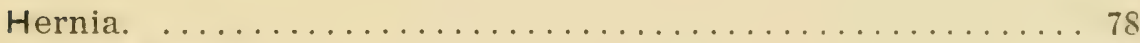

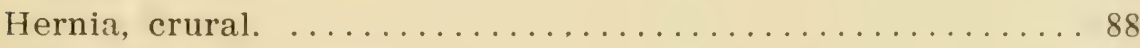

Hernia, false inguinal. ....................... 86

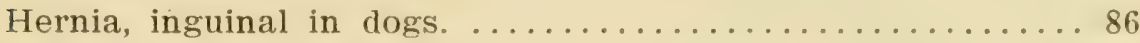

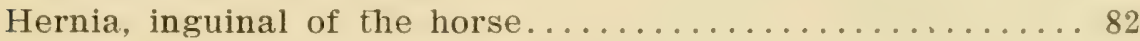

Hernia, inguinal in ruminants. ................ 86

Hernia, inguinal in swine. ..................... 86

Hernia, perineal. ....................... 88

Hernia, treatment of inguinal and scrotal............ 84

Hernia, umbilical. ......................... 80

Hernia, ventral. ....................... 88

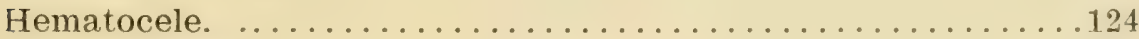

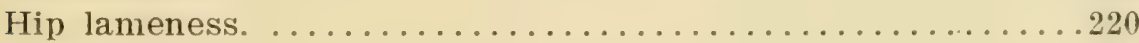

Hydrocele. ...............................

Impaction of the crop in birds. ................... 56

Infectious inflammation of the lower synovial sheath of the

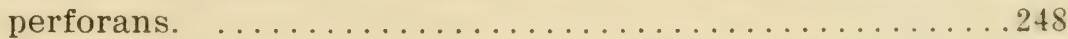

Inflammation of the articulation of the jaw .......... 36

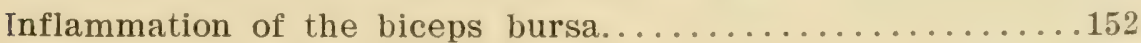

Inflammation of the bursa of the flexor pedis...........168

Inflammation of the bursa of the ligamentum nuche......50

Inflammation of the elbow joint. .................. 158

Inflammation of the flexor tendons. .................

Inflammation and new growths in the submaxillary lymph

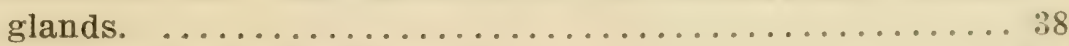

Inflammation of the hip joint. .......................

Inflammation of the lips and cheeks. .............. 10

Inflammation of the mucous membrane of the rectum and

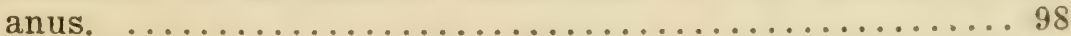

Inflammation of the posterior lagaments of the coronet joint.196 Inflammation of the prepuce in carnivora. ...........116

Inflammation of the prepuce in oxen................114 


\section{INTERROGATORY SURGERY.}

Inflammation of the spermatic cord. ................

Inflammation of the subcoronary connective tissue.......264

Inflammation of the surrounding rectal connective tissue...100

Inflammation of the tendon and bursa of the gluteus maximus

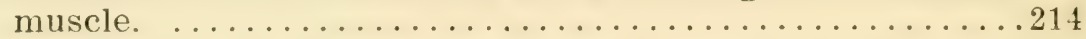

Inflammation of the tendon and bursa of the postea spinatus

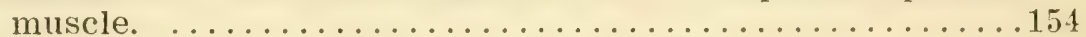

Inflammation of the testicle and epididymis. ........... 122

Inflammation of the urinary bladder. ..............112

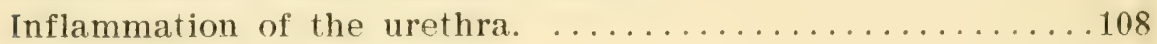

Inguinal and scotal hernia. ................... 82

Inguinal hernia in dogs. $\ldots \ldots \ldots \ldots \ldots \ldots \ldots \ldots \ldots \ldots$

Inguinal hernia in ruminants. ...................... 86

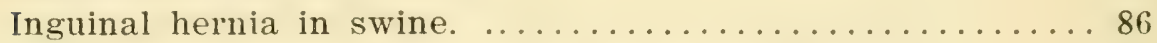

Injuries and acute inflammation of the stifle joint.......226

Injuries to the anterior surface of the knee............164

Injuries to the interdental space. .................. 14

Injuries to the muscles and fasciæ of the quarter........212

Injuries to the rectum and anal region.............. 98

Injuries to the penis. ............................

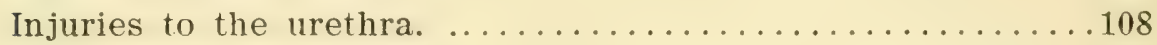

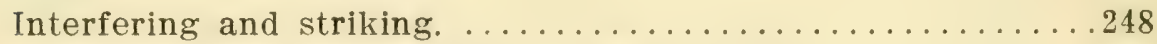

Intussusception or invagination of the bowel.......... 94

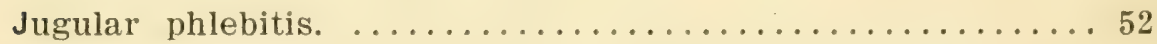

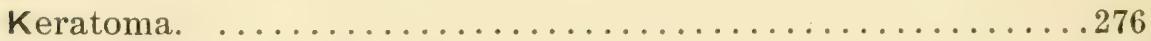

Knuckling over in foals. ..................... 180

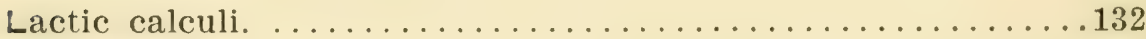

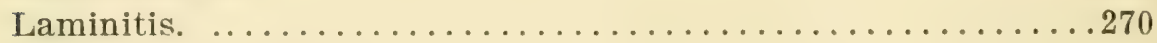

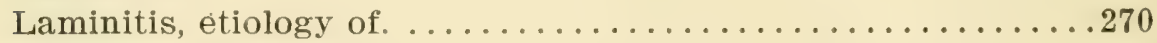

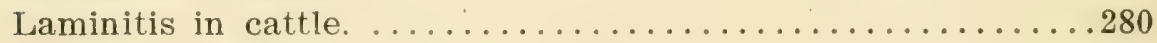

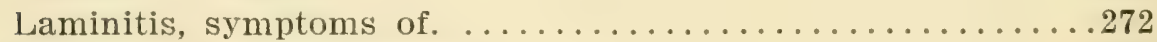

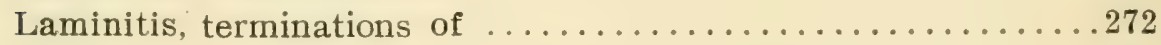

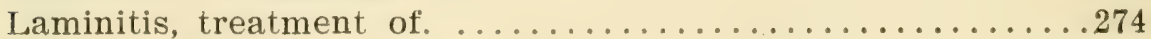

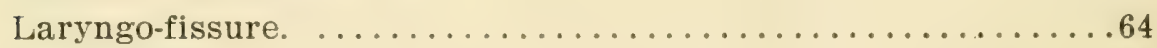

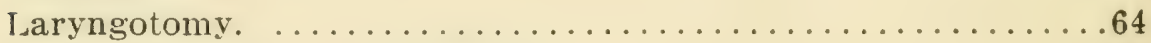

Lateral luxation of the patella. .....................224

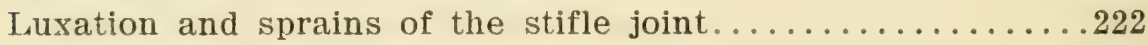

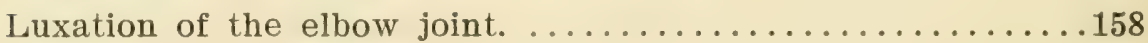

Luxation of the femur. .............................. 214 


\section{INTERROGATORY SURGERY.}

L.uxation and strains of the hock..................... 232

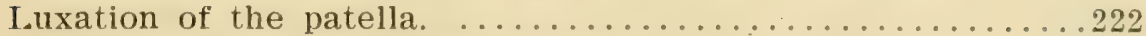

Luxation of the perforatus tendon. ................ 244

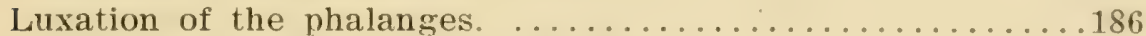

Luxation of the sacro-iliaco articulation. ............. 146

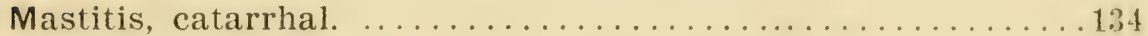

Mastitis, chronic catarrhal. .........................

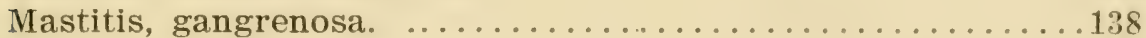

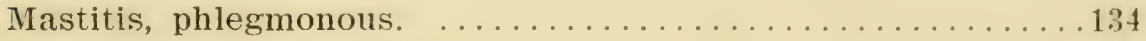

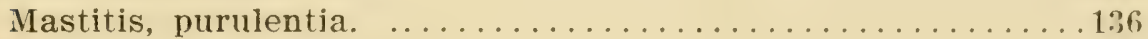

Median neurectomy. . . . . . . . . . . . . . . . 194

Mud fever. ............................206

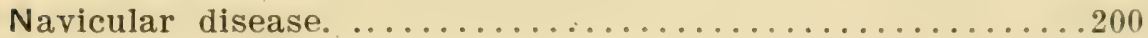

Necrosis of the lumbo-dorsal fascia.................... 148

Neoplasms of the gumis and alveoli................. 24

Nerve supply of the foot. . . . . . . . . . . . . . . 25t

Nervous diseases of the larynx..................60

New growths in the submaxillary lymph glands.......... 38

Operations on the cranial cavity.................44

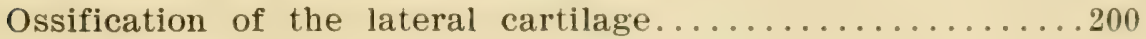

Otitis externa. ........................... 40

Otorrhea. .............................. 40

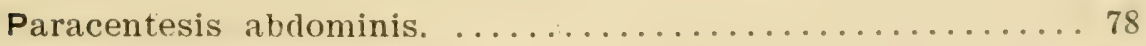

Paracentesis thoracis. ........................ 74

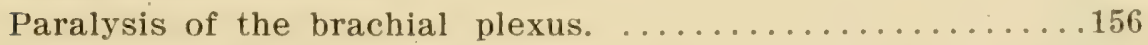

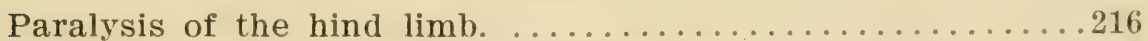

Paralysis of the muscles of mastication. ............ 36

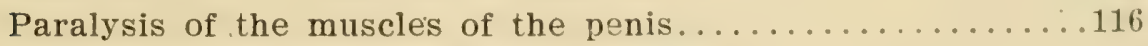

Paralysis of the pharynx and esophagus. ............ 56

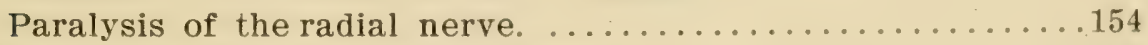

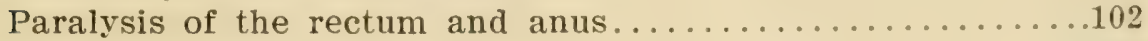

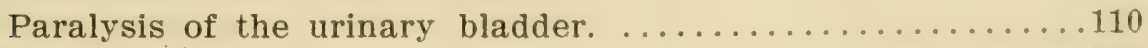

Paraphimosis. ............................... 116

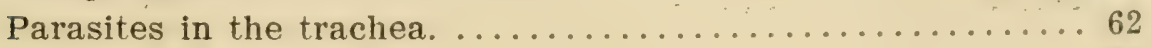

Perineal hernia. ........................ 88

Pervious urachus. ......................... 104

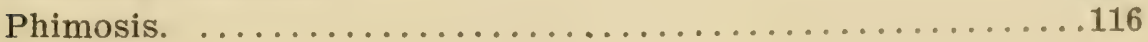




\section{INTERROGATORY SURGERY.}

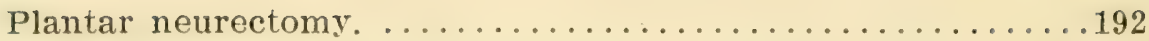

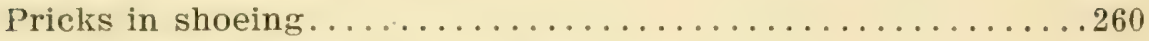

Prolapse and eversion of the bladder..................112

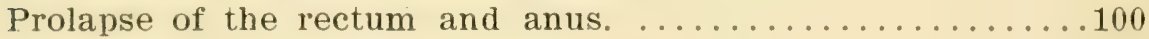

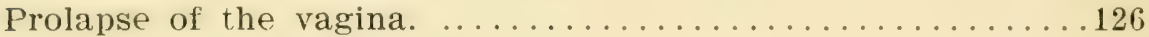

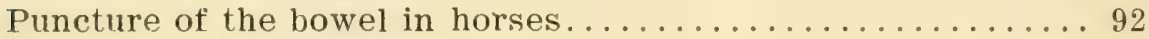

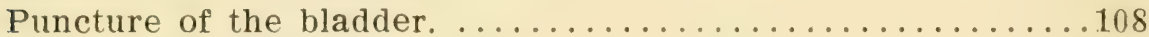

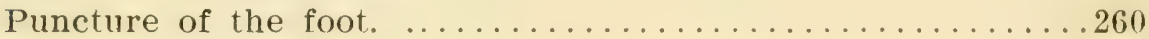

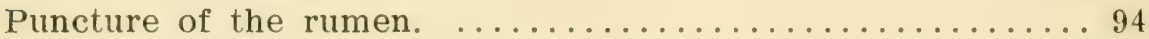

Purulent cellulitis of the fibro-fatty frog. ..............260

Purulent mastitis. .................................

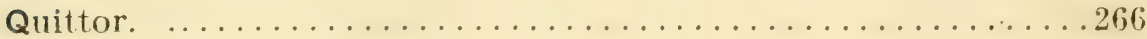

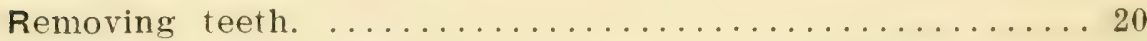

Resection of the plantar aponeurosis...............262

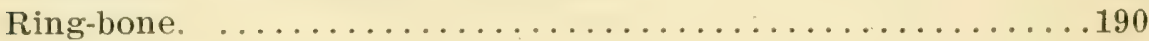

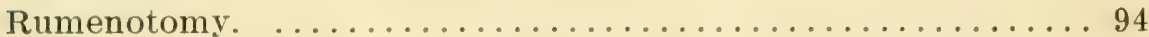

Rupture of the flexor metatarsi muscle..............230

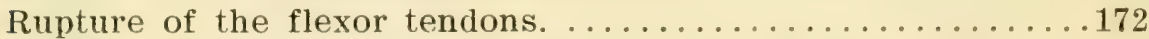

Rupture of the straight ligaments of the patella.........224

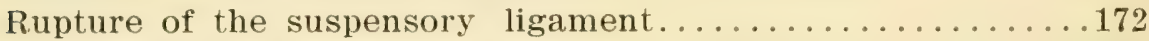

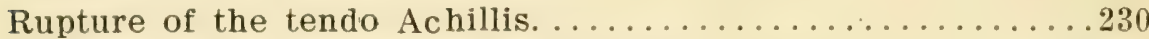

Rupture of the tibio-fibular interosseous ligament. .......230

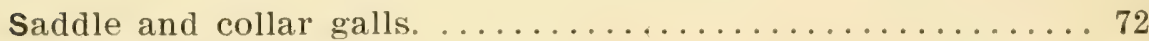

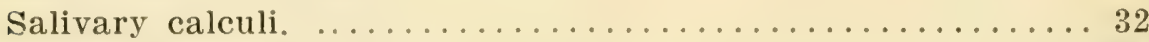

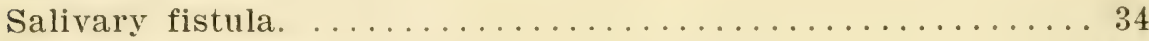

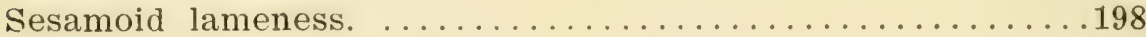

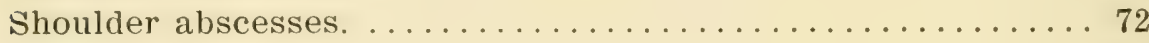

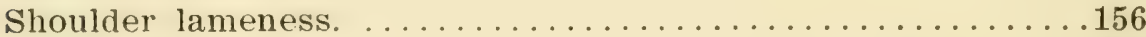

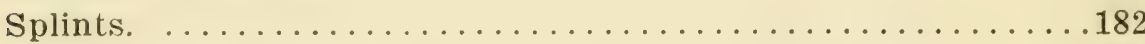

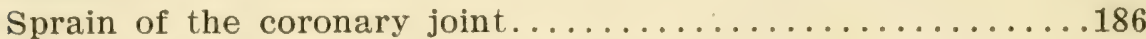

Stenosis and closure of the mammary duct.............140

Stenosis and compression of the esophagus........... 56

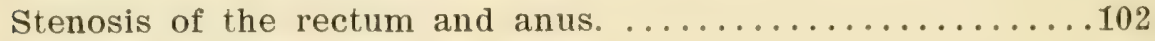

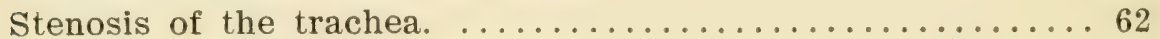

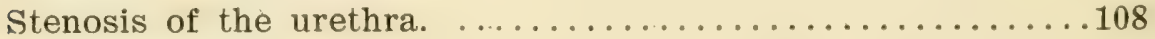

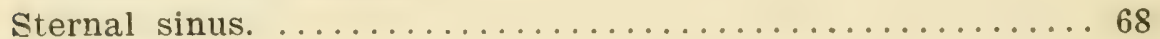

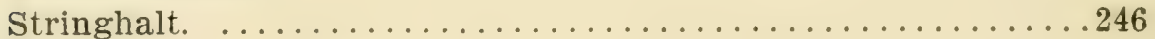

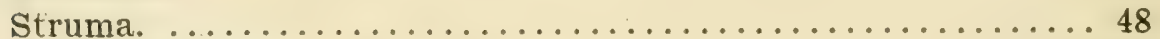

Surgical diseases of the abdomen. .............. 76 


\section{INTERROGATORY SURGERY.}

Surgical diseases of the posterior portion of the rectum and

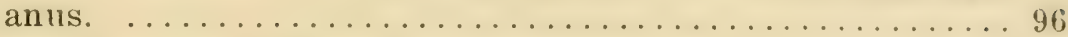

Surgical diseases of the stomach and bowels........... 90

Tapping the thoracic cavity ..................... 74

Teeth, diseases of the .......................... 14

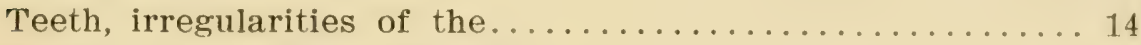

Teeth, irregularities of wear. ..................... 16

Thrombosis of the posterior aorta. ................. 218

Torticollis. ........................... 48

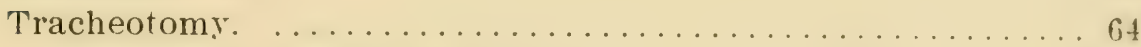

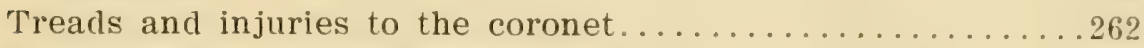

Treatment of inguinal and scrotal hernia............ 84

Trephining the maxillary and frontal sinuses.......... 28

Tuberculosis of the udder. .................... 140

Tumors in the urethra and bladder................... 114

Tumors of the lips and cheeks. .................... 10

Treatment of the knee in cattle................... 166

Tumors in the pharynx and esophagus............. 58

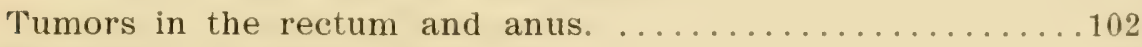

Tumors of the salivary glands. ..................... 34

Tumors of the sheath and penis. ..................

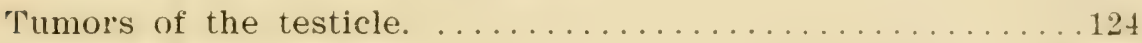

Tumors of the trachea. . . . . . . . . . . . . . . . 62

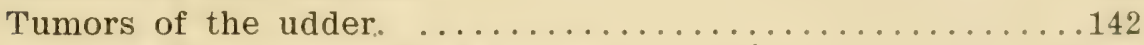

Tumors of the vagina and uterus. .................. 130

Twist or rotation of the colon.................... 96

Ulnar neurectomy. ........................... 196

Umbilical hernia. ....................... 80

Urethral calculi in ruminants. ....................

Urinary calculi. . . . . . . . . . . . . . . . . . . 10t

Urinary calculi in the dog. ........................

Urinary calculi in the horse. ......................

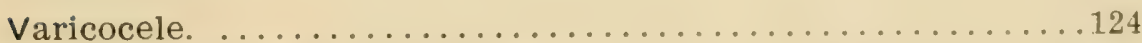

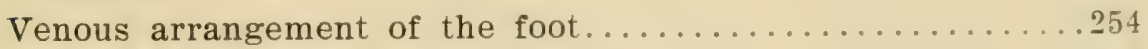

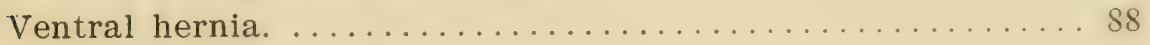

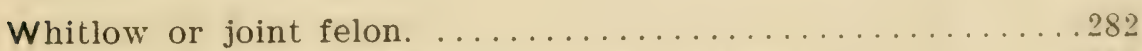

Wounds and acute inflammation of the hock...........23t 


\section{INTERROGATORY SURGERY.}

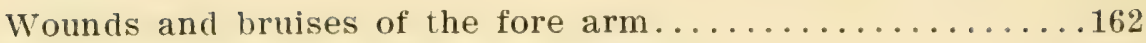

Wounds and bruises of the metacarpus. ............... 172

Wounds and bruises of the soft parts of the chest wall...668 Wounds and bruises of the udder. .....................

Wounds of the abdomen. ....................... 76

Wounds of the pleura. ....................... 76

\section{E R R A T A}

Page 30-Diseases of the Salivary Glands.

Page 68-Wounds and Bruises of the Soft l'arts of the Chest Wall Wounds without Perforations.

Page 212-Injuries to the Muscles and Fascia of the Quarter.

Page 246-Diseases of the Tendons and Tendinous Sheaths in the Tarsal and Metatarsal Region. 











OCT 171904 



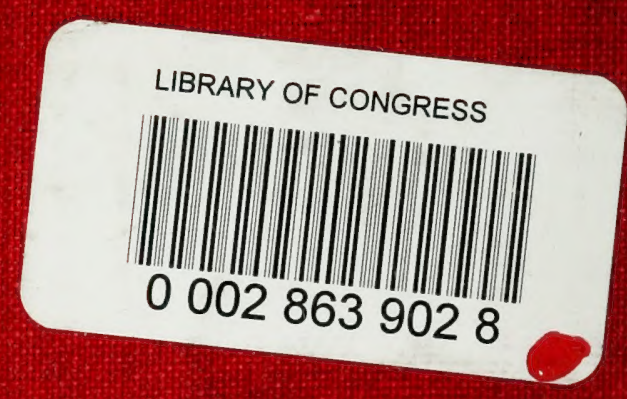

